Integrating intercultural telecollaboration in foreign language learning programmes:

The case of video communication and virtual worlds 
Published by

LOT

Kloveniersburgwal 48

1012 CX Amsterdam

The Netherlands phone: +31 205252461

e-mail: lot@uva.nl http://www.lotschool.nl

ISBN: 978-94-6093-341-7

NUR: 616

Copyright (C) 2020: Silvia Canto. All rights reserved. 


\title{
Integrating intercultural telecollaboration in foreign language learning programmes: The case of video communication and virtual worlds
}

Integratie van virtuele uitwisselingen in programma's voor vreemdetalenonderwijs: De casus van videocommunicatie en virtuele werelden

(met een samenvatting in het Nederlands)

\author{
Proefschrift \\ ter verkrijging van de graad van doctor aan de \\ Universiteit Utrecht \\ op gezag van de \\ rector magnificus, prof.dr. H.R.B.M. Kummeling, \\ ingevolge het besluit van het college voor promoties \\ in het openbaar te verdedigen op \\ vrijdag 6 maart 2020 des ochtends te 10.30 uur
}

door

\section{Silvia Canto Gutiérrez}

geboren op 5 juni 1971

te Barakaldo, Spanje 
Promotor:

Prof. dr. H.H. van den Bergh

Copromotor:

Dr. K. Jauregi Ondarra 


\section{Table of Contents}

Chapter 1 Introduction $\quad 1$

1.1 Intercultural language learning 2

1.2 Authentic language learning opportunities via telecollaboration 2

1.3 Technology mediated tasks and task based language teaching (TBLT) 4

1.4 Research context 6

1.5 Chapter overview

1.6 Final remark 8

1.7 References 8

Chapter 2 Verbal interaction in Second Life: Towards a pedagogic framework for task design $\quad 15$

2.1 Abstract 15

2.2 Context of the study 15

$\begin{array}{lll}2.3 \text { Task effectiveness for enhancing intercultural } & \\ \text { communication in cross-cultural encounters } & \end{array}$

2.4 Design principles for intercultural communicative tasks in $\begin{array}{ll}\text { virtual worlds } & 16\end{array}$

2.5 Case study on interaction carried out in Second Life 22

2.6 Discussion 34

2.7 Conclusions 35

2.8 References 36

2.9 Appendix. Task design format 38

Chapter 3 Collaborative tasks for negotiation of intercultural meaning in virtual worlds and video communication 39

3.1 Abstract 39

3.2 Authors' acknowledgement 40

3.3 Introduction 40

3.4 Background 41

3.5 Affordances of networked synchronous communication 42

3.6 Design principles for intercultural online tasks 44

3.7 Method 46

3.8 Findings 48

3.9 A look at negotiation of intercultural meaning 48

3.10 Support for intercultural learning 52

3.11 Perceptions of synchronous online tasks 54

3.12 Discussion and conclusion $\quad 56$

3.13 References $\quad 59$

3.14 Appendix. Global task descriptions. 64 
Chapter 4 Integrating cross-cultural interaction through video communication and virtual worlds in foreign language teaching programmes: burden or added value?

4.1 Abstract

4.2 Introduction

Studies on computer mediated communication

4.4 Research context

4.5 Research method 71

4.6 Results 74

4.7 Discussion $\quad 77$

4.8 Conclusions 78

4.9 References $\quad 79$

4.10 Appendix. Assessment grid for pre and post-tests 83

Chapter 5 Language learning effects through the integration of synchronous online communication: The case of video communication and Second Life.

5.1 Abstract 85

5.2 Introduction 85

$\begin{array}{lll}5.3 & \text { Research questions } & 87\end{array}$

$\begin{array}{lll}5.4 & \text { Methodology } & 88\end{array}$

5.5 Results 94

5.6 Discussion 104

5.7 Conclusions 105

5.8 References 106

5.9 Appendix. Assessment grid for pre and post-tests 112

Chapter 6 Virtual worlds in language education: towards meaningful learning through interaction, action and play. 113

6.1 Introduction 113

6.2 What are 3D virtual worlds?

6.3 Virtual worlds' properties 115

6.4 Virtual worlds' didactic uses 116

6.5 Colaboration tasks in virtual worlds 117

6.6 Telecolaboration projects with virtual worlds 118

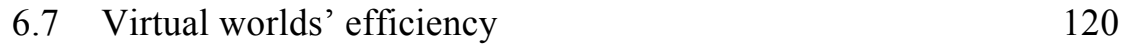

6.8 Conclusion 122

6.9 References 123

$\begin{array}{ll}\text { Chapter } 7 \text { Discussion } & 127\end{array}$

$\begin{array}{lll}7.1 & \text { General discussion } & 127\end{array}$

7.2 Some unresolved issues 131

7.3 References 134

Samenvatting $\quad 141$

Acknowledgements 149 




\section{Chapter 1}

\section{Introduction}

If language is a social practice in which to participate (Kramsch, 1994), language learning should not be just about mastering the forms and rules of a language. Traditionally, language has been viewed as a code, made up of words and rules to connect them. This approach to language learning just involves learning vocabulary and grammatical rules. Moreover, in this (limited) vision, the acquisition of grammar and vocabulary is its main goal. It does not consider language as a communicative reality, language is here simply viewed as a memory exercise.

In the era of grammar teaching, when emphasis was on structural patterns, language itself played the most important part in foreign language classrooms and formal correction was the most important and almost single goal in foreign language teaching.

In today's world, it is the learner and his place in society that sets the course for teaching programmes where adequacy of language use is indispensable in a move to increase learner autonomy, responsibility and cooperation (Slagter, 2000). Our aim as educators is to prepare language learners to communicate effectively, not only inside but especially outside the classroom. Therefore we have to provide them with adequate learning opportunities.

In order to accommodate learners in this respect computer mediated communication (CMC) has become an invaluable and indispensable tool. For instance, role-play scenarios which require learners to use language in all kinds of situations, or by means of video communication in which learners interact with native speakers through all kinds of language tasks. We do want to prepare them for a communicative reality and this can not be done by simply teaching them with grammatical exercises only. Or do we prepare ourselves for a triathlon by exercising our biceps only?

Education needs to be more learner and communication oriented. However, the focus is now on language (simply as a body of knowledge). Teacher directed instruction, which controls student responses limiting their output, should give way to a more student-student interactive learning environment (Slagter, 2000) where meaningful tasks and learner motivation are crucial (van den Branden, 2006; Dörnyei, 2001, 2002). We need to engage learners in active learning, focusing on what they can do with the language and not on what they know about the language. Language is a social practice where individuals participate not only to create and interpret meanings but also for social and interpersonal relationships (Kramsch, 1993). In order to facilitate this communication, foreign language learners need to learn about and understand the culture where a language is spoken (Hall, 2004).

The issues that shall be addressed in this study relate to effects of computer mediated communication (CMC) via telecollaboration on aspects of foreign 
language learning. Do these CMC practices improve students' intercultural communicative competence? Do they have any added value over the more traditional education or are they just another burden for teachers? Do these interventions have a positive effect on learners' spoken language proficiency when interacting with native speakers? What are the characteristics of these online exchanges that enhance interaction and promote learning? Questions like these will be touched upon in the following chapters. This means that concepts such as telecollaboration, virtual worlds or tasks will be elaborated upon and presented in this introduction in the sections below.

\subsection{Intercultural language learning}

Intercultural communicative competence is defined by Chen and Starosta (1996) as "the ability to negotiate cultural meanings and to execute appropriately effective communication behaviours that recognize the interactants' multiple identities in a specific environment" (pp. 358-359). In order for language learners to communicate effectively they need to be aware of the differences and similarities between their own culture (Byram, 1997) and that of the language they are learning (Alptekin, 2002; Byram, 2009). Culture and communication become inseparable, as culture governs communication and communication shapes and creates culture (Hall, 1959). Therefore the term languaculture (Agar, 1994) is introduced, and defines the necessary tie between language and culture. This term illustrates the close relatedness between language and culture. They are seen as indistinguishable.

According to Byram's model linguistic and sociolinguistic competences have to be considered when observing students' intercultural communicative competence development. At the same time, this intercultural competence requires certain attitudes, knowledge and skills, Byram's key saviors (1997): skills (acquiring new knowledge of the target culture and applying it through communication and interaction), attitudes (reforming values and believes), knowledge (understanding group and individual social actions), and critical cultural awareness (the ability to evaluate one's own and target cultures). The element that sets apart intercultural communicative competence from intercultural competence is the linguistic competence: a person's intercultural competence can be inferred from their ability to understand and interpret another culture, while for intercultural communicative competence interaction with people form other cultures is of the essence.

\subsection{Authentic language learning opportunities via telecollaboration}

As language learners develop their language skills through social interactions (Vygotsky, 1978; Warschauer, 1997; Ellis, 1999; Firth \& Wagner, 2007; Lantolf \& Thorne, 2006; Blaurock, 2011; Kurata, 2011) we should provide opportunities for the language learners for meaningful interaction. This means that we have to develop adequate tasks, which require meaningful communication between participants (Jauregi \& De Graaff, 2009).

Traditional foreign language education can be characterized by a lack of meaningful interaction in the target language. In most cases our language learners, 
studying in an institutional setting, do not interact in the foreign language as much as we would like them to do. We expect them to do it since the purpose of foreign language learning is to learn to communicate adequately in different situational contexts. Sadly, however, they are not taught how to. The lack of opportunities for meaningful interaction also influences learners' confidence in their communication skills (Bernales, 2016; Tsui, 1996; Wood, 2016; Zhang \& Cui, 2010; Zhou, 2015). Interaction between learners from a different languaculture and native speakers of a language not only facilitates intercultural communicative competence (Belz, 2002; Gimeno, 2018; Helm, 2009; Nakano, Fukui, Nuspliger \& Gilbert, 2011; O’Dowd, 2003; Schuetze, 2008; Zha, Kelly, Park, \& Fitzgerald, 2006), but also fosters learners' interaction skills while boosting their intercultural awareness.

The development of Internet technology provides teachers and learners many possibilities to contact and collaborate with speakers of other languages from around the world and makes direct communication between foreign language learners (and native speakers) more possible than ever before. These online intercultural exchanges are regarded as ideal environments for language and intercultural learning because they provide convenient, authentic, direct, and speedy access to native speakers and their cultures (Kramsch \& Thorne, 2002; Sykes, Oskoz, \& Thorne, 2008). Schrooten (2017), after examining research findings, summarizes the potential benefits of integrating information and communication technology (ICT) into language education as follows: ICT (1) allows for a high degree of differentiation, where individual needs and abilities can easily be accommodated, and also (2) offers enriched content and allows a more intense, multi- sensory learning process. According to his findings, working with ICT not only (3) elicits a high degree of learner motivation and involvement but also (4) makes teaching more efficient, since the teacher can focus more on supporting learners rather than having to focus on providing content.

The use of the Internet to connect language learners has gone under many different names (O'Dowd, 2013). Lamy and Goodfellow (2010) point out how problematic defining telecollaboration can be, since it covers an extremely wide range of online exchanges, ranging from loosely guided language practice of a target language, to chatting, to online collaborative writing, to elaborately designed project-based education. In this study we use a more pragmatic definition of telecollaboration, which describes telecollaboration as the application of synchronous and asynchronous online communication tools to bring together (classes of) language learners in geographically distant locations to develop their foreign language skills and intercultural competence through collaborative tasks and project work (O’Dowd, 2012).

Telecollaboration is one of the possible ways to operationalise interaction between learners and native speakers of a language who are in different locations. Hence, it is logical that telecollaboration has become one of the main pillars of the intercultural turn in foreign language education (Thorne, 2006; Corbett, 2010). Telecollaborative exchanges have the advantages of traditional face to face communication, and it is therefore not surprisingly that these (theoretical) advantages have also been demonstrated in empirical research. O'Dowd (2012), for instance, showed that telecollaboration contributes to intercultural learning, and 
provides learners with different types of cultural knowledge as well as multiple opportunities to develop cultural awareness (O'Dowd, 2003). It has also been shown that telecollaborative activities improve learner's writing skills (St. John \& Cash, 1995), improve learners' grammatical correctness (Brammerts, 1996; Lee 2002), foster lexical capacity (Dussias, 2006), develop higher order thinking skills (Von der Emde, Schneider, \& Kötter, 2001), and enhance oral communication skills (Blake 2000, Abrams, 2003). Moreover, telecollaboration contributes to the development of intercultural communicative competence (Belz, 2003, 2007; Chun, 2011; Helm, 2009; O’Dowd, 2003, 2006; Liaw \& Master, 2010; Schenker, 2012) and helps to promote learners' autonomy (Schwienhorst, 2002), develops digital literacies (Helm, 2014), and motivates the building of learning communities (Lee, 2006). These are 21 st century skills that students need in a highly globalised and technology driven world. In short, telecollaboration has at least the potential to contribute to learners' awareness of cultural differences in communicative practices and the development of pragmatic competence in foreign language learning (e.g. Belz \& Kininger, 2002, 2003; Blake, 2008; Furstenberg, Levet, English \& Maillet, 2001; O’Dowd \& Ware, 2009; Oskoz, Gimeno \& Sevilla, 2018; Thorne, 2003; Zhu, Gareis, O'Keefe Bazzoni, \& Rolland, 2005).

\subsection{Technology mediated tasks and task based language teaching (TBLT)}

The first results of empirical studies on telecollaboration, however, were not that promising, these studies concerned mostly rather superficial exchanges (O'Dowd, 2012). Therefore, researchers have called for more carefully designed telecollaborative tasks and projects. An increasing body of research has shown that tasks play an important role in determining the learning outcomes of telecollaboration (Guth \& Helm, 2011; Hauck \& Youngs, 2008; Müller-Hartmann, 2000; O'Dowd \& Ware, 2009). Task design seems the key for effective interaction, and should match the communicative affordances of the environments used in order to facilitate intercultural communicative competence (Hampel, 2014).

Much of the research on telecollaboration for language learning is situated within task based language teaching (TBLT), which conceptualises "task" as a set of activities designed to foster second language acquisition (Dooly, 2017). Long (1985) and Prabhu (1987) supported an approach to language education in which students are given functional tasks that invite them to focus primarily on meaning exchange and to use language for real world, non-linguistic purposes. Therefore, they steer away from teacher oriented and form focused second language classroom practice to task based language teaching. This idea of using language, rather than knowing something about the language, is one of the corner stones of TBLT.

In their search for optimal psycholinguistic environments for distance foreign language learning Doughty and Long (2003) proposed a series of methodological principles that are crucial in the task-based-language-learning philosophy. These criteria can be used to evaluate the quality (in terms of language learning potential) of multimedia environments or to design TBLT. Doughty and Long (2003) argued that language education should focus on tasks and not only on texts. Tasks will allow learners to experience language as a living entity by doing 
the tasks they will face beyond the classroom. On the contrary, text based courses focus on language as an object and watching someone else do a task or reading about it is not the same as learning how to do it oneself (Long, 2014 p. 305) (1). Further, Doughty and Long (2003) promote the use of language as opposed to talking about language, since carrying out real world tasks oneself is more likely to help transfer abilities learned in the classroom to the world outside (2). They do not rely on authentic texts but encourage the confrontation with elaborate input (3); they capitalise on rich and meaningful input (4) and encourage inductive "chunk" learning, such as collocations (5). As learners experience difficulties in a communicative context their attention to form will be usually triggered by a communication problem, making them aware of the form concerned without abstract knowledge of a rule (Long, 2014). This focus on form (6), a response to a difficulty, is not the same as teaching in advance grammar or vocabulary before they are encountered in a task (Long, 2014). Doughty and Long (2003) also advocate for providing negative feedback (7), such as clarification request or recasts, to prevent that learners without the negative evidence might remain unaware of errors that do not cause communication breakdowns. Tasks should also cater for individual differences in goals, interests, motivation and learning strategies in order to individualise instruction (8), and promote collaborative learning by requiring learners to work together for successful completion of tasks (9).

According to González - Lloret and Ortega (2014) technology mediated tasks should focus on meaning, rather than on grammatical forms, be learner centered, authentic and draw on real world processes of language use. Web 2.0 technologies generate opportunities for social discourse and casual conversation (Thorne 2008, 2010) and encourage learner's agency and confidence in language use (Thomas 2013; Zheng, Young, Brewer, \& Wagner, 2009). Well designed and motivating tasks are essential for learning to take place (Lee, 2007) but technology mediated tasks have to be considered as entities of their own, rather than assuming that tasks that are effective at eliciting interaction in face to face exchanges will also do so in telecollaboration. Telecollaboration exchanges should aim at intensive learner involvement and motivation providing the learner with relevant tasks that lead to meaningful exchanges. In these tasks, learners should be in control of the interaction, since this experience of control may enhance their sense of selfdetermination (Niemiec \& Ryan, 2009; Ryan \& Deci, 2000; Guthrie \& Wigfield, 2000), which has been shown to have a positive impact on the learner's task motivation (Dörnyei, 2001, 2002).

Although some of the web-based tools used to carry out these technology mediated tasks are vulnerable to technical difficulties (Bateson \& Daniels, 2012; Tian \& Wang, 2010) and practitioners might face challenges such as scheduling issues (Levy \& Stockwell, 2006) studies have found positive effects of using CMC. Amongst these positive effects are that it facilitates students' interactions (Belz, 2002), increases the possibilities for meaning negotiation (Blake, 2000) and promotes students' awareness of their linguistic competence (Blake 2000). They also offer opportunities for language students to experience authentic and meaningful intercultural communication across nations (Belz, 2005; Liu, Moore, Graham, \& Lee, 2002; Thorne, 2003; Zhu, Gareis, O’Keefe Bazzoni, \& Rolland, 
2005), and help improve language learners' confidence and participation by enhancing immediacy and interactivity (Hampel \& Hauck, 2004).

Despite these favorable results and the efforts made by researchers to encourage pedagogical digital innovation, the reality shows us how difficult it is to introduce changes in traditional educational settings (Howard 2013; Eetmer and Otterbreit-Leftwich 2010). Many of the research studies carried out to try to find out what the benefits of telecollaboration are for foreign language learning have reported on qualitative findings. We have presented here a mixed method research design focused on synchronous communication that can be replicated. However, further research studies that show more substantial research results are needed to validate the results obtained so far on telecollaboration exchanges.

\section{$1.4 \quad$ Research context}

The overall aim of this thesis is to build up on findings of previous research on how foreign language learners can improve their spoken language proficiency and understanding of target cultures through online interaction with native speakers. We wanted to start moving away from (mainly asynchronous) telecollaboration research whose focus was primarily linguistic and embrace an intercultural stance.

The studies presented here were made possible by means of the European project NIFLAR ${ }^{1}$ (Networked Interaction in Foreign Language Acquisition and Research). Eight universities cooperated in and outside Europe with the aim to make foreign language education more authentic and interactive through innovative elearning environments. Sixty tasks to stimulate the interaction between native speakers and foreign language learners were designed in Dutch, Russian, Portuguese and Spanish for the more than four hundred students that participated in the twenty experiments carried out via video communication and the virtual world of Second Life. In the first environment, video communication, participants can engage in multimodal communication, talking, chatting, sharing pictures, documents and sound files, taking part in collaborative writing processes while seeing each other through the webcam (Jauregi \& Bañados, 2008; 2010). On the other hand, 3D virtual worlds such as Second Life, simulate the real world, where avatars are the representations of real people who control them, the participants. Users can not only control their own appearance and movements (walk, fly, swim, etc.) but in some cases they can also have some control over their environment. These virtual worlds, which provide contextual richness since situations are made more explicit, include the possibility of interacting with other avatars, communicating through voice and/or text chat, and with a range of objects in real time (synchronous communication) and are primarily social spaces that exist for the purpose of humans interacting via their avatars (Sadler, 2017).

For the research presented in the following pages students from a group of learners of Spanish at a Dutch university were randomly allocated to three conditions: (1) face to face control group, (2) experimental interaction group with 
video communication, and (3) experimental interaction group with Second Life. Tasks were designed for the three above mentioned contexts and students, who were all following the same language course, carried out 5 communication tasks. Different data sources were gathered to measure the impact of the integration of the telecollaborative exchanges: (1) pre- and post-oral tests to measure communicative growth; (2) surveys to gather participants' experiences; and (3) recordings of communication sessions for qualitative in-depth analysis of interaction.

\subsection{Chapter overview}

In chapter $2^{2}$ (published in the Computer Assisted Language Learning Journal) we examine how a set of task design principles based on second language acquisition research can be applied in order to maximize authentic social interaction and intercultural awareness in a virtual environment. In order to show the effect of the quality of the tasks designed accordingly, the kind of interaction elicited is analysed. This first pilot enabled us to explore whether the specific affordances of the virtual environment can be adequately used for enhancing interaction.

How negotiation of linguistic and intercultural meaning takes place in virtual world tasks and video communication is analysed qualitatively in chapter $3^{3}$, published as a chapter in the book Technology mediated TBLT: Researching technology and tasks. In this chapter we also look into the potential of these environments to create authentic and interactive opportunities in foreign language learning contexts.

In the quasi-experimental study presented in chapter $4^{4}$ (published in the $\operatorname{ReCALL}$ journal) the effect that providing opportunities to engage in synchronous social interaction with native peers has in the development of foreign language learners' oral communicative competence is analysed. The study compares oral communicative growth of experimental groups (video communication and virtual worlds) and a control group (classroom setting) according to pre and post oral tests.

In chapter $5^{5}$ (published in the Journal of the European Confederation of Language Centres in Higher Education) we explore the learning opportunities that emerge in the interaction of two experimental groups (video communication and virtual worlds) as compared to the control group. Here we also present the impact that integrating opportunities to engage in interaction with native speakers through video communication and Second Life has in the development of the intercultural and communicative competence of foreign language learners.

2 Jauregi, K., Canto, S., De Graaff, R., Koenraad, T., \& Moonen, M. (2011). Verbal interaction in Second Life: towards a pedagogic framework for task design. Computer Assisted Language Learning, 24(1), 77-101.

3 Canto, S., De Graaff, R., \& Jauregi, K. (2014). Collaborative tasks for negotiation of intercultural meaning in virtual worlds and video web communication. In M. González- Lloret \& L. Ortega (Eds.), Technology-mediated TBLT: Researching technology and tasks (pp.183-212). Amsterdam: John Benjamins.

4 Canto, S., Jauregi, K. \& Van den Bergh, H. (2013). Integrating cross-cultural interaction through video communication and virtual worlds in foreign language teaching programmes. Burden or added value? ReCALL, 25(1), 105-121.

5 Canto, S., \& Jauregi, K. (2017). Language learning effects through the integration of synchronous online communication: the case of video communication and Second Life. Language Learning in Higher Education, 7(1), 21-53. 
In chapter $6^{6}$ we look at virtual world interactions and focus on the use of game like elements (avatars, quests, rewards, etc.) and game design techniques in non-game contexts (gamification) to enhance foreign language learning. This paper was a chapter (9) in the book, published in Spanish, Technology mediated communication: Learning and teaching foreign languages.

Finally, in chapter 7 we present the most relevant conclusions reached and point towards future research possibilities to support the findings and educational practice.

\subsection{Final remark}

Due to the fact that the chapters in this dissertation are set up as separate journal articles some overlap in the method sections and theoretical frameworks is inevitable, the advantage being that each one can be read independently.

The results of various chapters have been presented at national and international conferences such as EUROCALL, Pixel, CIEFE, Online Educa Berlin, ASELE and CALL Research.

\section{$1.7 \quad$ References}

Abrams, Z.I. (2003). The effect of synchronous and asynchronous CMC on oral performance in German. Modern Language Journal, 87(2), 157-167.

Agar, M. (1994). Language shock: Understanding the culture of conversation. New York: William Morrow.

Alptekin, C. (2002). Towards intercultural communicative competence in ELT. ELT Journal, 56, 57-64.

Bateson, G., \& Daniels, P. (2012). Diversity in technologies. In G. Stockwell (Ed.), Computer-assisted language learning: Diversity in research and practice (pp. 127-146). Cambridge: Cambridge University Press.

Belz, J. A. (2002). Social dimensions of telecollaborative foreign language study. Language Learning \& Technology, 6(1), 60-81.

Belz, J. A. (2003). Linguistic perspectives on the development of intercultural competence in telecollaboration. Language Learning and Technology, 7(2), $68-117$

Belz, J. A. (2005). Intercultural questioning, discovery, and tension in internetmediated language learning partnerships. Language and Intercultural Communication, 5(1), 3-39.

Belz, J. A. (2007). The development of intercultural competence in online interaction. In R. O'Dowd (Ed.), On-line intercultural exchange: A practical introduction for foreign language teachers (pp. 163-215). Clevedon, UK: Multilingual Matters.

Belz, J. A., \& Kinginger, C. (2002). The cross-linguistic development of address form use in telecollaborative language learning: Two case studies.

6 Jauregi, K. \& Canto, S. (2018). Mundos virtuales en la enseñanza de lenguas: hacia un aprendizaje significativo a través de la

interacción, la acción y el juego. In M. González-Lloret \& M. Vinagre Laranjeira (Eds.), Comunicación Mediada por Tecnologías

- Aprendizaje y Enseñanza de la Lengua Extranjera (pp. 88-107). Equinox eBooks Publishing, United Kingdom. 
Canadian Modern Language Review / Revue canadienne des langues vivantes, 59(2), 189-214.

Belz, J. A., \& Kinginger, C. (2003). Discourse options and the development of pragmatic competence by classroom learners of German: The case of address forms. Language Learning, 53(4), 591-647.

Bernales, C. (2016). Towards a comprehensive concept of willingness to communicate: Learners' predicted and self-reported participation in the foreign language classroom. System, 56, 1-12.

Blake, R. (2000). Computer mediated communication: A window on L2 Spanish interlanguage. Language Learning \& Technology, 4(1), 120-136.

Blake, R. J. (2008). Brave new digital classrooms: Technology and foreignlanguage learning. Georgetown, Washington, D.C.: Georgetown University Press.

Blaurock, R (2011). Computer mediated communication: A window on L2 Spanish interlanguage. Language Learning \& Technology, 4(1), 120- 136.

Brammerts, H. (1996). Language learning in tandem using the internet. In M. Warschauer (Ed.), Telecollaboration in foreign language learning (pp. 121-130). Honalulu, HI: University of Hawaaii Second Language Teaching and Curriculum Center.

Byram, M. (1997). Teaching and assessing intercultural communicative competence. Clevedon: Multilingual Matters.

Byram, M. (2009). The intercultural speaker and the pedagogy of foreign language education. In D. K. Deardorff (Ed.), The sage handbook of intercultural competence (pp. 321-332). London: Sage.

Canto, S., De Graaff, R., \& Jauregi, K. (2014). Collaborative tasks for negotiation of intercultural meaning in virtual worlds and video web communication. In M. González- Lloret \& L. Ortega (Eds.), Technology-mediated TBLT: Researching technology and tasks (pp.183-212). Amsterdam: John Benjamins.

Canto, S., \& Jauregi, K. (2017). Language learning effects through the integration of synchronous online communication: the case of video communication and Second Life. Language Learning in Higher Education, 7(1), 21-53.

Canto, S., Jauregi, K. \& van den Bergh, H. (2013). Integrating cross-cultural interaction through video communication and virtual worlds in foreign language teaching programmes. Burden or added value? ReCALL, 25(1), $105-121$.

Chen, G. M., \& Starosta, W. J. (1996). Intercultural communication competence: A synthesis. In B. Burleson (Ed.), Communication yearbook 19 (pp. 353383). Thousand Oaks: Sage.

Chun, D. M. (2011). Developing intercultural communicative competence through online exchanges. CALICO Journal, 28, 392-419.

Corbett, J. (2010). Intercultural language activities. Cambridge: Cambridge University Press.

Dooly, M. (2017). Telecollaboration. In C. A. Chapelle \& S. Sauro (Eds), The handbook of technology and second language teaching and learning (pp.169-182). Wiley. Hoboken, NJ: Wiley-Blackwell.

Dörnyei, Z. (2001). Motivational strategies in the language classroom. Cambridge: Cambridge University Press. 
Dörnyei, Z. (2002). The motivational basis of language learning tasks. In P. Robinson (Ed.), Individual differences in second language acquisition (pp. 137-58). Amsterdam/Philadelphia: John Benjamins.

Doughty, C. J., \& Long, M. H. (2003). Optimal psycholinguistic environments for distance foreign language learning. Language Learning \& Technology, $7(3), 50-80$.

Dussias, P. E. (2006). Morphological development in Spanish-American telecollaboration. In J. Belz \& S. Thorne (Eds.), Internet-mediated intercultural foreign language education (pp. 121-146). Boston: Heinle \& Heinle.

Eetmer, P.A., \& Otterbreit-Leftwich, A.T. (2010). Teacher technology change: How knowledge, confidence, beliefs, and culture intersect. Journal of Research on Technology in Education, 42, 255-284.

Ellis, R. (1999). Learning a second language through interaction. Amsterdam/Philadelphia: John Benjamins Publishing Company.

Firth, A., \& Wagner, J. (2007). Second/foreign language learning as a social accomplishment: Elaborations on a reconceptualized SLA. Modern Language Journal, 91, 800-818.

Furstenberg, G., Levet, S., English, K., \& Maillet, K. (2001). Giving a virtual voice to the silent language of culture: The CULTURA project. Language Learning \& Technology, 5(1), 55-102.

Gimeno, A. (2018). Learner expectations and satisfaction in a US-Spain intercultural telecollaboration project. Bellaterra Journal of Teaching \& Learning Language \& Literature, 11(3), 5-38.

González-Lloret, M., \& Ortega, L. (Eds.). (2014). Technology-mediated TBLT: researching technology and tasks. Amsterdam: John Benjamins.

Guth, S., \& Helm, F., (Eds.) (2011). Telecollaboration 2.0: language, literacy and intercultural learning in the 21st century. Bern: Peter Lang.

Guthrie, J. T., \& Wigfield, A. (2000). Engagement and motivation in reading. In M. L. Kamil, P. B. Mosenthal, P. D. Pearson, \& R. Barr (Eds.), Handbook of reading research, Vol. 3 (pp. 403-422). Mahwah, NJ, US: Lawrence Erlbaum Associates Publishers.

Hall, E. T. (1959). The silent language. New York, Anchor Books: Doubleday.

Hall, J.K. (2004). A prosaic of interaction: the development of interactional competence in another language. In Hinkel, E. (Ed.), Culture in second language teaching and learning (pp. 137-151). Cambridge: Cambridge University Press.

Hampel, R. (2014). Making meaning online: Computer-mediated communication for language learning. In A. Peti-Stantić \& M. M Stanojević (Eds.), Proceedings of the CALS Conference 20129 (pp.89-106). Frankfurt: Peter Lang.

Hampel, R., \& Hauck, M. (2004). Towards an effective use of audio conferencing in distance language courses. Language Learning and Technology, 8(1), 6682.

Hauck, M., \& Youngs, B. (2008). Telecollaboration in multimodal environments: The impact on task design and learner interaction. Computer Assisted Language Learning, 21(2), 87-124. 
Helm, F. (2009). Language and culture in an online context: what can learner diaries tell us about intercultural competence? Language and Intercultural Communication, 9(2), 91-104

Helm, F. (2014). The practices and challenges of telecollaboration in higher education in Europe. Language Learning \& Technology, 19(2), 197-217.

Howard, S.K. (2013). Risk-aversion: Understanding teachers' resistance to technology integration. Technology Pedagogy and Education 22(3), 357372.

Jauregi, K., \& Bañados, E. (2008). Virtual interaction through video-web communication: A step towards enriching and internationalizing learning programs. ReCALL, 20(2), 183-207.

Jauregi, K., \& Bañados, E. (2010). An intercontinental video-web communication project between Chile and The Netherlands. In S. Guth \& F. Helm (Eds.), Telecollaboration 2.0 (pp. 427-436). Bern: Peter Lang AG..

Jauregi, K. \& Canto, S. (2018). Mundos virtuales en la enseñanza de lenguas: hacia un aprendizaje significativo a través de la interacción, la acción y el juego. In M. González-Lloret \& M. Vinagre Laranjeira (Eds.), Comunicación Mediada por Tecnologías - Aprendizaje y Enseñanza de la Lengua Extranjera (pp. 88-107). Equinox eBooks Publishing, United Kingdom.

Jauregi, K., Canto, S., De Graaff, R., Koenraad, A., \& Moonen, M. (2011). Verbal interaction in Second Life: towards a pedagogic framework for task design. Computer Assisted Language Learning Journal, 24(1), 77-101.

Jauregi, K., \& De Graaff, R. (2009). Communicative tasks for language students and teacher trainees in videoweb communication and virtual worlds. In N. Brouwer, B. Giesbers, B. Rienties \& L. Van Gastel (Eds.), Student mobility and ICT: Dimensions of transition (pp. 191-201). Maastricht: FEVA ERD Press.

Jauregi, K., De Graaff, R., van den Bergh, H., \& Kriz, M. (2012). Native non-native speaker interactions through video-web communication, a clue for enhancing motivation. Computer Assisted Language Learning Journal, 25(1), 1-19.

Kramsch, C. (1993). Context and culture in language teaching. Oxford: Oxford University Press.

Kramsch, C., \& Thorne, S. (2002). Foreign language learning as global communicative practice. In D. Cameron \& D. Block (Eds.), Globalization and language teaching (pp. 83-100). New York: Routledge.

Kurata, N. (2011). Foreign language learning and use: Interaction in informal social networks. London: Continuum International Publishing Group.

Lamy, M. N., \& Goodfellow, R. (2010). Telecollaboration and Learning 2.0. In S. Guth \& F. Helm, F (Eds.), Telecollaboration 2.0: language, literacies and intercultural learning in the 21st century (pp. 107-138). Bern: Peter Lang.

Lantolf, J., \& Thorne, S. (2006). Sociocultural theory and the genesis of second language development. Oxford: Oxford University Press.

Lee, L. (2002). Enhancing learners'communication skills through synchronous electronic interaction and task-based instruction. Foreign Language Annals, 35(1), 16-24

Lee, L. (2006). A study of native and nonnative speakers' feedback and responses in Spannish-American networked collaborative interaction. In J. A. Belz \& S. 
L. Thorne (Eds.), Internet-mediated intercultural foreign language education (pp. 147-176). Boston, MA: Thomson Heinle.

Lee, L. (2007). Fostering second language oral communication through constructivist interaction in desktop videoconferencing. Foreign Language Annals, 40(4), 635-649.

Levy, M., \& Stockwell, G. (2006). CALL dimensions: Options and issues in computer assisted language learning. Mahwah, NJ: Lawrence Erlbaum Associates.

Liaw, M.L., \& Master, S. (2010). Understanding telecollaboration through an analysis of intercultural discourse. Computer Assisted Language Learning, 23(1), 21-40.

Liu, M., Moore, Z., Graham, L., \& Lee, S. (2002). A look at the research on computer-based technology use in second language learning: A review of the literature from 1990-2000. Journal of Research on Computing in Education, 34(3), 250-263.

Long, M. (1985). Input and second language acquisition theory. In S. Gass \& C. Madden (Eds.), Input and second language acquisition (pp. 377-393). Rowley, Mass.: Newbury House.

Long, M. (2014). Second language acquisition and task-based language teaching. Sussex, UK: Wiley-Blackwell.

Müller-Hartmann, A. (2000). The role of tasks in promoting intercultural learning in electronic learning networks. Language Learning \& Technology, 4(2), 129147.

Nakano, Y., Fukui, S., Nuspliger, B., \& Gilbert, J. (2011). Developing intercultural communicative competence through guest speaker sessions: Two case studies. Human Welfare (3)1, 23-52.

Niemiec, C. P., \& Ryan, R. M. (2009). Autonomy, competence, and relatedness in the classroom: Applying self-determination theory to educational practice. Theory and Research in Education, 7(2), 133-144.

O'Dowd, R. (2003). Understanding the "other side": Intercultural learning in a Spanish-English email exchange. Language Learning \& Technology, 7(2), $118-144$

O'Dowd, R. (2006). Telecollaboration and the Development of Intercultural Communicative Competence. Munich, Germany: Langenscheidt-Longman.

O'Dowd, R. (2012). Intercultural communicative competence through telecollaboration. In J. Jackson (Ed.), The Routledge handbook of language and intercultural communication (pp. 342-358). Abingdon: Routledge

O'Dowd, R. (2013). The competences of a collaborative teacher. The Language Learning Journal, 43(2), 194-207.

O'Dowd, R., \& Ware, P. (2009). Critical issues in telecollaborative task design. ComputerAssisted Language Learning, 22(2): 173-188.

Oskoz, A., Gimeno-Sanz, A., \& Sevilla-Pavón, A. (2018). Examining L2 learners' use of engagement strategies in telecollaborative written interactions. In B. Mousten, S. Vandepitte, E. Arnó, \& B. Maylath (Eds.), Multilingual writing and pedagogical cooperation in virtual learning environments (pp. 200-220). Hershey, PA: IGI-Global.

Prabhu, N.S. (1987). Second Language Pedagogy. Oxford: Oxford University Press. 
Ryan, R.M., \& Deci, E.L. (2000). Self-determination theory and the facilitation of intrinsic motivation, social development, and well-being. American Psychologist, 55, 68-78.

Sadler, R. W. (2017). The continuing evolution of virtual worlds for language learning. In C.A. Chapelle \& S. Sauro (Eds), The handbook of technology and second language teachingand learning (pp. 184-201). WileyBlackwell.

Schenker, T. (2012). Intercultural competence and cultural learning through telecollaboration. CALICO Journal, 29 (3), 449-470.

Schrooten, W. (2006). Task-based language teaching and ICT: Developing and assessing interactive multimedia for task-based language teaching. In $\mathrm{K}$. Branden (Ed.), Task-based language education: From theory to practice (pp. 129-150). Cambridge: Cambridge University Press.

Schuetze, U. (2008). Exchanging second language messages online: Developing an intercul-tural communicative competence? Foreign Language Annals, 41(4), $660-673$.

Schwienhorst, K. (2002). Why virtual, why environments? Implementing virtual reality concepts in computer-assisted language learning. Simulation \& Gaming, 33(2), 196-209.

Slagter, P. J. (2000). Learning by instructing, (dissertation). Utrecht: University of Utrecht.

St. John, E., \& Cash, D. (1995). Language learning via e-mail: Demonstrable success with German. In M. Warschauer (Ed.), Virtual connections: Online activities and projects for networking language learners (pp. 191-197). Honolulu, HI: University of Hawai'i, Second Language Teaching and Curriculum Center.

Sykes, J., Oskoz, A., \& Thorne, S. (2008). Web 2.0, synthetic immersive environments, and mobile resources for language education. CALICO Journal 25(3), 528-546.

Thomas, M. (2013). TBLT in Business English communication: an approach for evaluating Adobe Connect and Second Life in a blended language learning format. International Journal of Computer-Assisted Language Learning and Teaching, 3(1), 73-89.

Thorne, S. (2003). Artifacts and cultures-of-use in intercultural communication. Language Learning \& Technology, 7(2), 38-67.

Thorne, S. (2006). Pedagogical and praxiological lessons from Internet-mediated intercultural foreign language education research. In J. Belz \& S. Thorne (Eds.), Internet-mediated intercultural foreign language education (pp. 230). Boston: Heinle \& Heinle.

Thorne, S. L. (2008). Mediating technologies and second language learning. In D. Leu, J. Coiro, C. Lankshear, \& M. Knobel (Eds.), Handbook of research on new literacies (pp. 417-449). Mahwah, NJ: Lawrence Erlbaum.

Thorne, S. L. (2010). The 'Intercultural turn' and language learning in the crucible of new media. In F. Helm, \& S. Guth (Eds.), Telecollaboration 2.0 for Language and Intercultural Learning (pp. 139-164). Bern: Peter Lang: 139-164. 
Tian, J., \& Wang, Y. (2010). Taking language learning outside the classroom: Learners' perspectives of eTandem learning via Skype. Innovation in Language Learning and Teaching, 4(3), 181-197.

Tsui, A. B. M. (1996). Reticence and anxiety in second language learning. In K. M. Bailey \& D. Nunan (Eds.), Voices from the language classroom: Qualitative research in second language education (pp. 145-167). New York: Cambridge University Press.

Van den Branden, K. (2006). Introduction: Task-based language teaching in a nutshell. In K. Branden (Ed.), Task-based language education: From theory to practice (pp. 1-16). Cambridge: Cambridge University Press.

Von der Emde, S., Schneider, J., \& Kötter, M. (2001). Technically speaking: Transforming language learning through virtual learning environments (MOOs). Modern Language Journal, 85 (2), 210- 225.

Vygotsky, L. S. (1978). Mind in society. Cambridge, MA: Harvard University Press.

Warschauer, M. (1997). Computer-mediated collaborative learning: Theory and practice. Modern Language Journal, 81(4), 470-481.

Wood, D. (2016). Willingness to communicate and second language speech fluency: An idiodynamic investigation. System, 60, 11-28.

Zha, S., Kelly, P., Park, M.K., \& Fitzgerald, G. (2006). An investigation of communicative competence of ESL students using electronic discussion boards. Journal of Research on Technology in Education, 38(3), 349-367.

Zhang, X., \& Cui, G. (2010). Learning beliefs of distance foreign language learners in China: a survey study. System, 38, 30-40.

Zheng, D., Young, M. F., Brewer, B., \& Wagner, M. (2009). Attitude and selfefficacy change: English language learning in virtual worlds. The Computer Assisted Language Instruction Consortium Journal, 27(1), 205-231.

Zhou, N. (2015). Oral participation in EFL classroom: Perspectives from the administrator, teachers and learners at a Chinese university. System, 53, 3546.

Zhu, Y., Gareis, E., O’Keefe Bazzoni, J., \& Rolland, D. (2005). A collaborative online project between New Zealand and New York. Business Communication Quarterly, 68, 81-96. 


\section{Chapter 2}

\section{Verbal interaction in Second Life: Towards a pedagogic framework for task design ${ }^{1}$}

\subsection{Abstract}

Within a European project on networked interaction in foreign language acquisition and research (NIFLAR) Second Life was used as a 3D virtual world in which language students can communicate synchronously with native speakers in the target language, while undertaking action together. For this context, a set of design principles for interaction tasks was developed aiming at maximizing authentic social interaction and intercultural awareness, while exploiting the specific affordances of the virtual environment being used. These design principles were applied and tested in a case study in which two foreign language learners of Spanish and two preservice teachers carried out four interaction tasks in the virtual world of Second Life.

In this article we first present and discuss the framework for task development and assessment. We then show the results of the case study conducted in Second Life which aimed at (1) applying and assessing the design principles for task elaboration, (2) analysing the kind of interaction the tasks elicited in the virtual world, (3) exploring whether the specific affordances of the virtual environment were adequately used for enhancing interaction, and (4) studying whether and how the conditions anonymity versus familiarity may play a role in modelling virtual interaction.

\subsection{Context of the study}

The NIFLAR project (Networked Interaction in Foreign Language Acquisition and Research) is a two year project (2009-2010) which received a grant from the European Commission within the Lifelong Learning Programme. The NIFLAR ${ }^{2}$

\footnotetext{
1 This chapter has been published as: Jauregi, K., Canto, S., De Graaff, R., Koenraad, T., \& Moonen, M. (2011). Verba interaction in Second Life: towards a pedagogic framework for task design. Computer Assisted Language Learning, 24(1), 77101.

2 NIFLAR consists of a consortium of seven universities (Valencia and Granada in Spain, Coimbra in Portugal, Palacky in Olomouc Czech Republic, Nevsky Institute and Novosibirsk in Russia, and Concepción in Chile), two Secondary Schools (in Spain and The Netherlands), an e-learning consultancy organization (TELLConsult in The Netherlands) under the coordination of Utrecht University (The Netherlands), They all share the interest in exploring the added value of introducing blended educational learning systems for the development of communicative and intercultural competence in L2. The project target languages in NIFLAR are Dutch, Portuguese, Russian and Spanish
} 
project aims at enriching and innovating foreign language teaching and learning processes, by creating opportunities for enhancing authentic social interaction between peers (students of foreign languages and pre-service teachers) according to interaction tasks with a focus on intercultural awareness. The interactions take place in two innovative digital environments: video communication and voice-enabled 3D virtual worlds. The first one facilitates distant spoken and written interaction among dyads and group of students, and collaborative work sharing files (photos, presentations, films) while interlocutors are able to see each other. In the second environment, voiced-enabled 3D virtual worlds, students participate as avatars (participants cannot see the real "you"), can engage in textual and voiced interactions with other avatars and can undertake all kind of actions in different virtual locations. In this article we will focus on the experiences in virtual worlds.

\subsection{Task effectiveness for enhancing intercultural communication in cross- cultural encounters}

In current teaching practice, second language learning tasks are used to engage learners in different types of learning and communication processing. As Moonen, De Graaff, \& Westhoff (2006) and Moonen (2008) point out, there is not one single, generally accepted definition of a task in the field of second language acquisition (see for an overview e.g., Bygate, Skehan, \& Swain, 2001; Ellis, 2003). For example, the definition by Breen (1987) includes all classroom activities directed at language learning, such as practice exercises, communication tasks and language tests. According to Willis (1996), on the other hand, a task is a goal-oriented and communicative activity in which the learners are free to choose their own linguistic resources. Skehan (1998) presents an extensive definition, which includes, among other things, that tasks should be meaningful, related to real-world activities, and that tasks should be assessed according to their outcome. Bygate, Skehan and Swain (2001) define a task as an activity which requires learners to use language, with an emphasis on meaning, to attain an objective, and which is intended to lead to or stimulate acquisition. Ellis (2003, p. 3) defines tasks in a more general way as "activities that call for primarily meaning-focused language use".

Essential components of most of these definitions are meaning-orientation, goal-orientation and acquisition-orientation. For the present study we further include an orientation on intercultural awareness (Byram, 1997; Müller-Jacquier, 2000), and we specify task characteristics for exploiting the added value of a virtually supported distant communication setting (Deutschmann, Panichi, \& MolkaDanielsen, 2009; O’Dowd \& Ware, 2009).

\subsection{Design principles for intercultural communicative tasks in virtual worlds}

Design principles in the present framework take into account communicative and intercultural competence in L2 acquisition within the context of virtual interaction. 


\subsubsection{Design principles for communicative competence}

For promoting communicative competence we distinguish four components: (1) rich input; (2) elicitation of meaningful, contextually appropriate language use; (3) focus on language form alongside meaning; and (4) convergent communicative outcome as a result of negotiation of meaning.

1. Rich input implies exposure to authentic, multimodal and contextually relevant language (Westhoff, 2004; Doughty \& Long, 2003). During task performance, the input is elaborated by means of interactional modification or negotiation of meaning.

2. Elicitation of meaningful, contextually appropriate language use implies:

- that the learners use the target language pragmatically and communicatively, instead of simply displaying knowledge of the target language (Ellis, 2003, p. 9);

- that they use the target language to engage in communicative activities involving real-world processes of language use (Ellis, 2003, p. 9);

- that they are free to choose how they use the target language;

- that the task does not prescribe in advance which elements of the target language the learners are supposed to use. (Ellis, 2003, p. 9; Willis, 1996);

- that it involves some kind of "gap" (information, reasoning), which the learners have to 'close' by using the target language communicatively (Ellis, 2003, p. 10);

- that it promotes learning by doing (Doughty \& Long, 2003) by eliciting cognitive processes (Ellis, 2003) or mental actions (Westhoff, 2004) such as processing of input, production of (pushed) output and interaction (Westhoff, 2004; Willis, 1996; Ellis, 2003; Doughty \& Long, 2003);

- that it promotes collaborative learning (Doughty \& Long, 2003) such as negotiation of meaning by assigning complementary roles, information and perspectives to the participants/learners.

3. Focus on language form alongside meaning implies:

- that the task does not specify in advance which target language forms should be used by the learners (Willis, 1996; Ellis, 2003);

- that it creates a "semantic space" (Ellis, 2003, p. 10) which might predispose the learners to process specific linguistic forms;

- that it promotes the acquisition of useful chunks (Doughty \& Long, 2003);

- that it provides the learner with negative feedback, e.g. through corrective recasts (Doughty \& Long, 2003);

- that it provides different opportunities to focus on form when learners' need arises, such as input flood, input elaboration or enhancement, recasts and input processing (Doughty \& Long, 2003; Ware \& O'Dowd 2008). 
4. Convergent communicative outcome as a result of negotiation of meaning implies that the task has a clearly defined general purpose/goal, a clearly defined communicative end product, a more or less specified procedure (Ellis, 2003, p. 21), and a set of instructions that is tailor-made to meet the specific needs of the learners (Doughty \& Long, 2003).

\subsubsection{Design principles for intercultural competence}

For promoting intercultural competence we apply Byram's five 'savoirs' (1997, 5054). Tasks should elicit:

1. Attitudes of curiosity and openness, readiness to suspend disbelief about other cultures and belief about one's own.

2. Knowledge of social groups and their products and practices in one's own and one's interlocutor's country, and of the general processes of societal and individual interaction.

3. Skills of interpreting and relating: to interpret a document or event from another culture, to explain it and relate it to documents from one's own.

4. Skills of discovery and interaction: to acquire new knowledge of a culture and cultural practices and the ability to operate knowledge, attitudes and skills under the constraints of real-time communication and interaction.

5. Critical cultural awareness/ political education: to evaluate critically and on the basis of explicit criteria perspectives, practices and products in one's own and other cultures and countries.

We further apply Müller-Jacquier's (2000) linguistic awareness of cultures, who proposes a framework for intercultural communication including social meaning, speech acts, organization of conversation, choice and development of topics, directness / indirectness, register, para-verbal factors, non-verbal means of expression, culture-specific values and attitudes, and culture-specific behaviour.

More specifically, we propose tasks that take conceptions and misconceptions in daily life as a starting point, that focus on intercultural contrasts and similarities, that imply a need to understand each other's point of reference for task completion, and imply a need to evaluate one's own points of view by means of someone else's.

\subsubsection{Design principles for virtual worlds}

Although virtual worlds, and particularly Second Life, are becoming more and more popular among language teachers, up to date there are very few documented studies on the specific use of Second Life for teaching and learning of foreign languages (see Molka-Danielsen \& Deutschmann (2009) and Deutschmann, Panichi, \& MolkaDanielsen (2009) for an overview) and particularly on Second Life as a place where foreign language learners can meet native speakers of the target language (Kuriscak \& Luke, 2009) for engaging in meaningful communicative and social interaction while undertaking joint action. However, interactional spaces such as Second Life have been assessed as beneficial for learning and achieving communicative and 
intercultural competence (Bryant, 2006; Thorne, 2008). In these virtual worlds, users can experiment and interact with a variety of norms of social interaction (Steinkuehler, 2006) and it is in these 3D environments such as Second Life where learners can have the opportunity to experience life-like social interaction while at the same time engaging in meaningful learning activities (Cooke-Plagwitz, 2008). The realistic nature of the environment provides authentic learning conditions that are otherwise difficult to recreate in traditional classroom settings (Dieterle \& Clarke, 2008).

In order to best exploit the challenges and opportunities of a virtually supported distant communication setting for task development, we take into account the following issues elaborated by Deutschmann and Panichi (2009): complexities of the technological environment; learner and teacher perception of the environment, in combination with their beliefs regarding learning and SLA; selecting physical characteristics of and within the virtual world; personal and cultural anonymity; visual representation of self via the avatar; co-construction of reality and shared culture; physical simulations of real-life tasks. Deutschmann and Panichi further distinguish tasks that make use of the social, communicative or cognitive dimension; tasks that make use of the affective/creative dimension; and tasks that make use of the spatial/physical dimension.

Within this study we use Deutschmann and Panichi's framework to elaborate specific design principles for virtual worlds. In virtual worlds visual context around communication partners is relevant, context is specifically adapted to conversation topics, other interlocutors might interfere, contexts might be adapted in order to promote awareness and learning, and tasks should trigger oral communication, that is, intensive oral communication is needed for successful task completion.

\subsubsection{Task design grid}

The tasks designed for and carried out in the NIFLAR project are based on the design principles elaborated above. The following grid was used for task development and evaluation by all researchers involved in the study. 
Table 2.1. Task design and evaluation grid for intercultural communicative tasks in video communication or virtual worlds.

The task exposes the learners to rich target language input.

Does the task:

- $\quad$ provide input that is authentic/unmodified, relevant/challenging and multimodal?

- enhance interactional modification or negotiation of meaning?

- $\quad$ elicit the use of authentic resources both before and during performance?

elicit the use of both predefined resources and resources provided by the interlocutors themselves

The task elicits meaningful target language use

Meaningfulness: Do the learners:

- use the language pragmatically and communicatively?

- $\quad$ use the language to engage in activities involving real-world processes of $L$ use?

- have the choice how to use the language, that is, no linguistic forms are prescribed in advance?

Use: Does the task:

- $\quad$ involve some kind of gap (information, reasoning, culture)?

- have the right balance between language-demanding and content-demanding processing?

- $\quad$ promote learning by doing (processing and interaction)

- $\quad$ promote collaborative learning?

- complementary roles, information, perspectives

two-way information exchange

convergent, goal-specific communication

positive interdependence

shared responsibilities

○ individual accountability

The task requires the learners to focus on form

Does the task:

- create a "semantic space" in order to elicit processing specific L forms?

- $\quad$ promote the detection and use of relevant chunks?

- $\quad$ elicit feedback on form by the native speaker on language of the learner?

- $\quad$ Provide opportunities to focus on form when learner need arises (negotiation, elaboration, recasts etc.)?

The task has a clearly defined communicative outcome

Does the task:

- have a clearly defined purpose that is relevant for all interlocutors?

- $\quad$ have a clearly defined communicative end product?

- $\quad$ elicit following a logical, relevant and challenging procedure?

- $\quad$ provide instructions that meet the needs of all interlocutors?

- $\quad$ aim at subjective, personal information exchange, related to objective, factual resources?

- $\quad$ Is the task both open (not fixed, prescribed) and determined (goal-oriented)?

The task enhances strategic awareness on language learning and use

Does the task:

- $\quad$ elicit planning, feedback and reflection

$\circ$ on language use

on communication

$\circ \quad$ on intercultural issues 
The task enhances focus on intercultural linguistic competence

Does the task:

- require learners to focus on intercultural topics, beliefs, contrasts, reflect upon them and share experiences ?

- $\quad$ elicit focus on contrasting and common everyday, implicit cultural habits, and beliefs?

- create intercultural awareness, but providing topics that contrast students' own beliefs and habits with that of their interlocutors?

- $\quad$ elicit awareness and reflection not only on target culture, but on own cultural habits and beliefs as well?

Does the task enhance:

- Attitudes of curiosity and openness, readiness to suspend disbelief about other cultures and belief about one's own?

- Knowledge of social groups and their products and practices in one's own and one's interlocutor's country, and of the general processes of societal and individual interaction?

- Skills of interpreting and relating: to interpret a document or event from another culture, to explain it and relate it to documents from one's own?

- Skills of discovery and interaction: to acquire new knowledge of a culture and cultural practices and the ability to operate knowledge, attitudes and skills under the constraints of real-time communication and interaction?

- Critical cultural awareness: to evaluate critically and on the basis of explicit criteria perspectives, practices and products in one's own and other cultures and countries?

The task takes the communicative and intercultural competence level of all interlocutors into account

Does the task align with proficiency level on oral interaction and intercultural awareness:

- with respect to task goal?

- with respect to task topic?

- with respect to task procedure?

General:

- $\quad$ Are clear stages in task sequencing provided?

o introduction

comparison/contrasting

construction/conversion

production/publication

- reflection

The task makes effective use of the challenges and affordances of virtual worlds

- Is the virtual context sufficiently culture-specific/-focusing/-contrasting?

- Is the virtual context sufficiently relevant and attractive for the task goal?

- Is the virtual context sufficiently prototypical, without being a caricature?

- Is the virtual context used in a socially, cognitively, affectively, creatively and spatially effective and challenging way, e.g. by:

- learning by exploring

$\circ \quad$ learning by collaborating

- learning by being (development of avatar character)

$\circ \quad$ learning by building/constructing

$\circ \quad$ learning by championing (focusing on strengths and successes)

○ learning by expressing

- Does the virtual context provide a safe environment (e.g., no other listeners/interlocutors are present at lower levels)?

- Is the number of interlocutors relevant for the communicative goals, topic and procedure?

- Is sufficient familiarization provided with environment and technical aspects of virtual communication?

- Does the task trigger oral communication, that is, is intensive oral communication needed for successful task completion 


\subsection{Case study on interaction carried out in Second Life}

A small-scale case study with four participants was conducted in Second Life to test the application of the task design grid for effective networked interactive tasks. The case study aimed at studying the following issues: (1) to analyse the kind of interaction the tasks elicited in the virtual world, by means of the task evaluation grid; (2) to explore the possibilities of existing Second Life worlds for enhancing interaction; and (3) to study whether and how the conditions anonymity versus familiarity may play a role in modelling interaction. Results of the case study might help fine-tuning language learning tasks to the specific affordances of emerging educational communication environments such as $3 \mathrm{D}$ virtual worlds.

\subsubsection{Method}

The case study was conducted during June and July 2009. Tasks for enhancing communication between native and non-native speakers were developed by the NIFLAR research team according to the task design principles outlined above. The participants in the case study were two foreign language learners of Spanish (one female and a male) at B1 proficiency level, (according to the Common European Framework of Reference for the Languages) from Utrecht University in The Netherlands, and two native pre-service teachers of Spanish (two females) from the University of Valencia and the University of Granada in Spain. In this case study the pre-service teachers did not participate in the task design stage. All four participants volunteered to participate in the pilot experience with Second Life and had also been involved in a project using video communication during March and April 2009. In a video communication environment (also called video conferencing) interlocutors can see each other by the webcam while carrying out communication tasks. Comparing both environments with their specific affordances would help us answering the question of how anonymity (not seeing the real person speaking) versus familiarity (having access to facial cues) may influence communication processes.

The following steps were taken for organizing the case study:

a) The students were sent an invitation by e-mail describing the pilot objectives and content and inviting them to participate;

b) A face-to-face meeting with students in Utrecht and a virtual meeting with students in Spain was organised to share the global objectives of the pilot;

c) Participants' computers and their Internet connections at home were tested on line for adequate functioning in Second Life;

d) Tutorials about learning to use Second Life were organised. These tutorials lasted approximately 3 hours;

e) A virtual meeting within Second Life was organised where the student participants met each other and the NIFLAR team (two researchers and a technical expert). They exchanged information about the pilot project and the tasks they would be carrying out in the following weeks. Subsequently, they went all together on a guided tour through various Hispanic places in Second Life. They walked around and danced in virtual Barcelona, flew on 
a flying carpet in the virtual Alhambra, Granada, and explored quests in an intercultural awareness raising space. The virtual meeting lasted two hours and at the end this first group meeting in Second Life was evaluated. The first impressions were unanimous: all had enjoyed the session and were very positive about the sessions to come.

f) A week later the four weekly sessions started that are reported in this study.

g) Participants received the task instructions per e-mail and were responsible to schedule their meetings by themselves.

h) Interactions were recorded for further analysis.

i) At the end of the experience participants filled in a questionnaire to evaluate the project.

\subsubsection{Tasks}

Four tasks were developed for the case study:

Task 1

The main objective for this task was to reflect upon intercultural similarities and differences. Students were asked to meet at an intercultural learning space in Second Life (Bluepill, Sietar) http://slurl.com/secondlife/Bluepill/230/194/67. Once there, they had to individually complete a questionnaire related to a chosen nationality. The questions aimed at finding out how well they knew that culture, giving them situations and asking to choose from a list of possible reactions. Unfortunately, not all nationalities were available and from those available they were requested to complete the ones that offered a Spanish version of the questionnaire. Afterwards, all four students rejoined at the NIFLAR space and discussed their findings, trying to explain differences and similarities with their own culture.

Task 2

The objective of this task was to explore Hispanic locations in Second Life and to interact with other native speakers. The task was conceived as a preparatory step for task 3. To avoid unpleasant situations while touring unexplored locations in Second Life, students were paired: Dutch students together and Spanish pre-service teachers together.

The destinations that the Dutch students visited were Barcelona, Jalisco and Al-Aldalus. Before starting their trip they discussed their expectations of what they thought they would find there. In these destinations they had to try to engage in conversation with other avatars and ask them about their experiences with Second Life. The pre-service teachers were asked to explore some "Hot Spots, the places to be in Second Life" (http://b-places.com/). The landmarks had to be Hispanic-related and they had to discuss their adequacy for teaching and types of activities that could be done there.

Task 3

For this task, the students were paired native - non-native. The main objective was to share experiences and tour together in some of the locations visited in task 2 . 
They had to tell their partner about the three places they had visited in the previous session: what were the things that they liked/disliked, in which way were the three places similar and different, something that surprised them and their opinion about the conversations with other avatars. After that, they had to choose one of the three locations, teleport their partner there and show them around. They were also encouraged to make comparisons with the other places they had visited with their previous partners in task 2 .

\section{Task 4}

This task was conceived as an evaluation of the experience. The students met at the NIFLAR space in Second Life and were given a number of aspects to discuss: general evaluation of their experience in a virtual world, things that worked and things that didn't work, the most and the least interesting task, adequacy of Second Life for learning languages and a comparison between Second Life and video communications environments.

The instructions for all tasks were given in the target language, in this case Spanish, and after each task the students had to answer a few evaluation questions related to that particular task. Actual scenes from the case study can be viewed at http://niflar.ning.com/video, where students can be seen in action during task 3 touring in Mexico and Jalisco and task 4 where students compared the affordances of Second Life as opposed to video communication.

Tasks were designed following the task design format for intercultural communicative competence. For an example of how this was done for tasks 2 and 3 , please refer to the appendix.

\subsubsection{Data}

Two sets of data have been gathered for analysis: interaction recordings and questionnaires. Additionally, informal debriefing interviews were held. The interaction sessions had an average length of one hour. As for the questionnaires, these were administered to the participants at the end of the pilot. These questionnaires had open and closed items. For the closed items a five-point Likert scale was used: 1 indicating negative or low values and 5 indicating positive or high ones. Question items 6 to 15 asked about the learners' ICT background, items 16 to 27 dealt with technical concerns during the project, items 28 to 35 inquired about the adequacy of the tasks, 36 to 38 were about the speech partner, 39 to 42 referred to issues related to image: seeing the partner and the quality of the locations visited, 43 to 50 measured their learning experiences, and 51 to 59 compared the use of video communication versus Second Life.

These two sources of data were gathered to assess the tasks which had been elaborated for the pilot. Researchers were interested in (1) analysing the kind of interaction the tasks elicited in the virtual world, (2) exploring whether the affordances of the specific environment had been adequately used, and (3) studying whether and how the conditions anonymity versus familiarity may play a role in modelling interaction. 


\subsubsection{Results}

\section{Recordings}

When analysing the recordings a clear difference was found in terms of verbal engagement and interaction behaviour of participants between the first and the fourth task, on the one hand, and the second and the third task, on the other hand.

In the first task, after having completed individually the survey for a specific culture, the four students met at the NIFLAR space in Second Life and discussed their experiences with that specific culture comparing findings and sharing impressions. As for the fourth task, participants were asked to evaluate with each other the project experience in Second Life according to specific points. Both sessions were characterized by a dynamic verbal turn-taking exchange among participants, with almost no space for silences and with relatively little action. They met and exchanged information and impressions (I think...), to share opinions ( $I$ agree...), to show understanding (I know what you mean) and puzzlement (I was surprised about...), to share past experiences (I really enjoyed touring around) and different views (I think you could look at it from the perspective...), seeking to reach common ground

As for the second and third tasks, participants were asked to explore Hispanic places in Second Life with a peer (in task 2 foreign language learners went together, as did the pre-service teachers) and try to interview other avatars in those places, while in task 3 they took the other peer for a tour to the places that had been visited in session 2 . In these tasks there was much action and a lot of movement going on, but interactions were characterized by large episodes of silence while touring around, which contrasts with the other two tasks where information and opinion exchange was the focus of the task.

In tasks 2 and 3, interactions focused on action planning (we will first do $X$ and then will visit $X . .$. ), proposing activities (shall we go for a horse ride?), describing spaces (this is a sauna), evaluating experiences (this is really nice), giving directions (here we have to turn to the right, follow me), establishing comparisons with real life (it is the same in real life; we can fly with our horses, I like that), expressing preferences (there is nobody at the beach, I prefer this to the overcrowded Spanish beaches in July), and giving many explanations on how to technically achieve activities in Second Life: how to lie down, how to ride on a horse, how to get a guided tour on a dragonfly, how to activate music, etc.

In order to give a clearer picture of how interactions triggered in a virtual environment evolve, we now discuss some fragments of interactions elicited by task 1, the favorite task for the students (see table 2).

The session took 53:06 minutes and was carried out in group: two preservice teachers $(\mathrm{T} 1 \& \mathrm{~T} 2)$ and two students of Spanish (S1 \& S2). The group met around a campfire in order to exchange experiences after having answered individually the cultural surveys of their choice in SL http://slurl.com/secondlife/Bluepill/230/194/67).

The interaction starts with all participants greeting each other. The on-task talk is initiated by $\mathrm{T} 1$ reporting on the questionnaire on the British culture she has answered and evaluating the experience. When exchanging this information, all 
avatars are still standing around the campfire, it is dark and this in-world situation triggers a quite elaborate off-task talk. T1 first mentions rather surprised that it is night in the virtual world and then asks whether they will stay there for the discussion or move to the beach (¿Vamos a la playa o qué?). S1's reaction is quick and rather physical, as he starts walking towards the beach. The rest of the group follows. The atmosphere is relaxed, informal, there are many instances of laughter with plenty of space for spontaneous off-task talk triggered by the situation: when going to the beach (turn 2: ¿tenéis biquini? turn 3: no, triquini), informal talk about one's appearance (turn 4: ¿te has cambiado el pelo?), a good place to sit down (turn 10: aqui no hay para sentarse), S1 sitting on the shore with the feet in the sea (turn 13: mira S1, se está mojando los pies), S2 being probably lost (turn 24: Y S2 ise ha perdido?), S1 falling into the water (turn 38: he caido al agua), the technical difficulties $\mathrm{T} 1$ experiences in order to sit down with the group (turns 50-63) and the funny situation created as she sits down on the floor giving the back to the group, who make jokes and laugh.

\section{(01:48- 4.50)}

They all walk to the beach and while walking...

1 T1: vamos a seguir a $\mathrm{S}$

T2: ¿tenéis biquini?

T1: pues no /// triquini (laughter)

(4)

T1 : ¿te has cambiao de pelo?

5 T2: sí, me he cambiado de ropa=

$\mathrm{T} 1:=\mathrm{T} 2$ ! ¿y eso cómo se hace?

T2: pues en el inventario

S2: eh ¿dónde estáis? (muy bajito)

T1: ah vale vale (4)

(At the sea shore)

10 T1: aquí no hay para sentarse (4) ah me parece, sí sí aquí me parecía (6)

(S1 sits down at the shore with the feet in the sea)

15 T1:Yo es que [no puedo hacer eso], me voy a caer]

T2: [¿cómo está el agua, S1?]

T1: ¿está buena? //

T2: [S1!]

T1: [mira aquí mismo] en esta pantalla, mira aquí hay un silloncito (she walks towards a sitting space)

20 S1: ¿qué?

T1: que [cómo está el agua, si está fría

T2: [mira aquí atrás]

S1: [no]

T1: [y S2], ¿se ha perdido?

25 S1: está calor

T1: ¿está caliente?

S1: para los pies

T1: mira, aquí atrás hay un: hay sillones

T2: vale va, pues vamos ahí que es muy cómodo / Y S2 ¿la hemos perdido?

30 T1: S2 se ha perdido, S2! (5)
(01:48- 4.50)

They all walk to the beach and while walking..

1 T1: let's follow S1

T2: have you got bikinis?

(4)

T1: no /// trikini (laughter)

T1 : have you changed your hair?

5 T2: yes, I have changed clothes $=$

$\mathrm{T} 1:=\mathrm{T} 2$ ! and how do you do that?

$\mathrm{T} 2$ : in your inventory

S2: eh where are you? (very softly)

T1: ah ok, ok (4)

(At the sea shore)

10 T1: here there is nothing to sit down (4) ah I think, yes yes here I thought (6)

(S1 sits down at the shore with the feet in the sea)

15 T1:Well, I [can't do that], I am going to fall]

T2: [how is the water, S1?]

$\mathrm{T} 1$ : is it good? //

T2: [S1!]

T1: [look just here] in this screen, look here is an armchair (she walks towards a sitting space)

20 S1: sorry?

T1: [how is the water, is it cold?

T2: $\quad$ [look behind here]

S1: [no]

T1: [and S2], is he lost?

25 S1: it's warm

$\mathrm{T} 1:$ is it warm?

$\mathrm{S} 1$ : for your feet

$\mathrm{T} 1$ : look, behind here there is a : there are armchairs

T2: ok then, let's go there because it's very comfortable / And S2 have we lost her?

30 T1: S2 has got lost, S2! (5) 
(T1 \& T2 walk to the sitting space and sit down)

T1: pues vamos a sentarnos aquí, ¿no?

S2: no

T2: hay qué [bien con] vistas al mar

T1: [S2!]

35 T1: claro

S2: eh: ¿dónde estáis? ah eso

T1: ¿nos ves?

S1: he caído al agua

T2: (laughs)

S2: os veo os veo

40 T2: S1 se ha caído al agua

T1: (laughs)

(S2 appears in the scene)

S2: ah, hola! (laughs)

T1: ¿dónde está? // ah bien $\mathrm{S} 1$

S2: hola! (laughs)

T1: hola (laughs)

45 T2: S1 sigue nadando por ahí, ¿dónde está S2 no la veo?

S2: aquí aquí

T1: ah!

S2: hola

T1: ahí

(T2 sits down but T1 cannot sit down and moves around;. S1 \& S2 sit down)

50 T1: (8) yo no me puedo sentar

T2: uy y eso?

T1: porque se me ha olvidado el ratón. Estoy en casa de mi madre y se me ha olvidado el ratón y no sé cómo se le da con: /// con el con la mano, o sea sé que con el ratón es botón derecho pero aquí me lío. Vamos a ver, vamos ver, le doy dos veces... Ah! calla, calla! Sí sí, ya me acuerdo, claro,

S2: uhum (laughs)

S1: (laughs)

T1: con lo de abajo

(T1 manages to sit down but on the floor with her back to the rest of the group)

55 T2: (laughs) pero siéntate con nosotros S1: (laughs) ah sí

T1: ¿dónde me he sentao? (laughs)

S2 (laughs)

T1:s espérate

S2: detrás del sofa

60 T1: espera espera (laughs while standing up and going to the group) /// es que sin ratón, te acostumbras al ratón no puedo, espérate, uy por Dios (is moving around) vamos a ver, T1! Un momento, eh?

T2: tranquila

T1: vamos a ver, sí. Está. Ahí

S1: por el suelo
(T1 \& T2 walk to the sitting space and sit down)

T1: let's sit here, shall we?

S2: no

T2: it's [great with] a sea view

T1: [S2!]

35 T1: of course

S2: eh: where are you? ah this

T1: can you see us?

S1: I fell in the water

T2: (laughs)

S2: I see you I see you

40 T2: S1 has fallen in the water

T1: (laughs)

(S2 appears in the scene)

S2: ah, hi! (laughs)

T1: where is she? // ah ok S1

S2: hi! (laughs)

T1: hi (laughs)

45 T2: $\mathrm{S} 1$ is still swimming down there, where is S2 I can't see her?

S2: here here

T1: ah!

S2: hi

T1: there

(T2 sits down but T1 cannot sit down and moves around;. S1 \& S2 sit down)

50 T1: (8) I can't sit down

T2: uy why not?

T1: because I have forgotten my mouse. I am at my mum's house and I have forgotten my mouse and I don't know how to do it with: /// with my hand, well I know that with the mouse you have to right click but here I get all confused. Let's see, let's see, I double click ... Ah! I got it, I got it! Yes, yes, I remember now, of course,

S2: uhum (laughs)

S1: (laughs)

T1: with that thing under

(T1 manages to sit down but on the floor with her back to the rest of the group)

55 T2: (laughs) but sit down with us

S1: (laughs) oh yes

T1: where did I sit down? (laughs)

S2 (laughs)

$\mathrm{T} 1$ :s wait a sec

S2: behind the sofa

60 T1: wait wait (laughs while standing up and going to the group) /// without a mouse, you get used to the mouse I can't, wait a sec, uy oh God (is moving around) let's see, T1! One moment, yes?

T2: relax

T1: let's see, yes. It is. There

S1: on the ground

T1 (manages to join the group and to sit 
T1 (manages to join the group and to sit down on the sofa)

65 T1: bueno ahí mismo me siento, ahí mismo/// BUENO:: down on the sofa)

T1: well I'll just sit there, right there /// GOOD:

Communication exchanges triggered by the in-world situation emerged in all the sessions and are characteristic for the interactions conducted in virtual worlds: much of the talk is context triggered and unpredictable as real communication is. In this sense, participants reported in the questionnaires that this action related, context specific and unpredictable situation in which broad spontaneous talk is generated intensifies the added value of the environment (see table 4, item 54). This contrasts with the predictability and lack of authenticity of many interactions conducted in a classroom setting.

After this introductory off-task experience and once all participants are sitting on the sofas, they reinitiate the on-task talk by exchanging information about the countries they have elected for the cultural survey. Each participant took a different nationality: S1 China, S2 Spain, T1 Great Britain and T2 Russia. These differences in the target cultures elicit a dynamic communication exchange triggered by unexpected or unknown culture specific habits, which they explain, compare with their own customs and those of the other group, and approach from different but complementary angles: starting from the global national perspective and moving to a more specific, contextual and personal one.

After some short exchanges and in order to focus talk and stimulate the students' contribution to conversation development, T2 asks S2 to share her experiences with the Spanish survey. S2 starts talking but is quite nervous, she has difficulty expressing herself in Spanish and shares this with the group, who reacts supporting her and cheering her up.

(06:57-8:38)

1 T2: Bueno S2, cuéntanos algo del test de España, ya que no pudimos hablar contigo el otro día $=$

T1: =venga!

T2: ¿qué te parece?

S2: (4) ah: las preguntas eh eran muy eh difícil pero: eh eh: // creo que: eh: ya sabes mucho sobre eh España porque estudio español y eh: he estado en España algunas veces y eh y las las eh eh // las costumbres culturales son diferentes de Holanda pero // no son muy diferente creo, depende de depende de cultura pero depende de personas también

5 T2: uhum (3)

S2: si, por ejemplo si una persona u: pufff (laughs) ehm eh lo siento pero es muy difícil de hablar español para mí, porque no: eh no eh: hablando español por tres meses o algo y: ehem (laughs)

T2: que va, tranquila, [pero si hablas] muy bien
(06:57-8:38)

T2: Well S2, tell us something about the Spanish quiz, because we couldn't talk to you the other day $=$

T1: =come on!

T2: what do you think?

S2: (4) ah: the questions were eh were very eh difficult but: eh eh: // I think that: eh: you know a lot about eh Spain because I study Spanish and eh: I have been to Spain a few times and eh and the the eh eh // the cultural customs are different from Holland but // they are not very different I think, it depends on it depends on the culture but also it depends on the people too

5 T2: $\operatorname{uhum}(3)$

$\mathrm{S} 2$ : if, for example if a person $\mathrm{u}$ : pufff (laughs) ehm eh I'm sorry but it's very difficult to speak in Spanish for me, because I haven't : eh I haven't eh: speaking Spansih for three months or something and: ehem (laughs)

T2: that's not true, relax, [but you speak] 
T1:

S2: sí, sí, sí

[habla S2!]

0

T1: claro, si para si para eso hacemos esto $\mathrm{S} 2$, para que [vosotros practiquéis] también

S2: [sí, sí, sí]

T1: claro,

S2: sí, para practicar (laughs)

T1: claro para practicar (laughs), tú tranquila

15 S2: ah gracias, gracias (laughs)

(5)
T1: ${ }^{\text {very well }} \quad$ [speak S2!]

S2: yes,yes, yes

10 T1: of course, that's why that's why we are doing this $\mathrm{S} 2$, so [you can practice] too

S2: [yes, yes, yes]

T1: of course,

S2: yes, to practice (laughs)

T1: of course to practice (laughs), relax

15 S2: ah thanks, thanks (laughs)

(5)

Although interactions could be described as being horizontal (participants have a lot in common: they are all university students, sharing age, interests...), there is an intentional asymmetry due to the fact that on the one hand, the Spanish participants are natives and master the language they are using for communicating which gives them more power (Fairclough, 1989), and on the other, as pre-service teachers they have a different status in interaction, a more leading role in the conversation: they are the ones initiating and changing most topics, asking the questions and producing most quantity of talk. Pre-service teachers are aware that this situation might be quite threatening for the foreign language students and use affective strategies, that is, they invest in strengthening horizontal relationships by trying to create a safe, supportive atmosphere, stimulating the others to participate, and providing positive feedback.

After this group engages in an interesting discussion about the (in)adequacy of global surveys as those answered at the SL virtual space. The Spanish native speakers do not seem to accept the view that Spanish workers are envious (envidiosos), a quite stereotypical image, in their view. They ask the Dutch students whether Dutch workers are "envious", which triggers the next side-sequence: a sequence of negotiation of meaning this time, where S2 explains in the target language the meaning of the lexical item "envidia" to S1, who does not know it. The sequence ends up successfully with S2 understanding the meaning of the new lexical item that triggered the negotiation sequence.

$(10: 58-11: 35)$

T2: ¿pero, sabéis lo que es la envidia? (2)

T1: e[so es]

S1: [no]

S2: sí,

T1: ah

S2: yo sé [yo sé] yo sé

T1: [vale]

T2: [vale], qué es?

$\mathrm{T} 1$ : explícaselo, $\mathrm{S} 2$ !

T2: explícalo, S2! (5)

S2: sí, estar envidioso es eh si quieres algo que otra persona eh eh tengas

$\mathrm{T} 1$ : huhum, muy bien

S2: tiene
(10:58-11:35)

T2: but, do you know what envy is? (2)

T1: th[at is]

S1: [no]

S2: yes,

T1: ah

S2: I know [I know] I know

T1: [ok]

T2: [ok], what is it?

$\mathrm{T} 1$ : explain it to him, S2!

T2: explain it, S2! (5)

S2: yes, to be envious is eh when you want something that somebody else eh eh will have

T1: huhum, very good

S2: has 


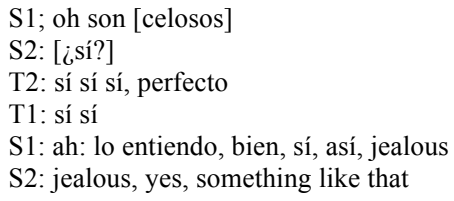

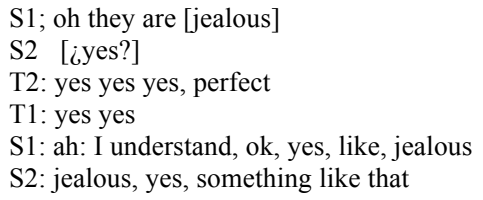

After this side sequence, participants engage again in on-task discussion and tackle the British workers topic who are described as a group having a great sense of humour in the surveys, a view T1 does not share. She has the impression that the British are orderly, always on time, very serious, etc. S2 resorts to her own personal experience, as she has several British colleagues at her work, and emphasizes that the British do indeed have a great sense of humour. T2 agrees and adds a different nuance referring to the Spanish and English humour as being quite different, the British one being more ironic than the Spanish one. This gives rise to a discussion around humour as being culture-specific, in which they address other different cultures such as the Japanese, Chinese, Russian, and Dutch.

S2 elicits a topic change when she asks the Spanish speakers whether they have been to The Netherlands, which triggers in turn a new subtopic on soft and hard drugs, Amsterdam and the differences both cultures view the use of drugs.

Further topics participants discussed from a cultural contrastive point of view are: hospitality, how to go about when paying consumptions in a bar, the meaning of gestures, how to react when one gets a present (this topic elicits a very rich and long information exchange sequence)

The on-task interaction is interrupted for the first time due to sound problems experienced by S2 (38:00). Meanwhile participants move to the welcome area. In their way back new unexpected action and spontaneous talk arises as they come across a gaming space and start playing memory in-world. S1 turns out to be really good at it and gets compliments from the other peers.

Once again T2 (40:25) retakes the survey topic to discuss and contrast information about (a) how the Russian culture interprets the fact of women managers going alone to a restaurant and (b) which clothing female managers have to wear in Britain.

The session comes to an end with partners negotiating the next appointment for virtual action (45:20-52:23) and saying goodbye (52:23-53:06).

\section{Questionnaires}

Table 2.2 shows the answers obtained from the questionnaires. The foreign language learners (student 1 and 2) rated the tasks towards the high end when asked if they found them interesting for interaction with native speakers. They also found the majority of the tasks useful for their language learning process and adequate to their language level. As for their learning experience, the most noticeable is the item regarding a gain in confidence when talking in the target language. 
Table 2.2: Questionnaire results for foreign language learners.

\begin{tabular}{lcc}
\hline & Student 1 & Student 2 \\
\hline 28. I found tasks interesting for interaction with the & \\
native speaker / pre-service teacher: & 5 & 4 \\
Task 1: How well do you know the English/ the French...? & 4 & 2 \\
Task 2: Travelling round Second Life [part 1] & 4 \\
Task 3: Travelling round Second Life [part 2] & 3 \\
Task 4: Impressions & 3 & 4 \\
29. I found tasks useful for my language learning process: & 2 & 4 \\
Task 1: How well do you know the English/ the French...? & 4 \\
Task 2: Travelling round Second Life [part 1] & 4 \\
Task 3: Travelling round Second Life [part 2] & 4 & 4 \\
Task 4: Impressions & 4 & 3 \\
30. The tasks were adequate to my language level & 4 & 4 \\
Learning experiences & & 4 \\
43. What have you learned during the sessions? & \\
a. To be aware of cultural contrasts and similarities & 2 & 3 \\
b. To talk more fluently & 3 & 3 \\
c. To become confident talking in the target language & 5 & 3 \\
d. New words & 3 & \\
e. Idioms & 2 & 3 \\
f. To use grammar more accurately & 3 & \\
\hline
\end{tabular}

Table 2.3 shows the attitude of the participants towards Second Life.Three out of the four participants scored high $(2,4,5,4)$ when asked if they would like virtual worlds such as Second Life to be part of their language courses. The quality of the locations visited was also rated positively $(4,3,3,4)$ and the majority of them felt being teleported there $(5,1,5,4)$ to be realistic.

Table 2.3. Attitude towards Second Life. Students and pre-service teachers.

\begin{tabular}{|c|c|c|c|c|}
\hline & Student 1 & Student 2 & Teacher 1 & Teacher 2 \\
\hline $\begin{array}{l}\text { 48. I would like Second Life [or other } \\
\text { virtual world] to be part of my } \\
\text { language courses. }\end{array}$ & 2 & 4 & 5 & 4 \\
\hline $\begin{array}{l}\text { 41. How do you value the quality of the } \\
\text { locations visited in Second Life? }\end{array}$ & 4 & 3 & 3 & 4 \\
\hline $\begin{array}{l}\text { 42. Did you feel "transported" to these } \\
\text { locations? How real did it feel? }\end{array}$ & 5 & 1 & 5 & 4 \\
\hline
\end{tabular}

Among the negative aspects of using Second Life for learning languages some problems with audio were mentioned that prevented the participants from doing the activity properly and left only the text chat option. One of the four participants reported that it was a disadvantage not to have access to facial expressions, as it made adequate interpretation of native speaker utterances more difficult.

The only negative thing I can think of is that sometimes we had problems with audio and couldn't do the activity properly. (Pre-service teacher)

Exploring a location on your own to discover its educational uses can be quite boring. There is still a lot to be done. In some locations avatars still communicate via text chat and not voice. More Spanish and less English. The language can be a limitation for future teachers and students. (Pre-service teacher) 
You can't see each other talking so you can't use face expressions to understand the language.
(FL student)

More topics to talk about, a new way of teaching and learning and a more relaxed way of talking due to its anonymity were some of the main positive aspects expressed by the participants:

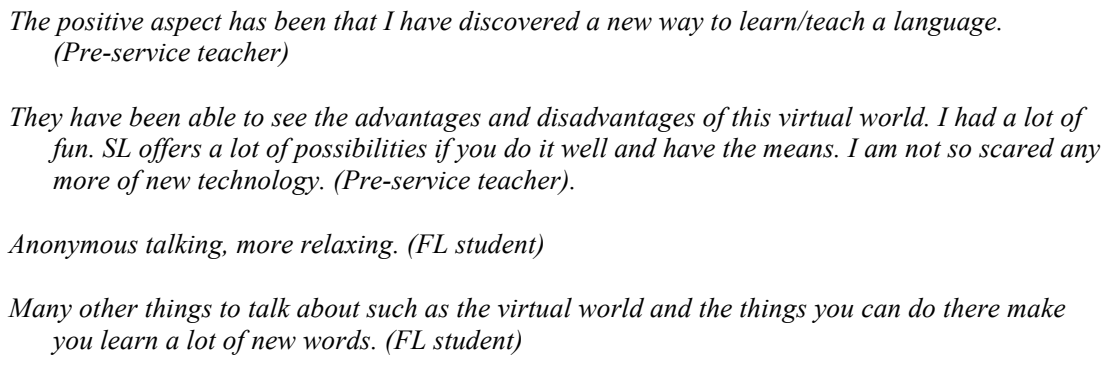

In the comparison between video communication and Second Life, participants did not feel remarkably different when taking part in one or the other: two participants felt slightly more comfortable in Second Life than in video communication (student 1: $5 / 4$ and student 4: 4/3). They mentioned problems logging in for video communication, anonymity being encouraging but lacking reality and the possibility to express oneself better when they can see each others' faces.

In Table 2.4 we present an overview of the comparisons the participants established between Second Life and video communication. The advantages of using Second Life over video communication as expressed by the participants were the flexibility that using an avatar gives in starting a conversation, the additional topics created by the environment, the discovery factor and elements of imagination. Although participants also noted some disadvantages, such as the availability of an up-to-date computer with a good Internet connection and not being able to see your interlocutor's face, they all preferred Second Life over video communication when asked which environment offers more possibilities to enrich their language learning experience. 


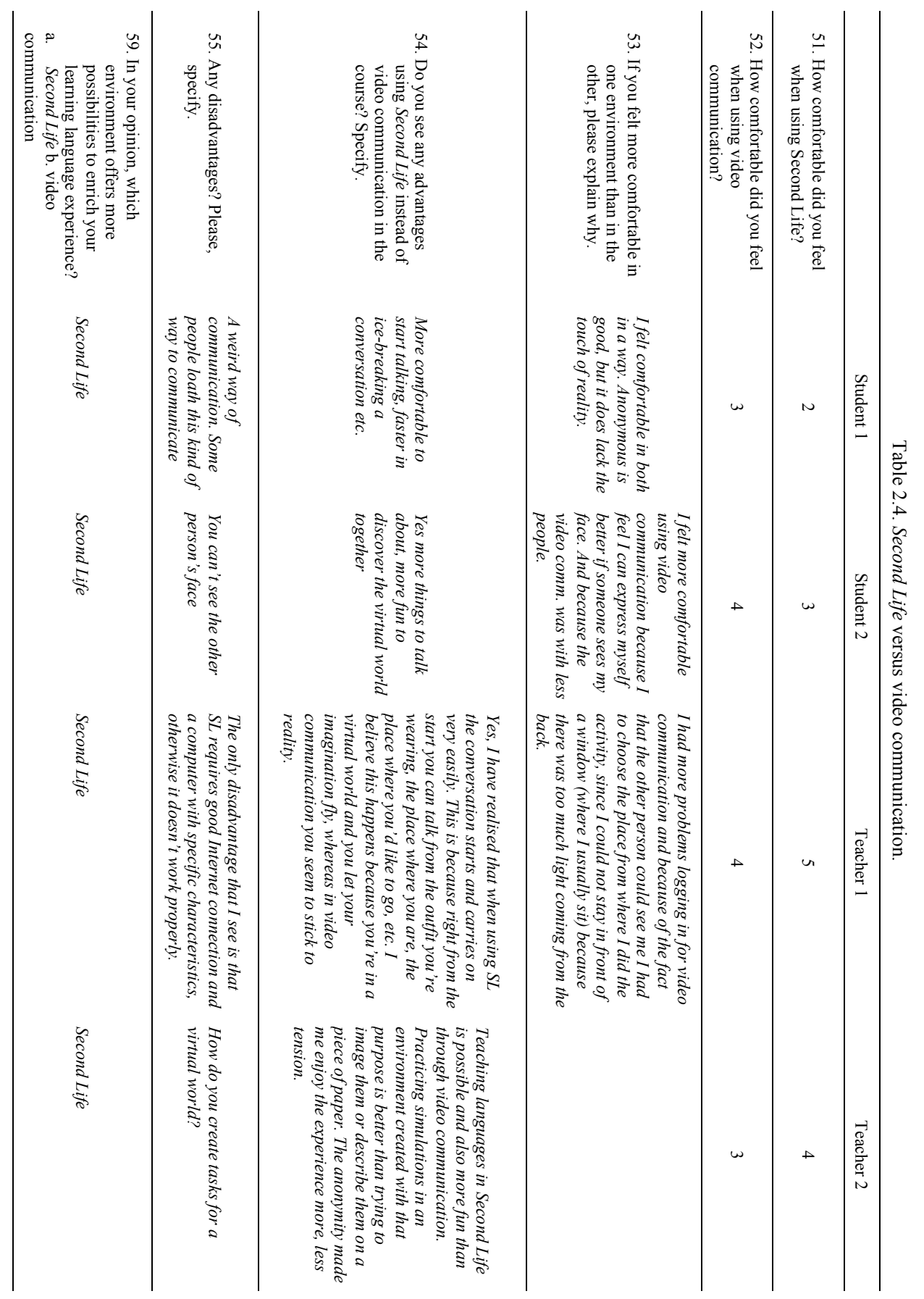




\subsection{Discussion}

The recordings show that the tasks elicited vivid and task-related interaction among the participants. There was negotiation of meaning, and interaction was used to engage in real-life activities. Some of the interaction was outcome directed, but part of the interaction was process oriented in the first place: how to fine-tune your avatar, how to move around in Second Life, for example. There was little focus on language form during task completion, although occasionally implicit correction took place.

Tasks stimulated participants to focus on intercultural issues; this did not seem to be artificial for the participants within the virtual setting. However, there were only few opportunities for intercultural interaction with unknown or anonymous avatars in Second Life. Passersby were not present, or not interested in communicating.

As for Byram's (1997) five savoirs, participants showed attitudes of curiosity and openness, not only towards each others' cultures, but also towards particular virtual world 'culture'; both the language students and the pre-service teachers used and expanded their knowledge of the interlocutor's society and daily life; they interpreted and related culture-specific events from the virtual world; they discovered and interacted to acquire new knowledge of both their interlocutors' culture and of the virtual world; they expressed critical cultural awareness towards practices and products of their own, the interlocutors' and the virtual world's cultural events. Interestingly, therefore, the tasks in the $3 \mathrm{D}$ virtual world environment did not only allow for intercultural communication with respect to the interlocutors' culture, but also triggered intercultural communication on cultural characteristics and events of the virtual world itself.

Although obviously the participants could not see the real person behind the avatar, the fact that they mostly interacted with the same partners who used their voices, highly contributed to create a pleasant and safe environment for them to interact and establish intersubjectivity. In this sense communicative exchanges in Second Life were not characterized by anonymity but by familiarity and rapport.

The more participants carried out Second Life specific tasks (task 2 and 3) the less oral communication took place. Task 1 and 4 were richer in communication, but were less context specific for Second Life. These tasks could have been carried out in other communication contexts (video communication or classroom) as well. Therefore, task design principles have to be further specified for $3 \mathrm{D}$ virtual world settings, focusing on enhancing rich oral interaction to be necessary for task completion, while exploiting at the same time the exploratory, functional and gaming possibilities of Second Life as much as possible.

The four participants in this case study all preferred oral communication in Second Life compared to video communication. However, their motivation for this does not show a clear picture: some preferred Second Life because they felt more comfortable communicating with virtual interlocutors, others preferred the topicspecific setting in which communication in Second Life took place, yet others had 
experienced fewer technical problems with Second Life than with video communication.

The results of this case study are limited with respect to their generalizability, due to the fact that only two language students and two pre-service teachers participated in the four tasks. In a later stage, the NIFLAR project will compare larger groups of students and pre-service teachers participating in parallel tasks in virtual worlds and video communication. However, small-scale case studies may serve as a discovery stage for the fine-tuning of language learning tasks to the specific affordances of emerging educational communication environments such as 3D virtual worlds. Furthermore, the small-scale case study has allowed for an indepth interactional analysis as illustrated in 4.4.1.

\subsection{Conclusions}

A key issue in foreign language education concerns the development and use of adequate interaction tasks which contribute to enhance effective intercultural communicative competence (ICC) while respecting learners' specific needs. In this article, criteria for elaboration of interaction tasks to be carried out in synchronous e-learning environments have been presented and applied in a case study conducted in Second Life which aimed at exploiting the specific affordances of the virtual environment in interaction processes.

The set of tasks developed for Second Life helped to gain insight into the creation of tasks for virtual worlds using the task design grid. It also contributed to form a clearer view of what students liked and did not like and how comfortable they felt interacting in the virtual environment. The recordings, questionnaires and interviews showed which activities worked well and which ones did not elicit the type of interaction we aimed at, and provided into the challenges to take full advantage of the affordances of Second Life to benefit students' ICC learning process. The pre-service teacher participants, although they had not participated in the task design stage, regarded their experience in this pilot as an eye opener that let them check out this virtual world for themselves and made it possible for them to see its benefits but also its flaws. They saw the advantages of a virtual world for teaching languages ("To be able to practice simulations in an environment created for that purpose is better than to imagine those situations or than writing them down on paper; it makes everything more realistic.") and expressed its usefulness to become aware of cultural contrasts and similarities.

We found that Second Life specific tasks that stimulated learners to explore virtual worlds together while exchanging information (task 2 and 3), triggered instances of dynamic communication exchange as well as quite large episodes of silence, whereas other tasks ( 1 and 4$)$ were richer in communication, but less context specific for Second Life. Therefore, task design principles have to be further adapted for 3D virtual world settings, focusing on enhancing rich oral interaction to be necessary for task completion, while exploiting at the same time the exploratory, functional and gaming possibilities of SL as much as possible. Although only two students and two pre-service teachers participated in this case study, we should take 
full advantage of the positive attitude these participants have expressed unanimously towards virtual worlds and of the powerful educational potential of these 3D environments. Efforts and resources should be geared towards the development of more life-like and challenging settings that would give foreign language learners the opportunity to enhance their intercultural communicative competence. The findings of this type of research will help us to further explore the powerful potential of virtual worlds for second language learning.

\section{$2.8 \quad$ References}

Breen, M. (1987). Learner contribution to task design. In C. Candlin and D. Murphy (Eds.), Language Learning Tasks (pp. 23-46). Englewood Cliffs, N.J.: Prentice Hall.

Bryant, T. (2006) Using World of Warcraft and other MMORPGs to foster a targeted, social, and cooperative approach towards language learning. Academic Commons.

Bygate, M., Skehan, P., \& Swain, M. (2001). Researching pedagogic tasks. Second language learning, teaching and testing. Harlow, UK: Pearson.

Byram, M. (1997). Teaching and assessing intercultural communicative competence. Multilingual Matters.

Cooke-Plagwitz, J. (2008). New Directions in CALL: An objective introduction to Second Life. CALICO Journal, 25 (3)

Deutschmann, M., \& Panichi, L. (2009). Instructional design, teacher practice and learner autonomy. In J. Molka-Danielsen and M. Deutschmann (Eds.), Learning and teaching in the virtual world of Second Life (pp. 27-44). Trondheim: Tapir Academic Press.

Deutschmann, M., Panichi, L., \& Molka-Danielsen, J. (2009). Designing oral participation in Second Life - A comparative study of two language proficiency courses. ReCALL, 21 (2), 206-226.

Dieterle, E., \& Clarke, J. (2008). Multi-user virtual environments for teaching and learning. In M. Pagani (Ed.), Encyclopedia of multimedia technology and networking. Hershey, PA: Idea Group, Inc.

Doughty, C., \& Long. M. (2003). Optimal psycholinguistic environments for distance foreign language learning. Language Learning and Technology, 7 (3), 50-75

Ellis, R. (2003). Task-based language learning and teaching. Oxford, UK: Oxford University Press.

Fairclough, N. (1989). Language and power. London: Longman.

Kuriscak, L.M, \& Luke C.L. (2009). Language learner attitudes toward virtual worlds: An investigation of Second Life. In G. Lord \& L. Lomicka (Eds.), The next generation: Online collaboration and social networking in CALL (173-207). San Marcos, TX: CALICO.

Molka-Danielsen, J., \& Deutschmann, M. (Eds.). (2009). Learning and teaching in the virtual world of Second Life. Trondheim, Norway: Tapir Academic Press.

Moonen, M. (2008). Testing the multi-feature hypothesis; Tasks, mental actions and second language acquisition (dissertation). Utrecht, the Netherlands: Universiteit Utrecht. 
Moonen, M., De Graaff, R., \& Westhoff, G. (2006). Focused tasks, mental actions and second language learning. Cognitive and connectionist accounts of task effectiveness. ITL - International Journal of Applied Linguistics, 152, 3553.

Müller-Jacquier, B. (2000). Linguistic awareness of cultures; principles of a training module. In J. Bolten (Ed.), Studien zur internationalen Unternehmenskommunikation (pp. 20-49). Leipzig: Popp.

O'Dowd, R., \& Ware, P. (2009). Critical issues in telecollaborative task design. Computer Assisted Language Learning, 22 (2), 73-188

Open Simulator project http://opensimulator.org/wiki/Main_Page.

Skehan, P. (1998). A cognitive approach to language learning. Oxford: Oxford University Press.

Steinkuehler, C. (2006). Massively multiplayer online videogaming as participation in a discourse. Mind, Culture \& Activity, 13 (1), 38-52.

Thorne, S. L. (2008). Transcultural communication in open Internet environments and massively multiplayer online games. In S. Magnan (Ed.), Mediating Discourse Online (pp. 305-327). Amsterdam: John Benjamins.

Ware, P., \& O'Dowd, R. (2008). Peer feedback on language form in telecollaboration. Language Learning and Technology, 12 (1), 43-63.

Westhoff, G. (2004). The art of playing a pinball machine. Characteristics of effective SLA-tasks. Babylonia, 12(3), 58-62.

Willis, J. (1996). A framework for task-based learning. Harlow, UK: Longman. 


\subsection{Appendix. Task design format}

Task design format for intercultural communicative competence in virtual worlds

\begin{tabular}{|c|c|}
\hline Task title & Traveling round Second Life \\
\hline General task objective & $\begin{array}{l}\text { To explore Hispanic environments in Second Life, reflect upon } \\
\text { other people's experiences in Second Life and value the } \\
\text { educational potential of other places present in Second Life }\end{array}$ \\
\hline $\begin{array}{l}\text { Target group: } \\
\text { Target language } \\
\text { Level (CEFR) } \\
\text { \# participants } \\
\text { Participating institutes }\end{array}$ & $\begin{array}{l}\text { Spanish } \\
\text { B1-C1 } \\
\text { Max } 4 \\
\text { Any }\end{array}$ \\
\hline $\begin{array}{l}\text { Task goals: } \\
\text { Language goals } \\
\text { Communicative } \\
\text { Linguistic } \\
\text { Intercultural goals }\end{array}$ & $\begin{array}{l}\text { After completing this task, the student can: } \\
\text { Express preferences } \\
\text { Plan activities } \\
\text { Exchange opinions } \\
\text { Ask for \& provide information } \\
\text { Compare and discuss with interlocutors the differences of places } \\
\text { visited } \\
\text { Be aware of \& talk about differences \& similarities in cultures } \\
\text { regarding interactive styles, and portrait of real life in SL } \\
\text { Contrast uses and customs }\end{array}$ \\
\hline $\begin{array}{l}\text { Task context: } \\
\text { Task function in curricular context } \\
\text { Additional activities outside VC/VW } \\
\text { ("blended learning") }\end{array}$ & $\begin{array}{l}\text { Final task on the objectives described above } \\
\text { During the f } 2 \mathrm{f} \text { traditional lessons the communicative objectives } \\
\text { of the final task will be handed on and practiced }\end{array}$ \\
\hline $\begin{array}{l}\text { Task outcome: } \\
\text { End products, e.g.: } \\
\text { Oral } \\
\text { Written } \\
\text { Individual or group? }\end{array}$ & $\begin{array}{l}\text { Oral: interviewing other avatars and discussing encounters with } \\
\text { other partners, acting as tour guide } \\
\text { A written summary [part of aftertask] as reference document for } \\
\text { discussions and information sheets for destinations. } \\
\text { Individual assignment }\end{array}$ \\
\hline $\begin{array}{l}\text { Task size / work load: } \\
\text { preparation time } \\
\text { performance time } \\
\text { evaluation time }\end{array}$ & $\begin{array}{l}\text { Max: } \\
\text { Preparation: } 1,5 \mathrm{~h} \text { [task } 2 \text { itself is the preparation phase] } \\
\text { Performance: } 1,5 \mathrm{~h} \\
\text { Post task: } 1 \mathrm{~h}\end{array}$ \\
\hline $\begin{array}{l}\text { Technical specifications: } \\
\text { VW needs } \\
\text { Additional materials and activities } \\
\text { support needed }\end{array}$ & $\begin{array}{l}\text { VW needs: } \\
\text { Common meeting point } \\
\text { In world browser }\end{array}$ \\
\hline $\begin{array}{l}\text { Evaluation and reflection: } \\
\text { Evaluation of task completion } \\
\text { Reflection and self-assessment }\end{array}$ & $\begin{array}{l}\text { By students and teachers: } \\
\text { After task activity }\end{array}$ \\
\hline $\begin{array}{l}\text { Pedagogical context: } \\
\text { Role of student teachers } \\
\text { Learning goals for student teachers }\end{array}$ & $\begin{array}{l}\text { Native language role models } \\
\text { Providers of cultural information } \\
\text { Tour guides of new locations } \\
\text { Learning goal: gathering criteria for using SL locations as } \\
\text { platforms for language teaching and discovering how SL in } \\
\text { coordination with adequate tasks may contribute to language } \\
\text { teaching }\end{array}$ \\
\hline
\end{tabular}




\section{Chapter 3}

\section{Collaborative tasks for negotiation of intercultural meaning in virtual worlds and video communication ${ }^{1}$}

\subsection{Abstract}

In many foreign language education settings, communication tasks in the target language mostly take place between non-native speaker classmates sharing the same mother tongue. 'Networked' environments such as voice-enabled 3D virtual worlds or video communication may have an added value in creating opportunities for language learners to synchronously communicate outside the classroom. As such, these tools may facilitate intercultural communication and collaboration with other (native) speakers of the target language. In the European Networked Interaction in Foreign Language Acquisition and Research (NIFLAR) project, innovative elearning environments were designed and studied for their potential to create authentic and interactive contexts that support the development of intercultural competence in foreign language learning contexts. The technology-mediated pedagogical tasks targeted intercultural communicative competence (following, e.g., Byram, 1997; Müller-Jacquier, 2003), in which intercultural awareness and social interaction seek to play a much larger role than it is possible in current classroombased foreign language education. The NIFLAR design also took into consideration the set of design principles that have emerged from TBLT research (Ellis 2003; Doughty \& Long, 2003; Long, 2009; Norris, 2009; Van den Branden, 2006; Willis, 1996). In this chapter we present NIFLAR's technology-mediated, task-based framework for the development of intercultural competence and discuss its application to both task-based video communication and the virtual world of Second Life by Dutch learners of Spanish communicating with native-speaker teachers of Spanish. We offer qualitative and quantitative data gleaned from the completion of two tasks and discuss the potential effects of technology-mediated TBLT in such environments, focusing on negotiation of intercultural meaning in communication between language learners and native speakers.

1 This chapter has been published as: Canto, S., De Graaff, R., \& Jauregi, K. (2014). Collaborative tasks for negotiation of intercultural meaning in virtual worlds and video communication. In M. González- Lloret \& L. Ortega (Eds.), Technologymediated TBLT: Researching technology and tasks (pp.183-212). Amsterdam: John Benjamins. 


\subsection{Authors' acknowledgement}

The European Networked Interaction in Foreign Language Acquisition and Research (NIFLAR) consists of a consortium of seven universities (Valencia and Granada in Spain, Coimbra in Portugal, Palacky in Olomouc, Czech Republic, Nevsky Institute and Novosibirsk in Russia, and Concepción in Chile), two Secondary Schools (in Spain and The Netherlands), and an e-learning consultancy company (TELLConsult in The Netherlands) under the coordination of Utrecht University in The Netherlands. We thank Nàdia Revenga of Valencia University for her valuable contribution to the sessions reported in this study. For more information, see www.niflar.eu. NIFLAR received a grant from the European Commission Life Long Learning Programme. This chapter reflects the views only of the authors; the Commission cannot be held responsible for any use which may be made of the information contained therein.

\subsection{Introduction}

Culture and language are inseparable and constitute "a single universe or domain of experience" (Kramsch, 1991, p. 217). Many would say that a language cannot be learned without an understanding of the cultural context in which it is used (Hinkel, 2004), among other things because interacting with others in a target language involves more than just knowing the correct syntax and lexicon and is also an issue of developing interactional competence according to specific cultural values (Hall, 2004). Teaching language then implies facilitating learning its culture, and both culture and language permeate social interaction (Lantolf, 2000; Lantolf \& Thorne, 2006). Any language teaching curriculum has to take the centrality of culture into consideration, and this is particularly true in foreign language contexts, where the language-culture connection is less accessible to learners.

In current teaching practice in many foreign language contexts, second language learning tasks are used to engage learners in different types of learning and communication processes. Tasks, we believe, should include an orientation to intercultural awareness (Müller-Jacquier, 2003) and allow for cultural or intercultural learner development to occur (Byram, 1997). Tasks designed with an intercultural focus can offer opportunities for interaction that elicits information on everyday cultural customs and provides opportunities for contrasting and comparing believes and habits in order to elicit awareness and reflections on both cultures. One way to do so is to seed tasks with cultural information gaps involving stereotypical situations from the L1 and L2 cultures that are likely to result in negotiation of intercultural content.

For some years now we have been involved in designing innovative elearning environments funded by the European Networked Interaction in Foreign Language Acquisition and Research (NIFLAR) project, where we have designed and studied online tasks for their potential to create authentic and interactive contexts that support the development of intercultural competence in foreign language learning contexts. While in many foreign language education settings, communication tasks in the target language mostly take place between non-native 
speaker classmates sharing the same mother tongue, 'networked' environments such as video communication or voice-enabled 3D virtual worlds may have an added value in creating opportunities for language learners to synchronously communicate outside the foreign language classroom. As such, we believe these tools have great potential to facilitate intercultural communication and collaboration with other (native) speakers of the target language.

This chapter examines evidence from the NIFLAR project involving the networked synchronous interactions of two triads composed each of two L1 Dutch students of Spanish and one L1 Spanish pre-service teacher in Spain. The two triads carried out the same two tasks, one interacting via Second Life, a well known virtual world environment, and the other one via a video communication platform. The tasks had been seeded with multiple information gaps often involving stereotypical situations from the L1 and L2 cultures that would call for intercultural negotiation. We hoped that online tasks designed with a built-in intercultural focus would incite negotiation of intercultural meaning related to the culture-specific connotations of concepts in the interaction.

\subsection{Background}

We take the development of intercultural communicative competence as a key goal of foreign language education (following Byram, 1997; Byram, Nichols, \& Stevens, 2001; Hinkel, 2004; Kramsch, 1991,1993; Müller-Jacquier, 2003). Byram and Zarate (1994) defined intercultural communicative competence as comprising the following abilities or 'savoirs': savoir-apprendre, the ability to learn about other cultures; savoir-faire, the ability to apply skills to unknown situations; savoir, cultural references and explicit knowledge of cultures; and savoir-être, respect and tolerance for other cultures. Byram (1997) stated that the goal of intercultural awareness raising in language courses is not to turn non-native learners into cultural natives, but rather to make them intercultural speakers, by developing intercultural understanding through different social and cognitive activities involving analysis, reflection, and interaction. He also fine-tuned the initial 1994 definition by describing the intercultural competent speaker as someone who has developed attitudes, knowledge, skills, and awareness about his/her own and the other culture, as someone who has acquired these five savoirs (Byram, 1997, pp. 50-54):

1. Attitudes of curiosity and openness, readiness to suspend disbelief about other cultures and belief about one's own.

2. Knowledge of social groups and their products and practices in one's own and one's interlocutor's country, and of the general processes of societal and individual interaction.

3. Skills of interpreting and relating: to interpret a document or event from another culture, to explain it and relate it to documents from one's own.

4. Skills of discovery and interaction: to acquire new knowledge of a culture and cultural practices and the ability to operate knowledge, attitudes and skills under the constraints of real-time communication and interaction. 
5. Critical cultural awareness / political education: to evaluate critically and on the basis of explicit criteria perspectives, practices and products in one's own and other cultures and countries.

By focusing on intercultural negotiation of meaning during task completion in the present study, our main goals are to show how online negotiation around cultural issues can support intercultural learning in the foreign language and also to demonstrate that tasks integrally designed in networked environments that take advantage of synchronous technologies are ideal for the targeting of intercultural competence as a goal in foreign language. Before presenting our study, we review the relevant literatures and explain our task design rationale.

\subsection{Affordances of networked synchronous communication}

It has become increasingly popular over the last two decades in language education to ask language students to collaborate synchronously (in a chat room, or a video/audio conferencing context) or asynchronously (in wikis, blogs, e-mails, bulletin boards) with their classmates, with foreign language learners elsewhere, or with native speakers. A wealth of research studies shows the relevance of networked interactions (or what is known in the specialised literature as computer mediated communication, or $\mathrm{CMC}$ ) in promoting the acquisition of foreign languages in general and of intercultural competence in particular by creating opportunities for learners to establish contacts with speakers from other cultures and engaging in meaningful intercultural communication in the target language (see review in O’Dowd, 2011; and also Belz \& Thorne, 2006; Furstenberg, Levet, English, \& Maillet, 2001; González-Lloret, 2008; Liauw, 2006; Tudini, 2007; Ware \& Kramsch, 2005).

The language learning affordances of synchronous on-line interactions more specifically, have been studied in different types of environments. Text-based chat sessions are by far the most often used in language classrooms and have been found to be effective to enhance language learning at syntactic, discourse, grammatical, lexical, and intercultural levels (Sauro, 2011), although in terms of promoting negotiation of meaning Ortega (2009) has reported that a closer look at studies of online text-based synchronous environments reveals mixed findings and insufficient evidence. Audiographic conferencing platforms are interesting in that they integrate audio, graphics, and text chat, presenting a unique opportunity for the development of multimodal communication in which oral communication (Lamy, 2004), writing processes (Ciekanski \& Chanier, 2008), and tutoring practices (Hampel \& Hauck, 2004; Hampel, Felix, Hauck, \& Coleman, 2005) can be promoted. Videoconferencing and audiovisual environments (such as Skype or Net Meeting) enable a form of communication in which a video connection is made through the Internet, and files can be exchanged. Such environments have been used in telecollaboration projects for developing intercultural competence (O'Dowd, 2011). In a pilot study, O'Dowd (2000) observed that his Spanish students of English, who participated with American students in three video communication 
sessions, had become more aware of their own body language and presentation skills due to the visual component of video communication. He also observed that when using their L1 to interact with non-native speakers, students adapted their output by speaking more slowly and clearly avoiding slang. When communication breakdowns emerged, interlocutors jumped in to help each other and explain things again adapting their output to their interlocutors' level. This effect of the video communication environment to promote a willingness to adapt and help each other is seen as an important aspect of the intercultural competent speaker. Not all findings are positive, however, and frustration with diverging communication styles and cross-cultural misunderstandings have also been reported in telecollaboration sessions (for an overview see Guth \& Maio's, 2010; Kramsch \& Thorne, 2002; O’Dowd \& Ritter, 2006).

Two synchronous networked environments have been employed in the NIFLAR project for their potential to support language and culture learning: Virtual Worlds, and video communication. Virtual worlds, such as Second Life, are becoming increasingly popular among language teachers (see Molka-Danielsen \& Deutschmann, 2009 for an empirical study, and Deutschmann, Panichi, \& MolkaDanielsen, 2009 for an overview), particularly as a space where foreign language learners can meet native speakers of the target language (Kuriscak \& Luke, 2009). They are thought to be optimal for engaging in meaningful communicative and social interaction (Jauregi, Canto, Graaff, Koenraad, \& Moonen, 2011) while undertaking joint action. In such voiced-enabled 3D virtual worlds, students participate as avatars (participants cannot see the real person they are communicating with), can engage in textual and oral interactions with other avatars, and can undertake all kind of actions (walk, sit, go cycling, sail, dance, ride a car) in different virtual locations (a museum, a restaurant, a shop, the parliament, ancient ruins). These interactional virtual spaces have been assessed as beneficial for learning and achieving communicative and intercultural competence (Bryant, 2006; Thorne, 2008), particularly because users can experiment and interact with a variety of norms of social interaction (Steinkuehler, 2006). In these 3D environments learners can have the opportunity to experience life-like social interaction while at the same time engaging in meaningful learning activities (Cooke-Plagwitz, 2008). The realistic nature of the environment provides authentic communication conditions that are otherwise difficult to recreate in traditional classroom settings (Dieterle \& Clarke, 2008). Not only can virtual worlds help the learners perform as information conveyors (providing areas in which students can make contributions), but also making them participants of authentic social activity with an impact beyond the classroom. Since students already live in information-rich virtual spaces outside the classroom, these virtual world activities bring the classroom into their outside world (Steinkuehler \& Squire, 2009).

Although it represents a more traditional type of networked environment than virtual worlds, video communication (also called desktop conferencing), has attracted considerable research interest as well. Adobe Connect, Elluminate or Visu (Guichon, 2010) are examples of video communication platforms being used for educational purposes. They allow for group interaction in a multimodal setting: Participants can talk, see each other, chat, and share documents (photos, audio/video 
fragments, power point presentations) within the environment and collaborate in the process of writing texts online. Jauregi \& Bañados $(2008,2010)$ describe an intercontinental project between Dutch students of Spanish and Chilean student teachers who collaborated through video communication and blogs on improving their communication skills, pedagogical competences, and on broadening up their intercultural competence. Results showed a positive impact on motivation and communication skills, particularly in language use and cultural matters (for other NIFLAR related studies of the affordances of video communication, see also Jauregi, 2011; Jauregi, Graaff, Bergh, \& Kriz, 2012).

\subsection{Design principles for intercultural online tasks}

As Moonen, De Graaff and Westhoff (2006) point out, there is not one single, generally accepted definition of a task in the field of second language acquisition. For the purpose of this study, we adopt Van den Branden's (2006) definition of language learning tasks: "A task is an activity in which a person engages in order to attain an objective, and which necessitates the use of language" (p. 4). We also considered as essential components of tasks: meaning-orientation, goal-orientation, outcome evaluation and real-world relationship (Ellis, 2003; Skehan, 1998). Norris (2009), referring to Long and Crookes (1993) and Long and Norris (2000), indicates that most TBLT approaches subscribe to the following elements: (1) needs analysis; (2) task selection and sequencing; (3) materials and instruction development; (4) teaching; (5) assessment; and (6) program evaluation. In this chapter we focus on elements (3) and (4), from the perspectives of a language learner and a pre-service teacher as interlocutor. Our goal was to design tasks according to TBLT principles that would also take into account communicative and intercultural competence in L2 acquisition within the context of synchronous networked computer mediated communication.

In terms of TBLT principles, and following essential components addressed by Chaudron, Doughty, \& Kim (2005) and Norris (2009), we sought to design tasks that would offer the following design affordances that are identified as central in the TBLT literature. First, our tasks had to offer substantial input to learners, that is, exposure to authentic, multimodal, and contextually relevant language (Westhoff, 2004). During task performance, it should be possible for learners to elaborate the input by means of interactional modification or negotiation of meaning (Doughty \& Long, 2003). Second, we also aimed at task design that would support sustained analytic work to facilitate focus on form, or tasks that create a semantic space (Ellis, 2003) which might predispose the learners to process specific linguistic forms, promote the acquisition of useful chunks (Doughty \& Long, 2003) and provide different opportunities to focus on form when learner need arises, such as input flood, input elaboration or enhancement, recasts, and input processing (Doughty \& Long, 2003; Ware \& O'Dowd 2008). Third, our tasks strove to include also interactive activities that maximize noticing form-function-meaning relationships, in which learners use the target language pragmatically and communicatively, instead of simply displaying knowledge of the target language (Ellis, 2003), and they engage in communicative activities involving real-world processes of language use 
(Ellis, 2003). In sum, the task design strove to foster learning by doing (Doughty \& Long, 2003) by eliciting cognitive processes (Ellis, 2003) or mental actions (Westhoff, 2004) such as processing of input, production of (pushed) output and interaction (Ellis, 2003; Doughty \& Long, 2003; Westhoff, 2004; Willis, 1996). Furthermore, task design promoted collaborative learning (Doughty \& Long, 2003) such as negotiation of meaning, by assigning complementary roles, information and perspectives to the participants/learners. Fourth, we were mindful that target-task performances be as a result of negotiation of meaning, which meant that we provided a clearly defined general purpose/goal, a clearly defined communicative end product, a more or less specified procedure for each task (Ellis, 2003), and a set of instructions that is tailor-made to meet the specific needs of the learners (Doughty \& Long, 2003).

For the purposes of promoting intercultural competence, on the other hand, we considered what it would mean for our task design to address opportunities for the development of Byram's 'savoirs' (1997), presented earlier: the ability to learn about other cultures; the ability to apply skills to unknown situations; cultural references and explicit knowledge of cultures; and respect and tolerance for other cultures. Müller-Jacquier's (2003) notion of linguistic awareness of cultures also influenced our task design. He proposes a framework for intercultural communication that is to include social meaning, speech acts, organization of conversation, choice and development of topics, directness/indirectness, register, paraverbal factors, non-verbal means of expression, culture-specific values and attitudes, and culture-specific behaviour. We considered tasks that foster the linguistic awareness of cultures by requiring learners to focus on intercultural topics, beliefs, and contrasts, to elicit information about everyday implicit cultural habits and beliefs, and to create intercultural awareness by taking content topics that are likely to provide opportunities for contrasting and comparing one's own beliefs and habits with those of interlocutors. That is, the task content should help elicit awareness and reflection not only on target culture, but on own cultural habits and beliefs as well, and create opportunities for negotiation of intercultural meaning, because we believe language learners become interculturally competent by interacting on and negotiating about issues that allow room for intercultural misunderstanding, miscommunication, unexpectedness, or surprise to occur and to possibly be solved.

As a result of our efforts at NIFLAR to integrate TBLT principles into the wider curricular and educational aim to further technology-supported goals for intercultural communication, five online tasks targeting the development of intercultural competence were designed, pilot tested, and refined for educational use. The five tasks developed were the following. In Gente Genial (Cool People, Task 1) students visited an apartment they were meant to share and after sharing first impressions and cultural information they had to discuss and choose an outing option. Gente y Aventura (People and Adventure, Task 2) consisted of planning a holiday and reflecting on past holiday experiences. Gente de Cine (Movie Celebrity People, Task 3) was a selection of different short scenes in which participants had to play different roles given the indications of a brief script. Gente con Corazón (People with Heart, Task 4) allowed students to impersonate different characters 
and experience the reactions caused on others. Finally, Gente y Culturas (People and Cultures, Task 5) was designed as a cultural television-game style contest between a Dutch and a Spanish team. All final tasks can be downloaded from the NIFLAR webpage (http://cms.hum.uu.nl/niflar).

\subsection{Method}

\subsubsection{Research questions and data}

The study reported in this chapter addresses the following research questions: How does negotiation of intercultural meaning take place in virtual worlds tasks and video communication? How successful were our intercultural online tasks in meeting our educational goals? In order to answer the first question, we analysed interaction sequences during online task performance, focusing on negotiation episodes during which meaning related to some cultural information of either the first or the second language is overtly discussed and some information gap or nonunderstanding is dispelled during task completion or non-task related communication. We took the analytical model for negotiation of meaning by Varonis and Gass (1985b) as a reference. This model presents a set of primes that occur in negotiation of meaning sequences: a trigger $(\mathrm{T})$ that sets the negotiation sequence, an indicator (I) that signals the misunderstanding, a response (R) to address the misunderstanding and an optional reaction to that response (RR). Although the nature of the triggers can vary (and Varonis and Gass (1985a, 1985b) focused mainly on linguistic negotiation), we focused on negotiating instances that were triggered by intercultural contrasts, surprises, unknown information that was made known in the unfolding interaction, or misunderstandings. Thus, our triggers may include cultural contexts, clarification requests, comprehension checks and questions involving interlocutors' society and culture. Indicators that something is being negotiated can manifest themselves in the form of echo (rising or falling intonation), an explicit statement of nonunderstanding or understanding with surprise, no response, inappropriate response, summary, and surprised reactions. The response from the interlocutor can range from repetition, expansion, rephrasing, acknowledgement or reduction (Varonis \& Gass, 1985a; Fernández-García \& Martínez-Arbelaiz, 2002). In order to answer the second question, we collected perception data via a questionnaire so as to ascertain how successfully our goals had been met, according to the learners' opinion after the networked task experience.

\subsubsection{Context of the wider NIFLAR project}

As part of the NIFLAR initiative, an intact class of 27 first year students of Spanish from Utrecht University in the Netherlands took part in five task-based interactive online sessions with 14 native speakers of Spanish, who were enrolled in a preservice teacher education program at Valencia University in Spain. Participants communicated in triads: The same two students carried out tasks with the same native speaker of Spanish throughout the five task sessions. The language 
proficiency level of this course was estimated at B1 of the Common European Framework of Reference for Languages (CEFR, 2001), which according to Vandergrift (no date) would correspond roughly with the Advanced-Low level in the American Council of the Teaching of Foreign Languages Proficiency Guidelines (ACTFL, 1999). The online module yielded benefits for both student and teacher participants. The students benefit in terms of language and culture learning because they could directly communicate in the second language, Spanish, with more expert peers. These expert peers, the native speaking pre-service teachers of Spanish, benefit in terms of experiencing, often for the first time, communication with actual foreign language learners. In addition, they engaged in action research in their own university program in Spain, related to their apprenticing roles as language teachers. Native speaker pre-service teachers participated in all the phases of task-based teaching as elaborated in Chaudron et al. (2005) and Norris (2009), and thus were involved as interlocutors and tutors in task completion with respect to language input, interaction, elaboration and performance during task work, and task follow up. This promoted the development and completion of real life intercultural tasks, as relevant intercultural topics were addressed for and elaborated by both the language learners and the native speaker pre-service teachers.

The course was considered blended learning, which meant that students met twice a week face to face with their teacher, whereas the third meeting was computer mediated with the native speakers, to be carried out weekly after the two face to face lessons. Although the online sessions in triads did not take place in the classroom, they were part of the regular course syllabus, in that the tasks were designed and aligned with the course contents and objectives, linked to units from the task-based syllabus used in the course. The 27 students were randomly assigned to do the same set of five tasks either via a Virtual Worlds (VW) or a Video Communication (VC) environment, and the 14 pre-service teachers were assigned to one of the two online environments according to their personal preferences. Tasks were as identical as possible for both groups; they were only adapted in order to take advantage of the specific affordances of the VW or VC medium. For example, in the $\mathrm{VW}$, each participant took the form of an avatar and interacted through text and voice while choosing to do actions like walking, sitting, riding a car, and so on, in different virtual locations (i.e., a museum, a restaurant, a shop). In the VC environment, on the other hand, participants met online and collaborated with each other by talking and sharing files (e.g., photos) on line while seeing each other through the webcam. The decision to use similar tasks in both settings was brought up by the fact that all participants were following the same course and tasks were aligned with course contents and objectives. The idea was to prevent differences and keep all course activities as similar as possible in all groups. Previous to the task sessions, language learners and pre-service teachers participated in $\mathrm{VW}$ and $\mathrm{VC}$ tutorials to become familiarized with the tools.

As for the selection of recordings for this study, two aspects were taken into account: (a) accessibility of the recordings and (b) representativeness. The recordings' database was sometimes difficult to navigate, since participants themselves were in charge of the recording process and file names were not always very clear. Easily identifiable files and quality of the recording were primary 
selection criteria. Once the file had been preselected we looked for representativeness: the participants were average students, their language command was not above or below average.

\subsection{Findings}

In our findings, first we report on an analysis of negotiation of intercultural meaning during the interactions of four voice recordings by two triads completing two of the tasks each, out of the full corpus we collected. The findings section ends with data about the perceptions of the NIFLAR experience by all 27 student and 14 preservice teacher participants.

\subsection{A look at negotiation of intercultural meaning}

All data reported in this first section of findings and the next are based on two triads working on Gente Genial (Cool People, Task 1) and Gente y Culturas (People and Cultures, Task 5). Task 1 had students imagine that they share a house, they had to explain their own culture via a television showing images depicting cultural aspects of both countries, and later they had to choose a outing from three options given (art gallery, cinema, and a walk in virtual Valencia). In VW students were teleported to the virtual location (e.g., art gallery) and in the VC setting they were presented photographs evoking the location (e.g., photographs of paintings). Task 5 was a game show or "Cultural Olympiad" in which the Dutch team (i.e., the two students) competed against the Spanish team (i.e., the pre-service teacher) in terms of cultural knowledge of the other country. Questions for which the teams could score points were displayed on a screen and the opponents had to judge the adequacy of the answers. More details for these two tasks can be found in the Appendix.

Triad 1 carried out both tasks on VW and Triad 2 did the same on VC. Task completion took over one hour for both triads, although it was shorter for Triad 2 on the VC (Task 1, $1 \mathrm{hr}$ and $15 \mathrm{~min}$; and Task 5, $1 \mathrm{hr}$ and $5 \mathrm{~min}$ ) than for Triad 1 on the Second Life VW (Task 1, $1 \mathrm{hr}$ and $51 \mathrm{~min}$; and Task 5, $1 \mathrm{hr}$ and $46 \mathrm{~min}$ ). Occasionally, a trigger for negotiation of intercultural meaning seemed to be ignored. We did exclude those from our analyses, as we were concerned with instances when triggers were overtly marked and responded to. The great majority of triggers, however, were followed by a complete negotiation routine. That is, as in the original model for the model for negotiation of meaning by Varonis and Gass (1985b) that we took as a reference for our analyses, there was a trigger, an indicator, and a response.

Table 3.1 summarises the intercultural negotiation routines we found in the voice recorded interactions by the two triads. It is first noteworthy that we found abundant occasions during these four one-to-two-hour recordings where negotiation of meaning was triggered by some intercultural content. Furthermore, intercultural negotiation routines accounted for a good part of the task time, as indicated by their density, which ranged from a lowest 1 episode every 8 minutes (for Triad 1 on VW Task 1) to a highest 1 intercultural negotiation per 2.7 minutes (for Triad 2 on VC Task 5). These densities are considerably higher than those reported by Ortega 
(2009) for negotiation of meaning episodes (i.e., targeting grammar and lexis) typically reported across studies of synchronous text-based second-language chat.

Table 3.1. Negotiation routines by task, environment/triad, trigger, and initiator.

\begin{tabular}{|c|c|c|c|c|c|c|c|c|}
\hline \multirow[b]{2}{*}{ Task } & \multirow[b]{2}{*}{ Triad } & \multirow[b]{2}{*}{$\begin{array}{c}\text { environ } \\
\text {-ment }\end{array}$} & \multicolumn{3}{|c|}{ Task-triggered } & \multicolumn{3}{|c|}{ Unplanned trigger } \\
\hline & & & $\begin{array}{c}\text { by } \\
\text { learner }\end{array}$ & $\begin{array}{c}\text { by } \\
\text { native } \\
\text { speaker }\end{array}$ & all & $\begin{array}{c}\text { by } \\
\text { learner }\end{array}$ & $\begin{array}{c}\text { by } \\
\text { native } \\
\text { speaker }\end{array}$ & all \\
\hline $\begin{array}{l}\text { 1: Gente } \\
\text { Genial }\end{array}$ & 1 & VW & 4 & 7 & 11 & 0 & 3 & 3 \\
\hline & 2 & $\mathrm{VC}$ & 14 & 9 & 23 & 1 & 1 & 2 \\
\hline 5: Gente y & 1 & VW & 20 & 13 & 33 & 2 & 1 & 3 \\
\hline & 2 & $\mathrm{VC}$ & 15 & 9 & 24 & 0 & 0 & 0 \\
\hline $\begin{array}{l}\text { Both } \\
\text { Tasks }\end{array}$ & & total & 53 & 38 & 91 & 3 & 5 & 8 \\
\hline
\end{tabular}

We notice that out of the 99 instances of intercultural negotiation of meaning, 91 were triggered by features of the task content that had been planned by design, via our seeded cultural gaps. Interestingly, we also found 8 episodes that were triggered by intercultural negotiations that arose from the interaction in an unplanned fashion. For both task-related and unplanned types of trigger overall, initiation was rather balanced: In the planned triggered negotiations 44 were native speaker initiated and 47 learner initiated moves. Of the 8 unplanned triggered negotiations, 5 were native speaker initiated and 3 were learner initiated. The technological environment also exhibited rather balanced patterns, as the number of negotiations between $\mathrm{VW}$ and VC was similar: 50 in VW and 49 in VC. This remains true when only learner initiated routines are inspected: 24 in VW and 23 in VC.

The only noticeable difference that can be found in Table 3.1 is for Task in only one of the triads working in only one of the modalities. Triad 2, who worked on the VC environment and took slightly over one hour to complete each task, generated similarly high amounts of negotiations of intercultural meaning for both tasks (25 and 24, respectively). By contrast, Triad 1, who interacted in the Second Life VW modality and took well over one hour to complete each task, produced many more negotiations of intercultural meaning on Task 5 than on Task 1 . Specifically, the VW triad produced 14 negotiation routines on Task 1, whereas the same three participants produced 36 negotiation routines on Task 5 . This difference is even more interesting if one considers that this triad took slightly shorter to complete Task 5 ( $1 \mathrm{hr}$ and $46 \mathrm{~min})$ than Task 1 ( $1 \mathrm{hr}$ and $51 \mathrm{~min})$, which resulted in this session showing the highest density of intercultural negotiation of the four (1 negotiation episode every 2.7 minutes). Thus, something in the nature or design of Task 5 in the Second Life VW environment might have encouraged more intercultural negotiation than Task 1 in the same environment, although analysis of interactions on these two tasks by the rest of the VW triads in the corpus would be needed before we are able to generalise this observation. We can impressionistically say here that Task 5 was by far students' favourite Virtual Worlds task. Not only did it combine culture and games in a relaxed and informal atmosphere where there 
were many instances of laughter, it also elicited a rich information exchange with genuine interests from both learners and pre-service teachers.

Examples 3.1 and 3.2 below, one from each triad, offer complete negotiation routines that occurred in Tasks 5 and 1, respectively. Example 3.1 is a negotiation triggered by a cultural information gap included in the design of the task itself, and Example 3.2 is a negotiation triggered by an unplanned negotiation of intercultural understanding that arose in the interaction and was extraneous to the task design per se. Both of them were initiated by the native speaker in each triad.

Example 3.1. Task triggered negotiation around "mochilas in The Netherlands" (Triad 2, VC, Task 5).

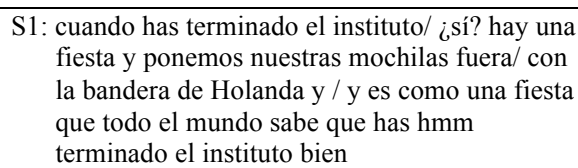

(I) NS: ¡Ah! ¿y entonces se quedan ahí las mochilas?

(R) S1) : sí/ fuera/ por dos semanas o así (risas)

(I) NS: ¡Ah!

(R) S1: porque es la idea que nunca tenemos que usar la mochila (risas)

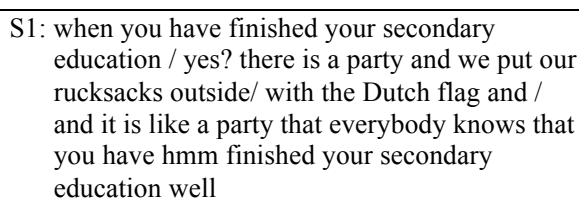
rucksacks outside/ with the Dutch flag and / and it is like a party that everybody knows that you have hmm finished your secondary education well

(I) NS: Ah! and then the rucksacks stay there?

(R) S1) : yes/ outside/ for two weeks or so (laughter)

(I) NS: Ah!

(R) S1: because the idea is that we don't have to use the rucksack anymore (laughter)

(RR) NS: Ah! how original!

(RR) NS: ¡Ah! ¡qué originales!

The task trigger for Example 3.1 was a photograph visible on the VC of a schoolbag hanging from a Dutch flag outside someone's house (see Picture 3.1). It was the L1 Spanish native speaker's turn to guess what it meant and after a few failed attempts one of the language learners decides to help explaining what it is (in the Netherlands, it indicates that someone has graduated from secondary education). The native speaker signals her surprised reaction not only with an indicator of meaning recognition ( $i A h !)$ but also followed by a clarification request ( $A h$ ! $i y$ entonces se quedan ahi las mochilas?/ Ah! and do the rucksacks stay there?). The response of the language learner is an acknowledgement with an expansion (si/ fueral por dos semanas o asi - yes/outsidel for two weeks or so) by the student, followed by another indicator of confirmation of understanding (a change-of-state token in Conversation Analysis (see Heritage, 1984)) by the native speaker which triggers another expansion response (porque es la idea que nunca tenemos que usar la mochila - because it is the idea that you don't have to use the rucksack anymore). The sequence is rounded off by the native speaker with a reaction to the response (;Ah! ¡qué originales! - Ah! how original!). 


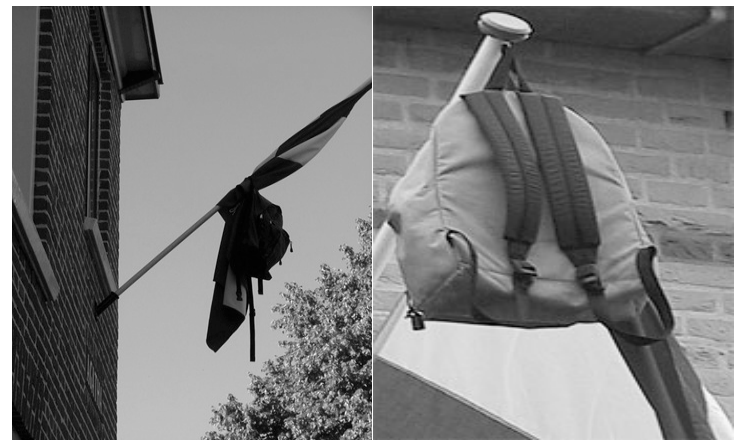

Picture 3.1. Photographs of a schoolbag hanging from a Dutch flag outside someone's house. Source: http://alt164-alt164.blogspot.com/2008_06_01_archive.html

Since the tasks employed for this study were based on set cultural topics and seeded with multiple overt information gaps to encourage intercultural awareness raising (both tasks provided visual aids in the form of photographs depicting stereotypical situations from both cultures), it is not surprising that most of the negotiations were task triggered, as in the Example 3.1 just presented. Negotiations of intercultural meaning arisen in an unplanned fashion from the interactional context, such as that shown in Example 3.2 below, were few (cf. Table 3.1) and tended to occur occasionally towards the end of the task.

Example 3.2. Unplanned trigger around "late lunch hours in Spain" (Triad 1, VW, Task 1).

\begin{tabular}{|c|c|}
\hline $\begin{array}{l}\text { S1: Ya es//eh es el uno/ y medio /[ oh, es } \\
\text { Sinterklaas] (picture appeared on the screen) }\end{array}$ & $\begin{array}{l}\text { S1: It's already //eh it's one / thirty /[ oh, it's } \\
\text { Sinterklaas] (picture appeared on the screen) }\end{array}$ \\
\hline $\begin{array}{l}\text { NS: } \\
\quad \text { tengo clase a las tres }\end{array}$ & $\begin{array}{l}\text { NS: } \\
\text { and I have a class at three }\end{array}$ \\
\hline S2: Tenemos que tener prisa & S2: We have to hurry up \\
\hline (T) S1: Yo tengo clase de conducir a las dos & (T) S1: I have a driving lesson at two \\
\hline (I) NS: ¿A las dos tienes clase? & (I) NS: do you have a lesson at two o'clock? \\
\hline (R) S1: Ya, clase de conducir & (R) S1: yes, a driving lesson \\
\hline $\begin{array}{l}\text { (I) NS: ah pues entonces tendremos que acabar } \\
\text { antes/ tienes que comer ¿no? ¿o ya has } \\
\text { comido? }\end{array}$ & $\begin{array}{l}\text { (I) NS: ah well then we will have to finish earlier/ } \\
\text { you have to eat, don't you? Or have you eaten } \\
\text { already? }\end{array}$ \\
\hline (R) $\mathrm{S} 1$ : No/ ya ha comido/yo he comid & $\begin{array}{l}\text { (R) } \mathrm{S} 1: \mathrm{No} / \text { he has eaten already/ I have eaten } \\
\text { already }\end{array}$ \\
\hline $\begin{array}{l}\text { (RR) NS: ah yo no/ yo tengo que comer todavía/ } \\
\text { aquí en España comemos a las dos o por ahí/ } \\
\text { bueno ya lo sabéis }\end{array}$ & $\begin{array}{l}\text { (RR) NS: ah I haven't / I still have to eat / here in } \\
\text { Spain we eat at around two o'clock/ well you } \\
\text { know it }\end{array}$ \\
\hline
\end{tabular}

In Example 3.2, the trigger appears when one of the L2 Spanish language learners in the Netherlands mentions that it is getting late and she has a driving lesson at two o'clock. The native speaker, surprised by the time of the lesson (two o'clock is lunch time in Spain) signals her non understanding/surprise with an indicator in the form of an echo with rising intonation (;a las dos tienes clase?/ do you have a lesson at two o'clock?) that is received by the student with a response in the form of repetition of the trigger. Another indicator plus response follows as a surprised reaction: the native speaker, seeing the time, may have assumed that they will have to finish soon because the student will most probably have to eat lunch. The 
response in this case is an expansion (she has already eaten) and the native speaker offers a reaction to that response by contrasting the information with the Spanish culture (Ah, yo no/ yo tengo que comer todavial aquí en España comemos a la dos por ahil bueno ya lo sabéis - Ah, I haven't/ I still have to eat/ here in Spain we eat at around two o'clock/ well you know it).

\subsection{Support for intercultural learning}

The design requirement of Tasks 1 and 5 to focus on intercultural topics and elicit information on everyday cultural customs ultimately had the goal to provide foreign language learners with opportunities for contrasting and comparing believes and habits so as to raise their awareness and ability to reflect on both cultures, that is, to support the development of intercultural communicative competence as understood by Byram (1997), Kramsch (1993), and Müller-Jacquier (2003) among others. We also found some evidence in the four recorded interactions that suggest participants were showing some signs of their ability to acquire intercultural knowledge and information that had been dealt with before and that now was being processed in a more practical or active way. We present three examples here.

In Example 3.3 we can see an illustration of a student having acquired intercultural information that had previously encountered.

Example 3.3. Evidence of intercultural learning around "top mantas" (Triad 2, VC, Task 1).

\begin{tabular}{|c|c|}
\hline NS: ¿y qué están vendiendo? & NS: and what are they selling? \\
\hline $\begin{array}{l}\text { S1: ya// como como los top manta/ pero no es } \\
\text { ilegal (risas) son son cosas ehm// de/ segunda } \\
\text { mano }\end{array}$ & $\begin{array}{l}\text { S1: well// like like the top manta/ but it's not } \\
\text { illegal (laughter) they are they are things ehm// } \\
\text { second hand things }\end{array}$ \\
\hline
\end{tabular}

Earlier on in the task participants had to discuss a photograph showing illegal street vendors in Spain (called "top manta") (see Picture 3.2) and language students learned why they were called that way. Later on, the native speaker in Spain is enquiring about Queen's day in The Netherlands and upon seeing a picture of people selling in the streets she asks what they are selling. The student is quick to make the connection with something she has just learned and compares it to the target culture ("top manta"). 


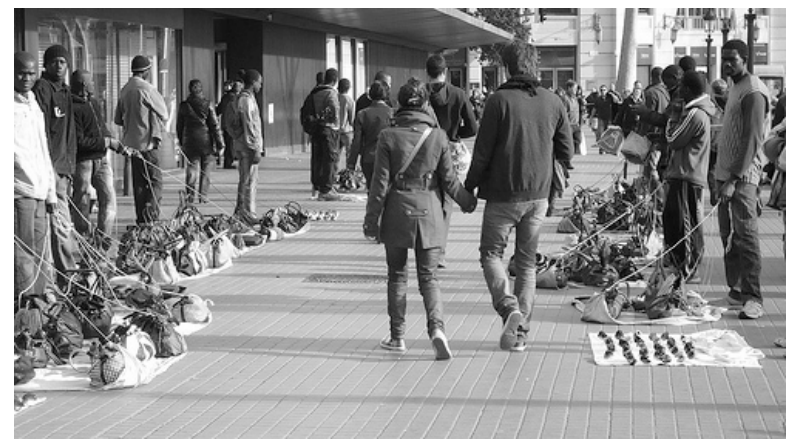

Picture 3.2. Photograph showing illegal street vendors in Spain. Source: http://www.flickr.com/photos/calafellvalo/3353549327/

Example 3.4 shows the native speaker making the connection during Task 1 to something they had been talking about at the beginning of the same task. They were talking about the size of student accommodation and the Spanish native speaker was surprised by the number of students that share a house in Holland. Later, when they had to distribute the rooms in the virtual house, the native speaker adds that they could accommodate in that space about eight people, with a special remark that showed the acquired knowledge "like in Holland".

Example 3.4. Evidence of intercultural learning around

"space in the Netherlands" (Triad 1, VW, Task 1).

\begin{tabular}{cc}
\hline NS: Aquí hay mucho espacio/ podemos meter aquí & NS: This is very spacious/ we can fit here eight \\
a ocho personas/ como en Holanda & people/ like in Holland \\
\hline
\end{tabular}

A final illustration is Example 3.5. The participants had been talking about eating habits and how eating in the streets is not very common in Spain. Later on, when they are making comments about eating chips, one of the students mentions jokingly that everybody in Spain will see that she is a tourist because she eats her chips in the streets.

Example 3.5. Evidence of intercultural learning around "street eating in Spain" (Triad 1, VW, Task 5).

S1: sí pero pues si estoy en eh (risas) España y come eh// algo por la calle toda la gente puede ver que estoy turista ¿no?

NS: sí sí sí/ los turistas podéis hacer lo que os dé la gana/ no pasa nada/ está todo permitido para vosotros (risas)
S1: yes but well if I am in eh (laughter) Spain and I eat eh// something in the street everybody can see that I am a tourist can't they?

NS: yes yes yes/ you tourists can do whatever you want/ it's alright/ everything is allowed for you (laughter) 


\subsection{Perceptions of synchronous online tasks}

Finally, in addition to considering patterns of interaction and evidence for learning, we also sought to evaluate participants' perceptions about their online experiences. For this part of the data, we report on the full sample of 27 students and 14 preservice teachers who participated in the five online sessions in triads. Post-course questionnaires were digitally distributed after the conclusion of the project in order to collect relevant perception evidence. These questionnaires had between 29 items (for the language learners) and 45 items (for the pre-service teachers) with open and five-point Likert scale closed questions about the virtual environment, the tasks, the speech partner, the learning potential of the project, organization, and global project evaluation. Our main interest in inspecting the perception data here relates to the participants' perceptions about the VW and VC environments as well as the perceived appropriateness of the tasks to enhance intercultural awareness and L2 learning gains. We report separately on the perceptions of the students and the preservice teachers.

In terms of the online environments, both virtual worlds and video communication were rated positively by language learners as well as pre-service teachers as is shown in Table 3.2 below.

Table 3.2. Evaluation of virtual environment used for interaction sessions.

\begin{tabular}{lccc}
\hline $\begin{array}{l}\text { How do you value the virtual environment you } \\
\text { have used for the interaction sessions? }\end{array}$ & Mean & SD & $\mathrm{n}$ \\
\hline Virtual Worlds - language learners & 3.64 & 0.50 & 14 \\
Video Communication - language learners & 3.54 & 0.97 & 13 \\
Virtual Worlds - pre-service teachers & 3.83 & 0.75 & 6 \\
Video Communication - pre-service teachers & 4.38 & 0.52 & 8 \\
\hline
\end{tabular}

Note. 1:bad; 5:good

In terms of the new possibilities offered by these environments participants mentioned "the opportunity to visit real places in a virtual world", "being able to do things that I can't do in the classroom", "practice oral skills in real situations", "learn to improvise", among all the comments referring to the value of being able to communicate with a native speaker of their own age, where distance doesn't matter via a medium that allows them to also share information supported by pictures, audio and documents.

With regard to task interest and perceived appropriateness of the tasks to enhance intercultural awareness, Table 3.3 and 3.4 indicate that the language learners and even more so the pre-service teachers found the tasks useful and motivating with respect to interaction and intercultural competence. Some individual comments from the pre-service teachers were: "simulations and games were entertaining for students and pre-service teachers" and "there was a constant and unlimited exchange of cultural elements from both cultures". 
Table 3.3. Language learners' $(n=27)$ responses about task interest.

\begin{tabular}{lcc}
\hline & Mean & SD \\
\hline I found tasks motivating & 3.67 & 0.62 \\
I found tasks useful for my language learning process & 3.85 & 0.77 \\
\hline Note 1: Strongly disagree; $5 \cdot$ Strongly agree & &
\end{tabular}

Note. 1: Strongly disagree; 5: Strongly agree,

Table 3.4. Pre-service teachers' $(n=14)$ responses about task interest.

\begin{tabular}{lcc}
\hline & Mean & SD \\
\hline $\begin{array}{l}\text { Were project tasks appropriate for furthering interaction in the target } \\
\text { language with the foreign language learner? }\end{array}$ & 4.50 & 0.65 \\
$\begin{array}{l}\text { Were project tasks useful to enhance the (intercultural) } \\
\quad \text { communicative competence of my foreign language learner? }\end{array}$ & 4.86 & 0.36 \\
Were tasks motivating? & 4.57 & 0.51 \\
\hline
\end{tabular}

Note. 1: No, not at all; 5: Yes, definately

Finally, in terms of learning potential, Table 3.5 shows that the language learners also reported that they were aware of cultural contrasts and similarities, had become more confident, were able to talk more fluently, and took more initiative. The Likert scale mean responses to most of these dimensions of learning approach (and in the case of vocabulary learning surpass) 4 out of a maximum positive answer of 5 .

Table 3.5. Language learners' $(n=27)$ responses about learning potential.

\begin{tabular}{lcc}
\hline What have you learned during the sessions? & Mean & SD \\
\hline To be aware of cultural contrasts and similarities & 3.85 & 0.82 \\
To talk more fluently & 3.89 & 0.70 \\
To become confident talking in the target language & 3.85 & 0.72 \\
To talk more & 3.48 & 0.85 \\
To take more initiative in the conversation & 3.33 & 1.00 \\
To be more motivated to talk & 3.26 & 0.98 \\
To use new words & 4.26 & 0.71 \\
To use idioms/expressions & 3.93 & 0.68 \\
To use grammar more accurately/correctly & 3.96 & 0.65 \\
\hline
\end{tabular}

Note. 1: Strongly disagree; 5: Strongly agree

Students' learning improvements were not only perceived by the students themselves, they were also corroborated in the perceptions by the pre-service teachers when asked to compare the first and last interaction sessions (Table 3.6). Among other things, the pre-service teachers clearly found that their language learner interlocutors had become more aware of cultural contrasts and similarities (this is the item attracting the highest mean response, $M=4.64$ ). 
Table 3.6. Pre-service teachers' $(n=14)$ responses about language learning learners' improvement.

\begin{tabular}{|c|c|c|}
\hline Comparing the first and the last session... & Mean & SD \\
\hline $\begin{array}{l}\text { I noticed an overall improvement in the communicative competence } \\
\text { of my foreign language learner comparing session } 1 \text { to the last } \\
\text { session. }\end{array}$ & 4.57 & 0.65 \\
\hline They talked more in the last session & 4.14 & 0.95 \\
\hline They were able to talk more fluently in the last session & 4.36 & 0.84 \\
\hline They took more initiative during the last session & 4.07 & 1.07 \\
\hline They asked more questions during the last session & 3.64 & 1.01 \\
\hline They became more confident talking in the target language & 4.50 & 0.94 \\
\hline They became more aware of cultural contrasts and similarities & 4.64 & 0.50 \\
\hline They enlarged their lexicon and used more adequate words & 4.43 & 0.65 \\
\hline $\begin{array}{l}\text { They have learned to talk more accurately in terms of grammatical } \\
\text { constructions. }\end{array}$ & 4.00 & 0.55 \\
\hline They were more motivated to talk in the last session & 4.21 & 1.19 \\
\hline
\end{tabular}

Note. 1: Strongly disagree; 5: Strongly agree

\subsection{Discussion and conclusion}

This chapter has explored how the development of intercultural competence can be facilitated with the use of current technologies such as virtual worlds tasks and video communication. We presented an overview of the NIFLAR effort to develop tasks related to design principles for the support of intercultural competence, and we aimed at providing some evidence of negotiation of intercultural meaning between language learners and native speaker interlocutors, in order to understand how such negotiation of meaning takes place and may best be stimulated in tasks designed in the two technological environments. Our data involved analysis of four online sessions in which intercultural meaning is negotiated by two triads carrying out the same two tasks each, although each in one of the two parallel synchronous environments in which we designed our tasks. Additional data on participants' perceptions about tasks and development of intercultural knowledge was gathered by means of questionnaires.

Results showed clear and frequent instances of (mostly planned but also occasionally unplanned) intercultural negotiation of meaning in both VW and VC tasks. While this was to be expected, given the design of the tasks where a cultural information gap was often the starting point, it was important not to take it for granted without empirical evidence, particularly since reports of great differences between task as work plan and task as process have haunted the TBLT literature (Breen, 1989; Coughland \& Duff, 1994; Eckerth, 2009). Negotiations of intercultural meaning arisen unexpectedly from the interactional context extraneous to the task design were few, but their scarcity notwithstanding, they constituted an interesting finding for their unplanned quality and for the authenticity of the intercultural content they made available to the participants. While the negotiation of intercultural information embedded in the tasks by design would have been difficult to engineer in tasks carried out in traditional classrooms, these unplanned episodes would have never occurred without the mediation of the synchronous technology: We believe they would have not been possible, had it not been for the synchronous communication environments that brought together learners and native 
speakers. We also found that intercultural negotiation routines as a whole accounted for a good part of the task time, as indicated by their high density of occurrence, well over the density of occurrence reported by Ortega (2009) for negotiation of meaning episodes (i.e., targeting grammar and lexis) across studies of synchronous text-based second-language chat. This high density of intercultural negotiation may have been fostered not only by our seeding the task design with opportunities for intercultural information gaps, but also by our voice-based synchronous environments of the virtual world of Second Life and the video communication platform. Some evidence for this claim is that repeating utterances with rising intonation and question utterances, both strategies unavailable in text-based chatting, were the most common indicators of some needed repair.

The negotiation of meaning sequences were both language learner and native speaker initiated. That is, native speakers did not dominate the initiation of the negotiations for meaning. The frequent instances of learners taking initiative and using intercultural learning strategies reinforces Byram's (1997) observation that the foreign language speakers, with their knowledge of both cultures, hold at least an equal position of power to that of the native speakers. The learner initiated negotiations may exemplify the ability to use questioning techniques as one marker of Byram's (1997) skills of discovery and interaction. Moreover, we can attest from a qualitative inspection of the interaction overall that both the language learners and the pre-service teachers demonstrated characteristics of Byram's (1997) intercultural communicative competence in the negotiation of meaning sequences. Namely, by initiating topical threads and engaging in negotiation of intercultural meaning and by displaying many indicators of interest, such as open-ended questions and laughter, they showed attitudes of curiosity and openness towards each others' cultures; they used and expanded their knowledge of the interlocutor's society and daily life; they interpreted and related culture-specific events; they discovered and interacted to acquire new knowledge of their interlocutors' culture; and they expressed critical cultural awareness towards their own and the interlocutors' culture.

Participation in task-based VW and VC interactions made these learners and their interlocutors more aware of intercultural differences and similarities, as virtual worlds and video communication tasks were developed in such a way that both language learners and pre-service teachers had to reflect on their interlocutors' and their own culture by discussing, explaining and understanding contrasts, similarities and misunderstandings. Therefore, the tasks carried out in these CMC environments enhanced collaborative intercultural communicative development, since successful task completion required participants to work together and share the cultural information, views, and connotations necessary to complete the tasks. Further, the perceived informal and interactive nature of the synchronous environments used may have permitted negotiation of intercultural meaning to occur during task completion with less disruption and embarrassment than would have resulted in formal classroom situations. The additional data from perception questionnaires consistently indicate that both the language learners and the native speakers found the tasks motivating and appropriate for enhancing intercultural competence. Tasks were perceived as conducive to raising awareness of cultural contrasts and similarities. 
At a curriculum development level, this study indicates that tasks mediated by synchronous technologies may be a powerful tool to create and facilitate interactions in which language learners can communicate effectively with native language speakers. Such opportunities for intensive oral communication on intercultural issues with native speakers are very difficult to create in traditional foreign language classroom settings. When online synchronous communication tasks can bring together language learners and language teachers from different cultural contexts, an optimal situation may come to exist for the shared development of intercultural competence by negotiation of meaning. Learner's ability to elicit, discuss and acquire knowledge is an appropriate expression of the skills of discovery and interaction that makes the language learners intercultural speakers (Byram, 1997). We thus see the potential of synchronous technology environments in combination with adequate intercultural-focused interaction tasks to promote the learner's negotiation strategies which can lead to improved intercultural competence. Following the recommendations of O'Dowd \& Ware (2009), educators seeking to implement telecollaborative projects should be aware of the different options available in telecollaborative task design as well as bear in mind that an online collaborative competence is required (ability to articulate to virtual partners the proposed learning objectives and pedagogical beliefs; openness to alternative pedagogical beliefs; willingness to adapt to other approaches to task design).

Although the positive results obtained in our study are very encouraging, we are aware of some limitations that might be worth taking into account when considering future studies. Firstly, our decision of using the same tasks for both platforms, VW and VC, might have limited the use of their affordances to full potential. Further research should consider that each environment may ask for modifications in task design to exploit the specific affordances of VW vs. VC. This could lead to a scenario where some tasks are better suited to a particular platform than others. Secondly, regarding the nature of the participants in this study, it has to be noted that the pre-service teacher identity of the native speaker interlocutors may have influenced the patterns observed, including the quantity and density of negotiation, either because pre-service teachers may be more inclined to be sympathetic interlocutors with learners, or more adept at negotiating. Future studies might compare results obtained from settings in which the native speaker role is not fulfilled by a (pre-service) teacher. The type of participants in our study (pre-service teachers and university students) provided a win-win situation: pre-service teachers would experience first-hand CMC teaching and foreign language learners would benefit from expert interlocutors. The content of our CMC sessions matched participants' profile (age, type of education) and task topics. Provided the appropriately designed tasks yield benefits for all participants the setting could be adapted to other types of participants and task contents. Thirdly, in the current study unnoticed triggers were not analysed. However, future research might look into whether they were ignored by the native speaker or by the language learner, whether they were task or interaction related and whether they were related to the CMC environment (Smith, 2003). A closer investigation of these unnoticed triggers would benefit further adjustments of task design. 
Evidently, the application of intercultural tasks in synchronous technology environments does not come without technical and organizational challenges. But the positive aspects revealed in the analysis of recorded interaction and questionnaires (and in participants' interviews that we have not reported here) are extremely encouraging: confidence gains when talking with native speakers, opportunity to practice what has been taught in the classroom with a native speaker, the opportunity the online synchronous environments offer them for cultural exposure, discovery, resolving cultural information gaps, and above all for real interaction. In other words, the NIFLAR VW and VC tasks offer a model for the integral combination of tasks and technology in that they created opportunities for negotiation of intercultural meaning in which participants engaged in order to attain an objective, and which necessitates the use of language (Van den Branden, 2006), by promoting participants' meaning-orientation, goal-orientation, outcome evaluation, and real-world relationships (Ellis, 2003; Skehan, 1998).

\subsection{References}

American Council on the Teaching of Foreign Languages (ACTFL). (1999). Standards for foreign language learning (2nd ed.). Yonkers, New York: ACTFL.

Belz, J.A \& Thorne, S.L. (Eds.). (2006). Internet-mediated intercultural foreign language education. Boston: Heinle \& Heinle.

Breen, M. (1987). Learner contributions to task design. In C. Candlin \& D. Murphy (Eds.), Language learning tasks (pp. 23-46). Englewood Cliffs, NJ: Prentice-Hall.

Breen, M. (1989). The evaluation cycle for language learning tasks. In R. K. Johnson (Ed.), The second language curriculum (pp. 187-206). Cambridge, UK: Cambridge University Press.

Bryant, T. (2006) Using World of Warcraft and other MMORPGs to foster a targeted, social, and cooperative approach toward language learning. Academic Commons.

Byram, M. (1997). Teaching and assessing intercultural communicative competence. Clevedon: Multilingual Matters.

Byram, M., Nichols, A., \& Stevens, D. (2001). Developing intercultural competence in practice. Clevedon, Multilingual Matters.

Byram, M. \& Zarate, G. (1994). Definitions, objectives, and evaluation of cultural competence. Strasbourg: Council of Europe.

Chaudron, C., Doughty, C., \& Kim, Y, (2005). A task-based needs analysis of a tertiary Korean as a foreign language program. In. M.H. Long (Ed.), Second language needs analysis (pp. 225-61). Cambridge: Cambridge University Press.

Ciekanski, M. \& Chanier, T. (2008). Developing online multimodal verbal communication to enhance the writing process in an audio-graphic conferencing environment. ReCALL, 20(2), 162-182.

Cooke-Plagwitz, J. (2008). New directions in CALL: An objective introduction to Second Life. CALICO Journal, 25(3), 547-557. 
Coughland, P., \& Duff, P. A. (1994). Same task, different activities: analysis of SLA Task from an Activity Theory Perspective. In J. P. Lantolf \& G. Appel (Eds.), Vygotskian Approaches to SL Research (pp. 173-194). Norwood, NJ: Ablex Publishing Corp.

Council of Europe. (2001). (CEFR) Common European Framework of Reference for Languages: Learning, teaching, assessment. Cambridge: CUP / Council of Europe.

Deutschmann, M., Panichi, L., \& Molka-Danielsen, J. (2009). Designing oral participation in Second Life - A comparative study of two language proficiency courses. ReCALL, 21(2), 206-226.

Dieterle, E., \& Clarke, J. (2008). Multi-user virtual environments for teaching and learning. In M. Pagani (Ed.), Encyclopedia of multimedia technology and networking (pp. 1033-1035). Hershey, PA: Idea Group, Inc.

Doughty, C., \& Long. M. (2003). Optimal psycholinguistic environments for distance foreign language learning. Language Learning and Technology, $7(3), 50-75$.

Eckerth, J. (2009). Negotiated interaction in the L2 classroom. Language Teaching, 42, 109-130.

Ellis, R. (2003). Task-based language learning and teaching. Oxford, UK: Oxford University Press.

Fernández-García, M., \& Martínez-Arbelaiz, A. (2002). Negotiation of meaning in non-native speaker-non-native speaker synchronous discussions. CALICO Journal, 19(2), 279-294.

Furstenberg, G., Levet, S., English, K., \& Maillet, K. (2001). Giving a virtual voice to the silent language of culture. The CULTURA project. Language Learning and Technology, 5(1), 55-102.

González-Lloret, M. (2008). Computer-mediated learning of L2 pragmatics. In E. A Soler \& A. Martinez-Flor (Eds.), Investigating Pragmatics in Foreign Language Learning, Teaching and Testing (pp. 114-132). Clevedon, UK Multilingual Matters

Guichon, N. (2010). Preparatory study for the design of a desktop videoconferencing platform for synchronous language teaching. Computer Assisted Language Learning, 23(2), 169 - 182.

Guth, S., \& Maio, M. (2010). Close encounters of a new kind: The use of Skype and Wiki in telecollaboration. In S. Guth \& F. Helm (Eds.) Telecollaboration 2.0 (pp.413-427). Bern: Peter Lang AG.

Hall, J.K. (2004). A prosaic of interaction: the development of interactional competence in another language. In Hinkel, E. (Ed.), Culture in second language teaching and learning. (pp. 137-151). Cambridge: Cambridge University Press.

Hampel, R., \& Hauck, M. (2004). Towards an effective use of audio conferencing in distance language courses. Language Learning and Technology, 8(1), 6682.

Hampel, R., Felix, U., Hauck, M., \& Coleman, J.A. (2005). Complexities of learning and teaching languages in a real-time audiographic environment. German as a Foreign Language Journal, 3, 1-30.

Heritage, J. (1984). A change-of-state token and aspects of its sequential placement. In J. M. Atkinson \& J. Heritage (Eds.), Structures of Social Action. Studies 
in Conversation Analysis (pp. 299-345). Cambridge: Cambridge University Press.

Hinkel, E. (Ed.) (2004). Culture in second language teaching and learning. Cambridge: Cambridge University Press.

Jauregi, K. (2011). La negociación de procesos de escritura a través de la videocomunicación. In Estévez, N., Gómez, J.R., \& Carbonell, M. (Eds.), .La comunicación escrita en el siglo XXI. Cuadernos de Filología, Estudios Lingüísticos, 16, 81-105.

Jauregi, K., \& Bañados, E. (2008). Virtual interaction through video-web communication: A step towards enriching and internationalizing learning programs. ReCALL, 20(2), 183-207.

Jauregi, K., \& Bañados, E. (2010). An intercontinental video-web communication project between Chile and The Netherlands. In S. Guth \& F. Helm (Eds.), Telecollaboration 2.0 (pp. 427-436). Bern: Peter Lang AG..

Jauregi, K., Canto, S., Graaff, de R., Koenraad, A., \& Moonen, M. (2011). Verbal interaction in Second Life: towards a pedagogic framework for task design. Computer Assisted Language Learning Journal, 24, 77-101.

Jauregi, K., Graaff, de R., Bergh van den H., \& Kriz, M. (2012). Native non-native speaker interactions through video-web communication, a clue for enhancing motivation? Computer Assisted Language Learning Journal, 2591), $1-19$.

Kramsch, C. (1991). Culture in language learning: A view from the States. In K. de Bot, R.B. Ginsberg, \& C. Kramsch (Eds.), Foreign language research in cross-cultural perspective (pp. 217-240). Amsterdam: John Benjamins.

Kramsch, C. (1993). Context and culture inlLanguage teaching. Oxford: Oxford University Press.

Kramsch, C., \& Thorne, S. (2002). Foreign language learning as global communicative practice. In D. Block \& D. Cameron (Eds.), Language learning and teaching in the age of globalization (pp. 83-100). London: Routledge.

Kuriscak, L.M, \&, Luke C. L. (2009). Language learner attitudes toward virtual worlds: An investigation of Second Life. In G. Lord \& L. Lomicka (Eds.), The next generation: Online collaboration and social networking in CALL (pp. 173-207). San Marcos, TX: CALICO.

Lantolf, J.P. (Ed.) (2000). Sociocultural theory and second language learning. Oxford: Oxford University Press.

Lantolf, J.P., \& Thorne, S.L. (Eds.) (2006). Sociocultural theory and second language learning. Oxford: Oxford University Press.

Lamy, M.N. (2004). Oral conversations on line: redefining oral competence in synchronous environments. ReCALL, 16(2), 520-538.

Liauw, M. (2006). E-learning and the development of intercultural competence. Language Learning \& Technology, 10(3), 49-64.

Long, M. (2009). Methodological principles for language teaching. In M. Long \& C. Doughty (Eds.), The handbook of language teaching (pp. 371-394). Malden, MA: Wiley-Blackwell.

Long, M.H., \& Crookes, G. (1993). Units of analysis in syllabus design: The case for task. In G. Crookes \& S. Gass (Eds.), Tasks in a pedagogical context: 
Integrating theory and practice (pp. 9-54). Clevedon, UK: Multilingual Matters.

Long, M.H., \& Norris, J.M. (2000). Task-based teaching and assessment. In M. Byram (Ed.), Encyclopedia of language teaching (pp. 597-603). London: Routhledge.

Molka-Danielsen, J., \& Deutschmann, M. (Eds.). (2009): Learning and teaching in the virtual world of Second Life. Trondheim, Norway: Tapir Academic Press.

Moonen, M., De Graaff, R., \& Westhoff, G. (2006). Focused tasks, mental actions and second language learning. Cognitive and connectionist accounts of task effectiveness. ITL - International Journal of Applied Linguistics, 152, 3553.

Müller-Jacquier, J. (2003). Linguistic awareness and cultures. In Jürgen (Ed.), Studien zur internationalen Internehmenskommunikation (pp. 20-49). Leipzig: Popp.

Norris, J. (2009). Task-based teaching and testing. In M. Long \& C. Doughty (Eds.), The handbook of language teaching (pp. 578-594). Malden, MA: WileyBlackwell.

O’Dowd, R. (2000). Intercultural learning via videoconferencing: a pilot exchange project. ReCALL, 12, 49-63.

O'Dowd, R. (2011). Online foreign language interaction: Moving from the periphery to the core of foreign language education? Language Teaching, 44, 368380.

O'Dowd, R. \& Ritter, M. (2006). Understanding and working with 'failed communication' in telecollaborative exchanges. CALICO Journal, 23(3), 120.

O'Dowd, R., \& Ware, P. (2009). Critical issues in telecollaborative task design. CALL Journal, 22, 173-188.

Open Simulator project. http://opensimulator.org/wiki/Main_Page.

Ortega, L. (2009). Interaction and attention to form in L2 text-based computermediated communication. In A. Mackey \& C. Polio (Eds.), Multiple Perspectives on Interaction in SLA: Research in Honor of Susan M. Gass (pp. 226-253). New York: Routledge.

Sauro, S. (2011). SCMC for SLA: A research synthesis. CALICO Journal, 28, 369391.

Skehan, P. (1998). A cognitive approach to language learning. Oxford: Oxford University Press.

Smith, B. (2003). Computer-mediated negotiated interaction: An expanded model. The Modern Language Journal, 87(1), 38-57.

Smith, B. (2004). Computer-mediated negotiated interaction and lexical acquisition. Studies in Second Language Acquisition, 26, 365-398.

Steinkuehler, C. (2006). Massively multiplayer online videogaming as participation in a discourse. Mind, Culture \& Activity, 13(1), 38-52.

Steinkuehler, C., \& Squire, K. (2009). Virtual worlds and learning: Introduction to the special issue. On the Horizon, 17(1), 8-11.

Thorne, S. L. (2008). Transcultural communication in open internet environments and massively multiplayer online games. In S. Magnan (Ed.), Mediating Discourse Online (pp. 305-327). Amsterdam: John Benjamins. 
Tudini, V. (2007). Negotiation and intercultural learning in Italian native speaker chat rooms. Modern Language Journal, 91(4), 577-601.

Van den Branden, K. (2006). Introduction: task-based language teaching in a nutshell. In K. van den Branden (Ed.), Task-based language education (pp. 1-17). Cambridge: Cambridge University Press.

Varonis, E. M., \& Gass, S. (1985a). Miscommunication in native/non-native conversation. Language in Society, 14(3), 327-343.

Varonis, E. M., \& Gass, S. (1985b). Non-native/non-native conversations: A model for the negotiation of meaning. Applied Linguistics, 6, 71-90.

Ware, P., \& Kramsch, C. (2005). Towards an intercultural stance. Teaching German and English through telecollaboration. Modern Language Journal, 89, 190205.

Ware, P., \& O'Dowd, R. (2008). Peer feedback on language form in telecollaboration. Language Learning and Technology, 12(1), 43-63.

Westhoff, G. (2004). The art of playing a pinball machine. Characteristics of effective SLA-tasks. Babylonia, 12(3), 58-62.

Willis, J. (1996). A framework for task-based learning. Harlow, UK: Longman. 


\subsection{Appendix. Global task descriptions.}

Task 1 Gente genial

\begin{tabular}{|c|c|}
\hline Task title & Gente genial \\
\hline Environment & Video-web communication or virtual worlds \\
\hline Short description & $\begin{array}{l}\text { Students are meant to share a house and are encouraged to explain aspects } \\
\text { of their own culture via a television showing images depicting cultural } \\
\text { aspects of both countries. Afterwards, they have to organise an outing from } \\
\text { three options given [art gallery, cinema and a walk in virtual Valencia]. } \\
\text { Once the destination is chosen, they are teleported to the specific location } \\
\text { where they have to talk about the art in the gallery; choose, view and } \\
\text { comment the trailer of a film; walk around the virtual city comparing it to } \\
\text { their own and link it to a famous person from that area in their country: a } \\
\text { painter, a film director or actor, a historical character, etc. }\end{array}$ \\
\hline $\begin{array}{l}\text { Target group: } \\
\text { Target language } \\
\text { Level (CEFR) } \\
\text { \# participants } \\
\end{array}$ & $\begin{array}{l}\text { Spanish } \\
\text { B1-B2 } \\
\text { Max } 4 \text { (native and non native speakers) }\end{array}$ \\
\hline $\begin{array}{l}\text { Task goals: } \\
\text { Language goals }\end{array}$ & $\begin{array}{l}\text { Express taste \& preferences } \\
\text { Describe a picture } \\
\text { Express preferences } \\
\text { Plan activities } \\
\text { Make suggestions }\end{array}$ \\
\hline Intercultural goals & $\begin{array}{l}\text { Refer to individual and group customs } \\
\text { Contrast uses and customs } \\
\text { Compare contrasting situations } \\
\text { Explain stereotypical situations in own culture } \\
\text { Recognize stereotypical situations in target culture }\end{array}$ \\
\hline $\begin{array}{l}\text { Task size: } \\
\text { preparation time } \\
\text { performance time } \\
\text { evaluation time }\end{array}$ & $\begin{array}{l}\text { Preparation: } 0,5 \mathrm{~h} \\
\text { Performance: } 1,0 \mathrm{~h} \\
\text { Evaluation: } 0,5 \mathrm{~h}\end{array}$ \\
\hline $\begin{array}{l}\text { Technical specifications: } \\
\text { VC needs } \\
\text { Additional materials and } \\
\quad \text { activities }\end{array}$ & $\begin{array}{l}\text { Pictures to be uploaded in the video-web communication are necessary: } \\
\text { Pictures of the house they will be sharing } \\
\text { Pictures reflecting cultural diversity in both target cultures } \\
\text { Documents related to the activity to be undertaken: } \\
\text { Cinema: movie posters and links to the trailers } \\
\text { Art gallery: pictures of paintings } \\
\text { Pictures of the city where one of the partners comes from [native speaker]. }\end{array}$ \\
\hline $\begin{array}{l}\text { Evaluation and reflection: } \\
\text { Evaluation of task } \\
\quad \text { completion } \\
\text { Reflection and self- } \\
\quad \text { assessment }\end{array}$ & $\begin{array}{l}\text { Questionnaire [students and pre-service teachers] } \\
\text { Evaluation of language learners level according to a list of criteria }\end{array}$ \\
\hline $\begin{array}{l}\text { Pedagogical context: } \\
\text { Role of student teachers } \\
\text { Focus of student teachers } \\
\text { Task function in curricular } \\
\quad \text { context }\end{array}$ & $\begin{array}{l}\text { Native language role models } \\
\text { Providers of cultural information } \\
\text { Gathering criteria for using video-communication as platforms for } \\
\text { language teaching and discovering how video-communication in } \\
\text { coordination with adequate tasks may contribute to language teaching } \\
\text { Final task on the objectives described above corresponding to course book }\end{array}$ \\
\hline
\end{tabular}


Task 5: Gente y culturas

\begin{tabular}{|c|c|}
\hline Task title & Gente y culturas \\
\hline Environment & video-web communication or virtual worlds \\
\hline Short description & $\begin{array}{l}\text { This task takes the form of a game show, a "Cultural Olympiad". The } \\
\text { Dutch team will compete against the Spanish team in terms of cultural } \\
\text { knowledge of the other country. Questions for which the teams can } \\
\text { score points are displayed on a screen and the opponents have to judge } \\
\text { the adequacy of the answers. }\end{array}$ \\
\hline $\begin{array}{l}\text { Target group: } \\
\text { Target language } \\
\text { Level (CEFR) } \\
\text { \# participants }\end{array}$ & $\begin{array}{l}\text { Spanish } \\
\text { B1-B2 } \\
\text { Max } 4 \text { (Native and non native speakers) }\end{array}$ \\
\hline $\begin{array}{l}\text { Task goals: } \\
\text { Language goals }\end{array}$ & $\begin{array}{l}\text { Refer to individual and group customs } \\
\text { Present briefly a variety of cultural aspects } \\
\text { Show surprise } \\
\text { Describe a picture }\end{array}$ \\
\hline Intercultural goals & $\begin{array}{l}\text { Describe habits from their own culture and compare them to those of the } \\
\text { target language } \\
\text { Explain and recognize stereotypical situations in own culture and in target } \\
\text { culture } \\
\text { Understand certain behaviours from the other culture to try to avoid } \\
\text { cultural misunderstandings. }\end{array}$ \\
\hline $\begin{array}{l}\text { Task size: } \\
\text { preparation time } \\
\text { performance time } \\
\text { evaluation time }\end{array}$ & $\begin{array}{l}\text { Preparation: } 1 \mathrm{~h} \\
\text { Performance: } 1,0 \mathrm{~h} \\
\text { Evaluation: } 0,5 \mathrm{~h}\end{array}$ \\
\hline $\begin{array}{l}\text { Technical specifications: } \\
\text { VW needs } \\
\text { Additional materials and } \\
\quad \text { activities }\end{array}$ & $\begin{array}{l}\text { Pictures (see appendix) will be uploaded to the videocommunication } \\
\text { environment. }\end{array}$ \\
\hline $\begin{array}{l}\text { Evaluation and reflection: } \\
\text { Evaluation of task } \\
\quad \text { completion } \\
\text { Reflection and self- } \\
\quad \text { assessment }\end{array}$ & $\begin{array}{l}\text { Questionnaire [students and pre-service teachers] } \\
\text { Evaluation of language learners level according to a list of criteria }\end{array}$ \\
\hline $\begin{array}{l}\text { Pedagogical context: } \\
\text { Role of student teachers } \\
\text { Focus of student teachers } \\
\text { Task function in curricular } \\
\quad \text { context }\end{array}$ & $\begin{array}{l}\text { Culture source in judging the answers } \\
\text { Native speaker interlocutors in the game } \\
\text { Understand cultural clash for language learners } \\
\text { What do language learners consider (non)-stereotypical in my culture and } \\
\text { why? } \\
\text { Discovering how video-web communication in coordination with adequate } \\
\text { tasks may contribute to language teaching } \\
\text { Final task on the objectives described above corresponding to course book }\end{array}$ \\
\hline
\end{tabular}





\title{
Chapter 4
}

\section{Integrating cross-cultural interaction through video communication and virtual worlds in foreign language teaching programmes: burden or added value? ${ }^{1}$}

\begin{abstract}
4.1 Abstract
Organizing and implementing telecollaboration projects in foreign language curricula is not an easy endeavour (Belz \& Thorne, 2006; Guth \& Helm, 2010), as pedagogical, organizational and technical issues have to be addressed before crosscultural interaction sessions can be carried out (O'Dowd \& Ritter, 2006; O'Dowd, 2011). These issues make many teaching practitioners reluctant to try to integrate telecollaboration in their teaching, as they are more aware of the burden such initiatives might impose than of the benefits they might have for language learners.

Within the European project NIFLAR we have tried to study the added value that integrating synchronous collaboration projects through video communication or the virtual world of Second Life might have in language learning. The study presented in this paper measures the oral communicative growth of language students, who were allocated at random to one of three research conditions: (1) the VC experimental group carried out interactions with native peers through video communication; (2) the SL experimental group carried out the same tasks with native peers in Second Life and (3) the control group performed the tasks face to face with classroom peers and had no opportunity to interact with native experts. Communicative growth was measured by comparing pre- and post-oral tests across conditions. Results show significant differences, the experimental groups outperforming the control group.
\end{abstract}

\subsection{Introduction}

The NIFLAR project ${ }^{2}$ aims at enriching and innovating foreign language teaching and learning processes, by creating opportunities for enhancing authentic social interaction between students of foreign languages and native student teachers. For

1 This chapter has been published as: Canto, S., Jauregi, K., \& Van den Bergh, H. (2013). Integrating cross-cultural interaction through video communication and virtual worlds in foreign language teaching programmes. Burden or added value? ReCALL, 25(1), 105-121.

2 NIFLAR, Networked Interaction in Foreign Language Acquisition and Research, a two year project (2009-2011), received a grant from the European Commission within the Lifelong Learning Programme (www.niflar.eu). 
this purpose, interaction tasks were developed for the project languages (Dutch, Portuguese, Russian and Spanish) with a focus on intercultural awareness.

The interaction sessions took place in two digital environments: video communication and voice-enabled 3D virtual worlds. The first one facilitates distant spoken and written interaction among dyads or groups of students. They work collaboratively, by sharing files while communicating and seeing each other through the webcam. The interaction sessions were conducted in Adobe Connect.

In the second environment, voice-enabled 3D virtual worlds, students participate as avatars, can engage in textual and voiced interactions with other avatars while carrying out actions together (walking, dancing, taking and giving objects, even building); avatars can be teleported to different countries, cities or public and private spaces (a house, shops, restaurants, hospitals, hotels, courtroom, parliament, theatre, museum), just by a simple mouse click. These different scenarios and the possibilities of undertaking action while communicating with others, make 3D virtual worlds a potentially interesting environment for foreign language teaching and learning. In NIFLAR experiences were conducted in Second Life (tertiary education) and Open Sim (teenagers).

One of the main objectives of NIFLAR is to find out whether there is an added value in incorporating these new technologies and the possibilities they offer for intensifying interaction in language learning processes, an issue we will be addressing in this paper.

\subsection{Studies on computer mediated communication}

Computer mediated communication (CMC) is being increasingly embraced by language teachers, as students can communicate in the target language (a)synchronously through a computer with their teacher, classmates, foreign language learners elsewhere or even with native speakers. Educational practices with different virtual environments have been described pointing at positive (students like it and feel sessions contribute to the learning process) and negative aspects (technical problems, organizational burden and pragmatic misunderstandings leading to irritations) (see Belz \& Thorne, 2006; Guth \& Helm, 2010; O’Dowd, 2007, 2011).

Researchers have tried to show the relevance of CMC in promoting second language acquisition. The initial studies showed that written (mostly asynchronous) CMC contributes to: (1) breaking down the barriers and inhibitions when using the target language, helping the L2 learner to become more confident about his/her language use (Kern, 1996); (2) stimulating foreign language learners to experiment with and produce more target language (Kelm, 1992; Kern, 1996); and (3) enabling a more coherent (Felix \& Lawson, 1996) and lexically and syntactically more complex production of language (Warschauer, 1996). In the last years the study of intercultural competence in CMC has received major focus of attention (Belz, 2003; Belz \& Thorne, 2006; Liauw, 2006; Müller-Hartmann, 2000; O’Dowd, 2003, 2006, 2007; Ware \& Kramsch, 2005).

As for synchronous CMC, most research has been carried out on chat sessions. Chat sessions are said to be effective communicative tools to enhance 
language learning at syntactic (Sotillo, 2000), discourse (Warschauer, 1996), grammatical (Pellettieri, 2000), lexical (Smith, 2004), and intercultural levels (Belz \& Thorne, 2006; Toyoda \& Harrison, 2002; Tudini, 2007), although Ortega (2009) has reported that a closer look at text-based synchronous computer mediated communication (SCMC) research reveals mixed findings and insufficient evidence (see also Sauro, 2011).

As far as audio(visual) synchronous environments are concerned experiences have been reported making use of (1) audiographic conferencing (Lamy, 2004; Ciekanski \& Chanier, 2008; Hampel \& Hauck, 2004; Hampel, Felix, Hauck \& Coleman, 2005); (2) videoconferencing (O’Dowd, 2000, 2006); (3) voiced chats like MSN, Skype, Netmeeting (Develotte, Guichon, \& Vincent, 2010; Guth \& Maio, 2010; Wang, 2004, 2006, 2007); and more sophisticated audiovisual web communication platforms like Adobe Connect, Elluminate or Visu (Guichon, 2010; Jauregi \& Bañados, 2008, 2010). Most of these research studies, although they provide interesting information, are explorative and describe experiences as being motivating and contributing to communicative or intercultural development, but do not offer strong empirical evidence for it.

An interesting study analysing the benefits and drawbacks of engaging students in voiced chats is that by Bueno Alustey (2011). She worked with two condition groups: a control group that interacted face to face with classmates in English on task performance, and the experimental group who carried out the tasks in the target language (English) through Skype with students in Turkey. After triangulating and analysing different sources of data (general proficiency pre- and post test scores, oral ppt presentation grades, questionnaires and diaries) she found significantly better achievements for the SCMC group as opposed to the control group and a clear increase of positive factors to language learning in the experimental group: satisfaction, feelings of improvement and decreased speaking anxiety.

In the last few years virtual worlds, such as Second Life, are becoming increasingly popular among language teachers (see Molka-Danielsen \& Deutschmann, 2009; Deutschmann, Panichi, \& Molka-Danielsen, 2009 for an overview), particularly as a space where foreign language learners can engage in interaction (Deutschmann, Panichi, \& Molka-Danielsen 2009; Peterson, 2010), meet native speakers of the target language (Kuriscak \& Luke, 2009) for engaging in meaningful communicative and social interaction (Jauregi et al., 2011) while undertaking joint action. Interactional virtual spaces in virtual worlds have been assessed as beneficial for learning and achieving communicative and intercultural competence (Bryant, 2006; Thorne, 2008) as users can experiment and interact with a variety of norms of social interaction (Steinkuehler, 2006). In these 3D environments learners can have the opportunity to experience life-like social interaction while at the same time engaging in meaningful learning activities (Cooke-Plagwitz, 2008). The realistic nature of the environment provides authentic learning conditions that are otherwise difficult to recreate in traditional classroom settings (Dieterle \& Clarke, 2008). However, as Peterson reports (2011), research on virtual worlds remains largely exploratory in nature and is subject to significant limitations. Clearly more research is necessary that analyses whether and how 
interactions through audiovisual platforms and/ or virtual worlds can contribute to foster (intercultural) communicative competence.

\subsection{Research context}

Organising telecollaboration projects can be a complicated endeavour as O'Dowd and Ritter (2006) have shown. Problems can arise at individual, classroom and/or socioinstitutional levels (see Figure 4.1). This organizational burden increases when synchronous tools are being used in telecollaboration projects.

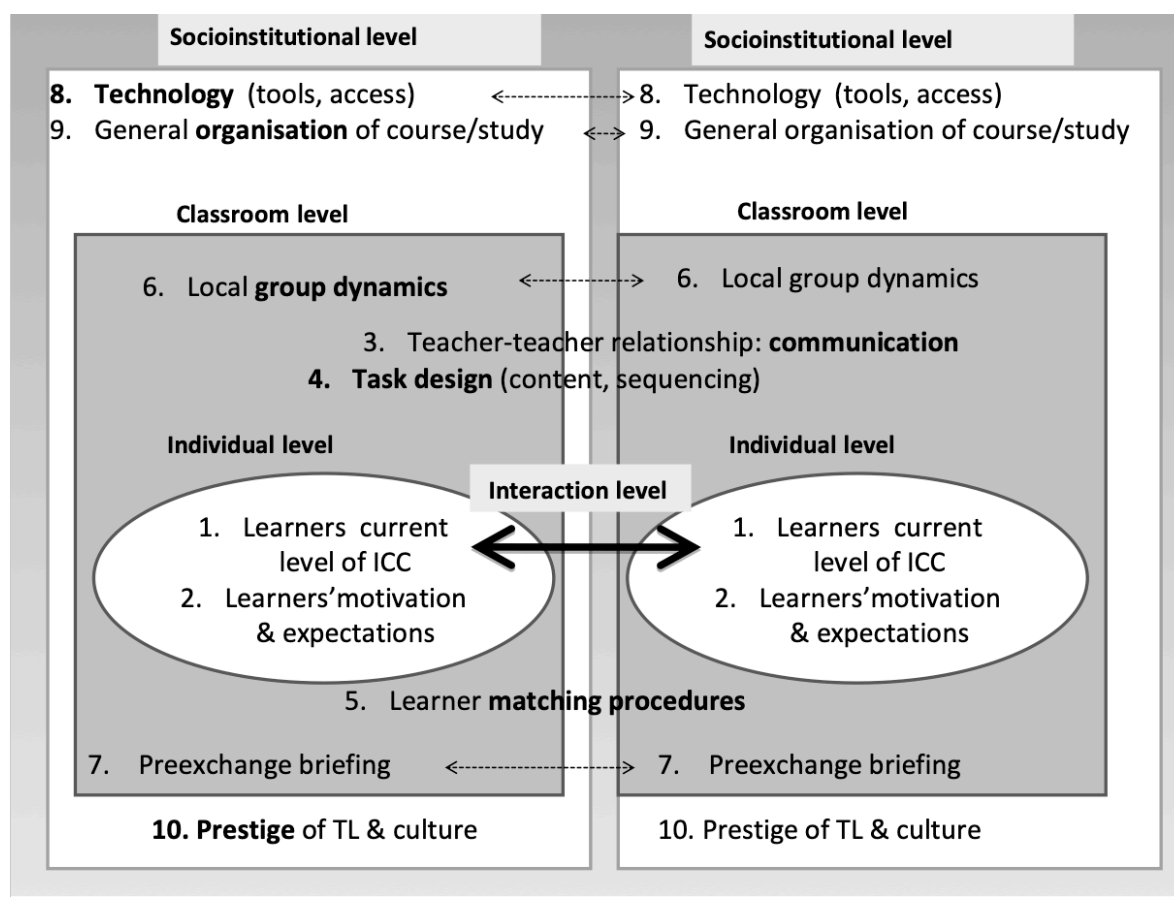

Figure 4.1. Difficulties when trying to organise telecollaborative projects, based on O’Dowd \& Ritter (2006).

There is a clear need to come to know whether including telecollaboration sessions in language curricula has an added value in language learning processes; and this is the main research question we address in this paper: Is there any indication suggesting that learners learn more if they have the opportunity to engage in networked interaction with expert peers according to relevant tasks through video communication or Second Life than when they have not? In other words,

RQ1: Is there a significant difference comparing oral communicative growth of experimental groups (those engaged in networked interactions with expert peers though video communication and virtual worlds) and a control group (those carrying 
out the tasks face to face with classmates in the classroom setting) according to preand post-oral tests?

RQ2: What are participants learning experiences?

2.1 Do foreign language learners have the impression they learn in the interaction sessions?

2.2 Do pre-service teachers feel that their foreign language learners' oral communicative competence increases comparing the first and the last interaction sessions?

In order to answer these questions, this study assessed a group $(n=36)$ of university students on measures of communicative language competence based on descriptors that were inspired by the scales proposed by the Common European Framework of Reference for languages (CEFR). It then investigated whether there was any relationship between the effectiveness of the three different interaction conditions (virtual worlds and video communication with native student teachers or non-native - non-native interaction in the classroom) and communicative competence. Finally, information elicited from the post-questionnaire was used in order to answer subquestions 2.1 and 2.2 and triangulate results.

\subsection{Research method}

The study was conducted at the University of Utrecht in The Netherlands, where the first year language learners of this study were enrolled, in collaboration with the University of Valencia in Spain where the fourteen participants followed a preservice teacher education programme. Language students $(n=36)$ were randomly assigned to one of three research conditions: video communication (VC), Second Life (SL) or Control (C) group and pre-service teachers were assigned to one of the conditions according to their personal preferences. During the period of observation (February - April 2010) the participants carried out five tasks at intervals of once a week. All five tasks were tested in a pilot study before. Previous to the task sessions, language learners and pre-service teachers participated in VC and SL tutorials to become familiarized with the tools.

The data collection sources for this study were pre- and post-oral tests, which assessed learners on measures of (a) range of language, (b) grammatical accuracy, (c) fluency, (d) thematic development and (e) coherence in order to measure communicative growth; and post-questionnaires.

\subsubsection{Instructional treatments}

Language participants at Utrecht University were enrolled in a Spanish language course estimated at B1 (CEFR). The course for both VC and SL groups was considered blended learning, which meant that each group would meet twice a week face to face with their teacher (the same one for all three groups) whereas the third meeting was computer mediated with the native speaker to perform an interaction task. Participants in the experimental groups communicated in triads: two language 
students carried out tasks with one native speaker of Spanish during five task sessions. In the case of the control group, the third weekly session was the performance of the same interaction tasks as the experimental groups, in groups of four language learners in the language classroom. The type of instruction that the control group followed (without telecollaboration with native speakers) is the one that most closely approximated to the model that the majority of students experience in language courses where they carry out tasks with each other in the classroom setting.

The tasks were designed and aligned with the course contents and objectives, as they were linked to units from the task-based syllabus used in the course. Tasks were the same for all three groups; they were only adapted in order to take advantage of the specific affordances of the VC or SL medium. Where participants from the SL group could virtually visit the Spanish city their interlocutor was from, go together on a skiing holiday or play a cultural game, the VC group was able to do the same with a native speaker too through the affordances of the medium via images, video and sharing of information. The control group on the other hand, had the aid of images and video to contextualise tasks but had no native interlocutors playing the expert role. All task sessions were part of the course syllabus.

The five tasks developed ${ }^{3}$ were the following: In the first task "Gente genial" (Cool People) participants, as exchange students in a Erasmus program, were asked to (1) visit an apartment they were meant to share, (2) talk about themselves and exchange cultural information triggered by pictures and (3) choose an outing option (go to the cinema, to a museum or to walk in the city). The second task "Gente y Aventura" (People and Adventure) consisted of planning a holiday and reflecting on past holiday experiences. The third task "Gente de cine" (Movie Celebrity People), was a selection of different short scenes in which participants had to play different roles given the indications of a brief script. The fourth task, "Gente con corazón" (People with Heart), allowed students to impersonate different characters and experience the reactions caused on others. Finally the fifth task, "Gente y culturas" (People and Cultures), was designed as a cultural televisiongame style contest between a Dutch and a Spanish team.

All tasks had a preparatory and performance phase with support materials in the form of documents to guide them through the tasks.

\subsubsection{Instruments}

In order to answer the main research question pre- and post-oral tests were taken prior and after the interaction sessions which would allow us to measure communicative growth. Participants' experiences were evaluated at the end of the course in a survey and additional interviews were recorded.

3 The project tasks can be downloaded from http://cms.hum.uu.nl/niflar/ 
Oral tests

The pre- and post-test were the same for the three research conditions. Language learners were assessed on measures of communicative language competence based on descriptors that were inspired by the scales proposed by the Common European Framework of Reference for languages (CEFR). Five were the measures assessed on a 10 point scale each: (a) range of language, (b) grammatical accuracy, (c) fluency, (d) thematic development and (e) coherence (see Appendix).

The test consisted of 11 open questions that ranged from personal information and studies ( 3 items), previous experiences in Spanish speaking countries (1 item), student life (3 items), weather and gastronomy (2 items), economy (1 item) and recommendations for foreigners visiting their country (1 item). The questions were video recorded by a native student teacher.

The oral tests were administered via a computer in a language lab. Every student sat in front of a computer, activated the video and answered orally the 11 questions. The recording was done automatically. Students could spend as long as they wanted in each answer since they had access to a panel control to pause after each question. All recorded answers were given a code so that when assessing them the researchers would not know beforehand if it was a pre- or a post-test they were assessing.

Two native speakers of Spanish rated separately the tests on five aspects: (a) range of language, (b) grammatical accuracy, (c) fluency ,(d) thematic development and (e) coherence, however, since there was a high correlation between all five indicators $(.89 \leq r \leq .98)$, they were collapsed into one measure of oral skill. An estimate of inter-rater agreement between both raters was calculated and proved to be high $(\alpha=0.91)$.

Surveys

After the conclusion of the project a final survey was digitally distributed to all three groups of language learners and native student teachers in order to evaluate participants' experiences and triangulate results. The survey for VC and SL groups had 29 items with open and closed questions about the virtual environment (10 items), the tasks ( 2 items), the speech partner (4 items), the learning potential of the project (4 items), organization (1 item) and global project evaluation (5 items). The control group survey consisted of eight items referring to personal data (2 items), native speaker interactions (2 items), the language course (1 item), learning outcomes from interactions with native speakers (1 item) and preference of interaction styles ( 2 items). In all three surveys for the closed items a five-point Likert scale was used.

\subsubsection{Data analysis}

The effect of the virtually mediated interaction with native speakers on communicative growth was analysed in two different ways. First, the mean differences between pre- and post-test scores and conditions were tested by means of analysis of variance for repeated measurements. In this analysis we were 
primarily interested in the interaction effect between moment of measurement and condition, as this states that the average progress differs between conditions.

In the second analysis, so-called aptitude-treatment interactions (Cronbach, 1957) were explicitly tested to see whether the regression from post-test on pre-test scores varied between conditions as one condition might be more effective for lower achieving students, whereas another condition might be better suited for high achievers. These aptitude-treatment interactions are tested by means of multiple regression analysis in which both the intercept and the regression from post- on pretest scores are allowed to vary between conditions.

Comparing mean scores in pre- and post-tests across conditions allows us to (1) determine if students achieved more on the post-test than on the pre-test, and (2) establish in which of the three groups students' progress is largest. Comparing pre- and post-test scores of individual students (in a multiple regression) allows for more nuanced conclusions as the effect of a pedagogical treatment might depend on students' communicative competence level when beginning the course.

\subsection{Results}

The results with respect to the added value of implementing synchronous networked interaction with native speakers are presented here.

\subsubsection{Indicators of learning growth}

Figure 4.2 shows that there was a difference between the average score in the pretest and average score in the post-test in all groups, that is, there was communicative learning growth in both experimental (VC and SL) and control groups.

As can be seen in Figure 4.2 the averages on oral language proficiency increases from pre- to post-test $(F(1,34)=147.7 ; p<0.001)$. Hence, on average students scores on the post-test are higher than the scores on the pre-test. Also the interaction between condition and moment of measurement proved significant $(F(2$, $34)=5.01 ; p=0.12$ ). This means that the increase in oral skills differs between the three conditions. In the control condition the increase in students' oral skills is significantly less than in either the VC, or SL condition. So on average both VC and $\mathrm{SL}$ are more effective as traditional education in the control condition.

In a second analysis, the increase in scores appears to be dependent on students' pre-test scores as well (see Figure 4.3); low achievers in the pre-test are likely to be low achievers on the post-test and high achievers on the pre-test are likely to be high achievers on the post-test as well $(t=12.52 ; p<.001)$. However, the relation between pre- and post-test scores differs between conditions. In both the $\mathrm{VC}$ and SL condition the relation between pre- and post-test scores is less strong as compared to the control condition $(t=-4.46 ; p<0.001$ respectively $t=-3.16 ; p=$ $0.004)$. In Figure 4.3 these effects are graphically illustrated. 


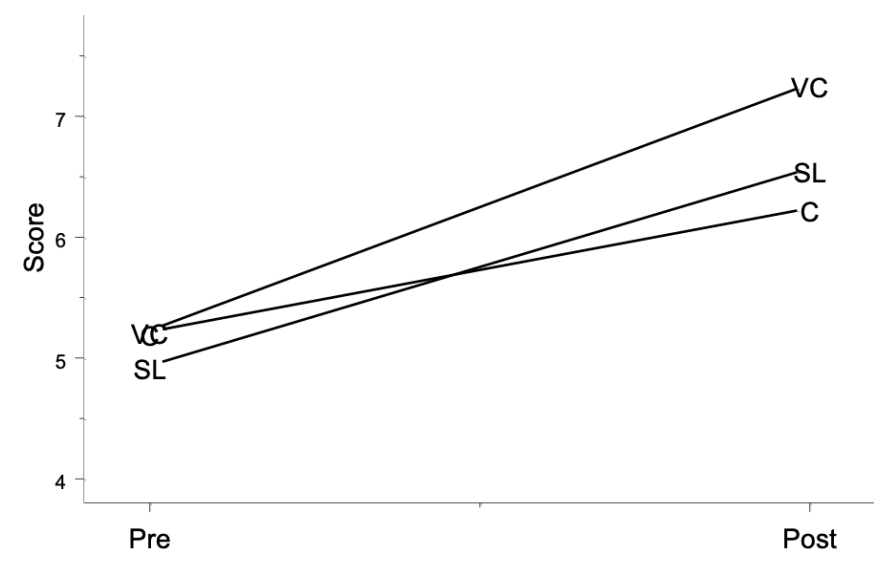

Figure 4.2. Oral language proficiency: Mean scores for pre- and post- oral tests of experimental and control groups (VC: video communication; SL: virtual worlds- Second Life; C: control).

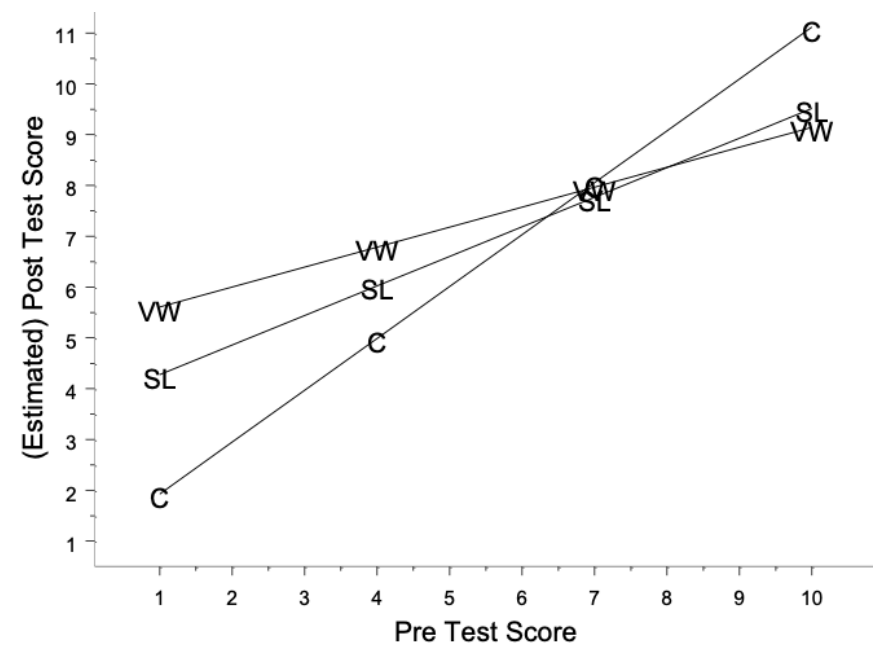

Fig. 4.3. Relation between pre-test (x-axis) and post-test scores for the three research conditions: VW, video communication; SL, Second Life; $\mathrm{C}$, Control group.

From Figure 4.3 it appears that students with poor oral skills at the start of the experiment learn more in both the VC and SL conditions as compared to the control condition. The high achieving students on the pre-test seem not to profit as much from networked interactions with expert peers. 


\subsubsection{Language learners' experiences}

The experiences were very positively evaluated, tasks were felt to be motivating and useful, interactions with pre-service native teachers highly contributing to enhance learning processes and motivation, and the environments, in spite of technical problems, described as being effective in enabling distant native non-native speaker interaction. The usefulness and motivation of the tasks was not only found by language learners of all three groups, it was also observed by the pre-service teacher interlocutors in the VC and SL experimental groups.

Language learners that had had the opportunity to collaborate with native speakers (VC and SL groups) also reported that the telecollaboration sessions had made them more aware of cultural contrasts and similarities, that they had become more confident, were able to talk more fluently, and took more initiative (Table 4.1). From a statistical test it appeared that only the question on motivation to talk does on average not differ from neutral answer 3 (in all other cases $t \geq 1,71 ; d f=26 ; p \leq$ 0.049).

Table 4.1. VC and SL language learners' evaluation responses about learning experiences on a 5-point Likert scale (1: disagree; 5: agree; $n=27$ ).

\begin{tabular}{lcc}
\hline What have you learned during the sessions? & Mean & SD \\
\hline To be aware of cultural contrasts and similarities & 3.85 & 0.82 \\
To talk more fluently & 3.89 & 0.70 \\
To become confident talking in the target language & 3.85 & 0.72 \\
To talk more & 3.48 & 0.85 \\
To take more initiative in the conversation & 3.33 & 1.00 \\
To be more motivated to talk & 3.26 & 0.98 \\
To use new words & 4.26 & 0.71 \\
To use idioms/expressions & 3.93 & 0.68 \\
To use grammar more accurately/correctly & 3.96 & 0.65 \\
\hline
\end{tabular}

When participants in the control group were asked if they thought that given the opportunity to interact with a native speaker they would improve their confidence, fluency, knowledge about the target culture, they would learn to speak better, more vocabulary and understand more, answers pointed towards an affirmative score. (see Table 4.2).

Table 4.2. Control group language learners' $(n=14)$ evaluation responses on a 5-point Likert scale about possible learning experiences when interacting with a native speaker.

\begin{tabular}{lcc}
\hline $\begin{array}{l}\text { Do you think that having the opportunity to conduct interaction } \\
\text { tasks with native speakers }\end{array}$ & Mean & SD \\
\hline you learn to understand better the target language & 4.14 & 0.770 \\
you learn to speak better & 3.93 & 0.730 \\
you learn to speak more fluently & 3.93 & 0.917 \\
you learn more vocabulary & 3.86 & 0.663 \\
you learn to become more confident talking to native speakers & 4.21 & 0.802 \\
\hline
\end{tabular}


Students' learning improvements in VC and SL groups were not only perceived by the students themselves, they were also noticed by pre-service teachers when asked to compare the first and last interaction sessions (Table 4.3).

Table 4.3. Pre-service teachers' $(n=14)$ evaluation responses about language learning learners' improvement on a 5 point Likert scale.

\begin{tabular}{lll}
\hline Comparing the first and the last session: & Mean & SD \\
\hline $\begin{array}{l}\text { I noticed an overall improvement in the communicative competence } \\
\quad \text { of my foreign language learner comparing session 1 to the last }\end{array}$ & 4.57 & 0.65 \\
$\quad$ session. & 4.14 & 0.95 \\
They talked more in the last session & 4.36 & 0.84 \\
They were able to talk more fluently in the last session & 4.07 & 1.07 \\
They took more initiative during the last session & 3.64 & 1.01 \\
They asked more questions during the last session & 4.50 & 0.94 \\
They became more confident talking in the target language & 4.64 & 0.50 \\
They became more aware of cultural contrasts and similarities & 4.43 & 0.65 \\
They enlarged their lexicon and used more adequate words & & 0.55 \\
They have learned to talk more accurately in terms of grammatical & 4.00 & 1.19 \\
$\quad$ constructions. & 4.21 & \\
They were more motivated to talk in the last session &
\end{tabular}

\subsection{Discussion}

Experimental second language acquisition research typically investigates the effectiveness of instruction in terms of overall group gains. That is, the average effectiveness of particular learning conditions is compared. The results of this study suggest that on average participants in VC and SL groups show more improvement of their oral proficiency than students who did not participate in this type of interactions. However, the improvement appears to be dependent on the initial proficiency of language learners. Students with lower oral language skills seem to profit more from VC and SL conditions than the more proficient learners.

For the VC and SL groups task completion took between 60 and 90 minutes but there was no real time limit to the task; we observed that the majority of interactions took 90 minutes or longer. The control group carried out the task during classroom time and spent 30 minutes to perform it. The fact that the control group's interaction sessions were shorter might have influenced the results. On the other hand, the added value of integrating networked interactions is that it intensifies authentic learning, creating more opportunities for spontaneous exchanges, which in turn will increase learning possibilities.

According to Robinson (2005) the effects that learning contexts, pedagogic interventions and cognitive processes have in interaction come together with the patterns of abilities learners bring to those contexts, that is, some learners may be suited to learn under one condition or from one technique versus others. Individual differences, such as motivation, language aptitude, learning styles and learning strategies may also interact with L2 tasks characteristics to systematically affect speech production and learning, such that one type of learner may be systematically more fluent, accurate on one type of task versus another (Robinson, 2005). Other 
research (Dörney, 2009) also indicates that the interaction between the language learner and the environment matters.

The significant correlations between gain scores for the experimental VC and SL groups, where students with lower pre-test scores did better at the post-test, suggest that they were the ones who benefited more from the instruction method where virtual interactions were included. Previous studies within the NIFLAR project (Jauregi, De Graaff, Kriz, \& Bergh, 2011) analysed whether implementing networked interaction sessions with native speakers had an impact on the motivation of foreign language learners. The results yielded were positive, indicating that that was the case for learners with a lower proficiency level. The results from this current study seem to be in line with those found by Jauregi et al. 2011.

Positive outcomes such as this study showing the benefits of integrating online exchanges into the foreign language classroom should encourage other language practitioners to integrate this type of collaboration into their foreign language learning programmes. Not only did it show a positive effect on learners' oral proficiency, these telecollaborations also underlined the important role of culture in learning a foreign language and helped understand what intercultural skills and attitudes are required by speakers of foreign languages (Thorne, 2006). Another contribution, as noted also by O'Dowd (2011), is the way in which it increases the level of authenticity in classroom practices and content: learners are able to engage in authentic interaction with speakers of the target culture while still benefiting from the guidance and support of their tutors and classmates.

Studies carried out by Warschauer \& Ware (2008) and O’Dowd (2011), where foreign language instructors were interviewed, suggest that telecollaboration is unfortunately seen as an 'add-on' activity and is not considered an integrated part of study programmes. In our research we have found indicators showing that these online exchanges make a positive contribution to foreign language learning processes, and we suggest that they should need to be an integral part of language programmes. We, as our study shows, are convinced of the benefits of telecollaboration and think that its potential can be exploited by all teachers and not only be the reserve of a few instructors, like it seems to be the case according to O'Dowd's findings (2011).

\subsection{Conclusions}

The added value of networked interactions points towards cultural, linguistic, interpersonal and motivational benefits. Within NIFLAR telecollaboration, in spite of the organizational burdens, was experienced as challenging, motivating and innovative. The synchronous learning environments used in conjunction with effective interaction tasks and the opportunities to engage in meaningful interaction with expert peers (native student teachers) contributed to empower intercultural learning experiences.

There are several factors that need to be taken into consideration when interpreting the results of this study. There is a need for additional research that investigates the relationship between the effectiveness of integrating these virtual interactions and individual differences. The effects measured in this study were at 
short term, further research would need to look into what would happen in the long term. Another aspect that needs further research is to find out how the scores of the high scoring pre-test participants would be affected were they to have more telecollaboration sessions, as learning in the first stages of language acquisition evolves quickly but not at advanced levels. In addition, future research should analyse and compare the effect that interacting with native speakers has on learners' communicative competence according to the affordances of the specific environment being used: video communication or Second Life.

We consider the positive results that answer our research questions very encouraging: they show that there is a significant difference in oral communicative growth between experimental groups (engaged in networked interactions with expert peers though video communication and virtual worlds) and a control group (carrying out the tasks face to face with classmates in the classroom setting) with those participating in networked interactions outperforming those who did not (RQ1); and this type of telecollaboration has a positive impact on language learners' learning experiences, since they have the impression that they learn from them (RQ2.1) and it is so perceived by pre-service teachers (RQ2.2).

\subsection{References}

Belz, J. A. (2003). Linguistic perspectives on the development of intercultural competence in telecollaboration. Language Learning and Technology, 7(2), 68-117.

Belz, J.A., \& Thorne, S.L. (Eds.) (2006). Internet-mediated intercultural foreign language education. Boston: Heinle \& Heinle.

Bryant, T. (2006) Using World of Warcraft and other MMORPGs to foster a targeted, social, and cooperative approach toward language learning. Academic Commons.

Bueno Alastuey, M.C. (2011). Perceived benefits and drawbacks of synchronous voice-based computer mediated communication in the foreign language classroom. CALL Journal, 24(5), 419-432.

Ciekanski, M., \& Chanier, T. (2008). Developing online multimodal verbal communication to enhance the writing process in an audio-graphic conferencing environment. ReCALL, 20(2), 162-182.

Cooke-Plagwitz, J. (2008). New directions in CALL: An objective introduction to Second Life. CALICO Journal, 25(3), 547-557.

Cronbach, L.J. (1957). The two disciplines of scientific psychology. American Psychologist, 12, 671-684.

Deutschmann, M., Panichi, L., \& Molka-Danielsen, J. (2009). Designing oral participation in Second Life - A comparative study of two language proficiency courses. ReCALL, 21(2), 206-226.

Develotte, C., Guichon, N., \& Vincent, C. (2010). The use of the webcam for teaching a foreign language in a desktop videoconferencing environment, $\operatorname{ReCALL} 23(3), 293-312$.

Dieterle, E., \& Clarke, J. (2008). Multi-user virtual environments for teaching and learning. In M. Pagani (Ed.), Encyclopedia of multimedia technology and networking (pp. 1033-1040). Hershey, PA: Idea Group, Inc. 
Dornyei, Z. (2009). Individual differences: Interplay of learner characteristics and learning environment. Language Learning 59(1), 230-248.

Felix, U., \& Lawson, M. (1996). Developing German writing skills by way of Timbuktu: A pilot study comparing computer-based and conventional teaching. ReCALL, 8(1), 12-19.

Guichon, N. (2010). Preparatory study for the design of a desktop videoconferencing platform for synchronous language teaching. Computer Assisted Language Learning, 23(2), 169-182.

Guth, S., \& Helm, F. (Eds.) (2010). Telecollaboration 2.0. Bern: Peter Lang AG.

Guth, S., \& Maio, M. (2010). Close encounters of a new kind: The use of Skype and Wiki in telecollaboration. In Guth, S., \& Helm, F. (Eds.), Telecollaboration 2.0 (pp. 413-427). Bern: Peter Lang AG.

Hampel, R., \& Hauck, M. (2004). Towards an effective use of audio conferencing in distance language courses. Language Learning and Technology, 8(1), 6682.

Hampel, R., Felix, U., Hauck, M., \& Coleman, J.A. (2005). Complexities of learning and teaching languages in a real-time audiographic environment. In T. R. Dvorak and J. F. Lee (Eds.), German as a Foreign Language Journal (pp.146-157). New York: Newbury House.

Jauregi, K., \& Bañados, E. (2008). Virtual interaction through video-web communication: A step towards enriching and internationalizing learning programs. ReCALL, 20(2),183-207.

Jauregi, K. \& Bañados, E. (2010). An intercontinental video-web communication project between Chile and The Netherlands. In S. Guth \& F. Helm (Eds.), Telecollaboration 2.0 (pp. 427-436). Bern: Peter Lang AG.

Jauregi, K., Canto, S., Graaff, de R., Koenraad, A., \& Moonen, M. (2011). Verbal interaction in Second Life: towards a pedagogic framework for task design. Computer Assisted Language Learning Journal, 24(1), 77-101.

Jauregi, K., De Graaff, R., van den Bergh, H., \& Kriz, M. (2012). Native/non-native speaker interactions through video-web communication; a clue for enhancing motivation? CALL Journal, 25(1), 1-19.

Kelm, O. R. (1992). The use of synchronous computer networks in second language instruction: A preliminary report. Foreign Language Annals, 25, 441-545.

Kern, R. (1996). Computer-mediated communication: Using e-mail exchanges to explore personal histories in two cultures. In Warschauer, M. (Ed.), Telecollaboration in Foreign Language Learning (pp. 105-119). Hawai'i: Second Language Teaching and Curriculum Centre.

Kuriscak, L.M, \& Luke C. L. (2009). Language learner attitudes toward virtual worlds: An investigation of Second Life. In G. Lord \& L. Lomicka (Eds.), The next generation: Online collaboration and social networking in CALL (pp. 173-207). San Marcos, TX: CALICO.

Lamy, M.N. (2004). Oral conversations on line: redefining oral competence in synchronous environments. ReCALL, 16(2), 520-538.

Liauw, M. (2006). E-learning and the development of intercultural competence. Language Learning \& Technology, 10(3), 49-64.

Molka-Danielsen, J., \& Deutschmann, M. (Eds.). (2009). Learning and teaching in the virtual world of Second Life. Trondheim, Norway: Tapir Academic Press. 
Müller-Hartmann, A. (2000). The role of tasks in promoting intercultural learning in electronic learning networks. Language Learning and Technology, 4, 129147.

O’Dowd, R. (2000). Intercultural learning via videoconferencing: a pilot exchange project. ReCALL, 12, 49-63.

O'Dowd, R. (2003). Understanding the "other side": Intercultural learning in a Spanish-English e-mail exchange. Language Learning \& Technology, 7(2), $118-144$

O'Dowd, R. (2006). The use of videoconferencing and e-mail as mediators of intercultural student ethnography. In J.A Belz \& S.L.Thorne (Eds.), Internet-mediated intercultural foreign language education (pp. 86-120). Boston: Heinle \& Heinle.

O'Dowd, R. (2007). Evaluating the outcomes of online intercultural exchange. ELTJournal, 61(2), 144-152.

O'Dowd, R. (2011). Online foreign language interaction: Moving from the periphery to the core of foreign language education?" Language Teaching Journal, 44(3), 368-380.

O’Dowd, R., \& Ritter, M. (2006). Understanding and working with 'failed communication' in telecollaborative exchanges. CALICO Journal, 23(3), 120.

Ortega, L. (2009). Interaction and attention to form in L2 text-based computer mediated communication. In A. Mackey and C. Polio (Eds.), Multiple perspectives on interaction (pp. 226-253). New York: Routledge.

Pellettieri, J. (2000). Negotiation in cyberspace: The role of chatting in the development of grammatical competence. In M. Warschauer and R. Kern (Eds.), Network-based language teaching: concepts and practice (pp. 5986). Cambridge: Cambridge University Press.

Peterson, M. (2010). Learner participation patterns and strategy use in Second Life: an exploratory case study. ReCALL, 22(3), 273-292.

Peterson, M. (2011). Towards a research agenda for the use of 3D virtual worlds in language learning. Calico, 29(1), 67-80.

Robinson, P. (2005). Aptitude and second language acquisition. Annual Review of Applied Linguistics, 25, 45-73.

Sauro, S. (2011). SCMC for SLA: a research synthesis. Calico, 28(2), 1-23.

Smith, B. (2004). Computer-mediated negotiated interaction and lexical acquisition. Studies in Second Language Acquisition, 26, 365-398.

Sotillo, S.M. (2000). Discourse functions and syntactic complexity in synchronous and asynchronous communication. Language Learning and Technology, $4(1), 82-119$

Steinkuehler, C. (2006). Massively multiplayer online videogaming as participation in a discourse. Mind, Culture \& Activity, 13(1), 38-52.

Thorne, S. L. (2006). Pedagogical and praxiological lessons from internet-mediated intercultural foreign language education research. In J. A. Belz \& S. L. Thorne (Eds.), Internet-mediated intercultural foreign language education (pp. 2-30). Boston, MA: Heinle \& Heinle.

Thorne, S. (2008). Transcultural communication in open Internet environments and massively multiplayer online games. In S. Magnan (Ed.), Mediating Discourse Online (pp. 305-327). Amsterdam: John Benjamins. 
Toyoda, E., \& Harrison, R. (2002). Categorization of text chat communication between learners and native speakers of Japanese. Language Learning and Technology, 6, 82-99.

Tudini, V. (2003). Using native speakers in chat. Language Learning and Technology, 7 (3), 141-159.

Tudini, V. (2007). Negotiation and intercultural learning in Italian native speaker chat rooms. Modern Language Journal, 91(4), 577-601.

Wang, Y. (2004). Supporting synchronous distance language learning with desktop videoconferencing. Language Learning \& Technology, 8(3), 90-121.

Wang, Y. (2006). Negotiation of meaning in desktop videoconferencing-supported distance language learning. ReCALL, 18(1): 122-145.

Wang, Y. (2007). Task design in videoconferencing-supported distance language learning. CALICO Journal, 24(3): 562-590.

Ware, P. D., \& Kramsch, C. (2005). Toward an intercultural stance: Teaching German and English through telecollaboration. Modern Language Journal, 89, 190-205.

Ware, P., \& O'Dowd, R. (2008). Peer feedback on language form in telecollaboration. Language Learning and Technology, 12(1), 43-63.

Warschauer, M. (1996). Comparing face-to-face and electronic communication in the second language classroom. CALICO, 13(2), 7-26.

Warschauer, M., \& M. Ware (2008). Learning, change, and power: Competing discourses of technology and literacy. In J. Coiro, M. Knobel, C. Lankshear \& D. J. Leu (Eds.), Handbook of research on new literacies (pp. 215-240). New York: Lawrence Erlbaum 
4.10 Appendix. Assessment grid for pre and post-tests

\begin{tabular}{|c|c|c|c|c|c|}
\hline$\overline{0}$ & $\checkmark$ & un & $\omega$ & - & \\
\hline 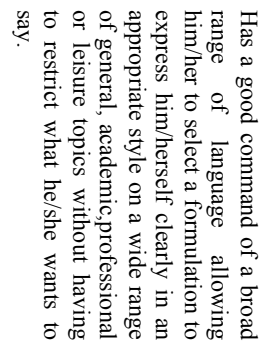 & 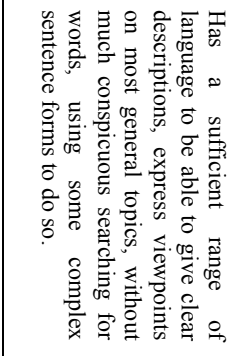 & 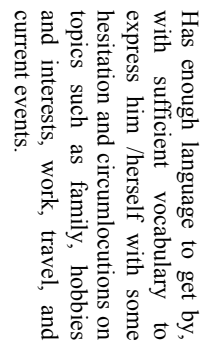 & 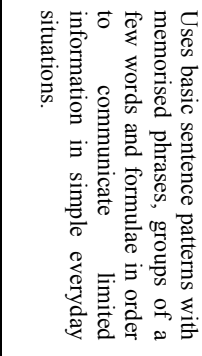 & 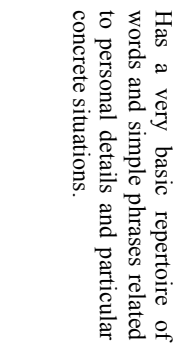 & 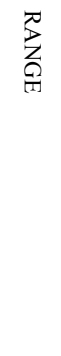 \\
\hline 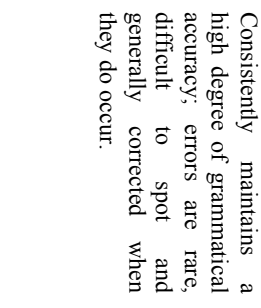 & 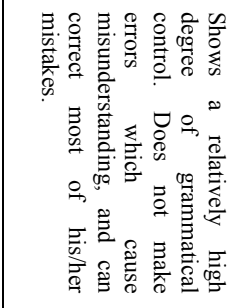 & 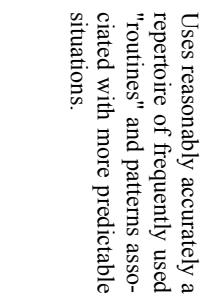 & 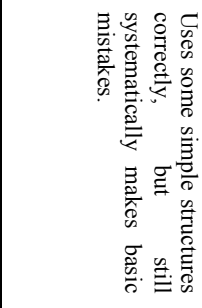 & 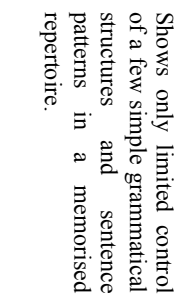 & 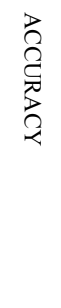 \\
\hline 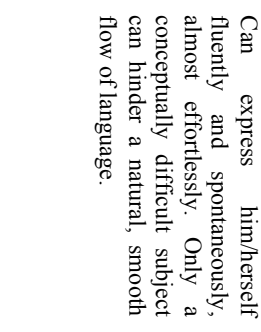 & 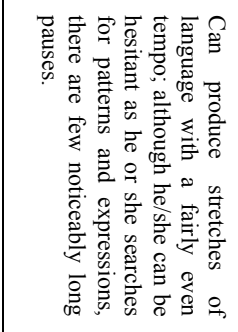 & 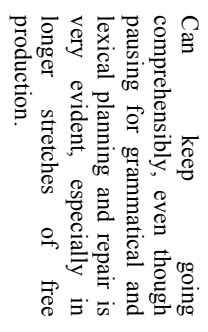 & 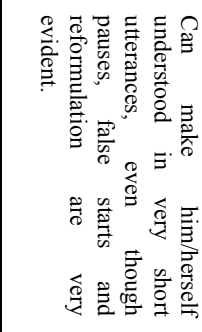 & 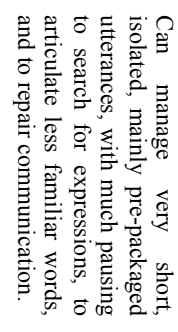 & $\begin{array}{l}\text { 壱 } \\
\text { 罗 } \\
\stackrel{2}{2}\end{array}$ \\
\hline 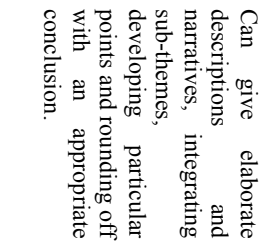 & 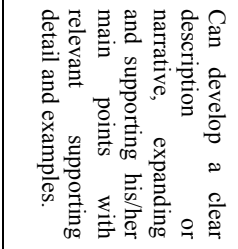 & 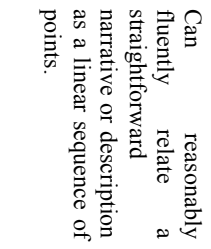 & 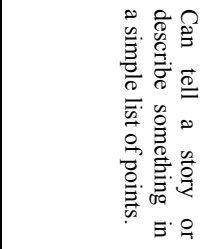 & & 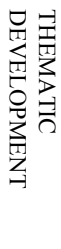 \\
\hline 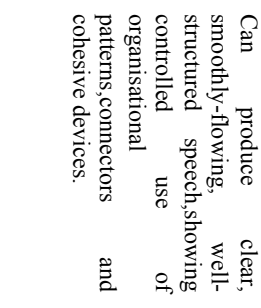 & 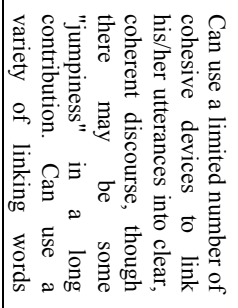 & 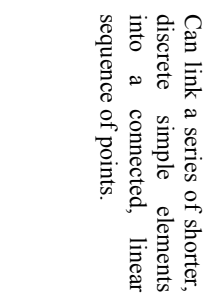 & 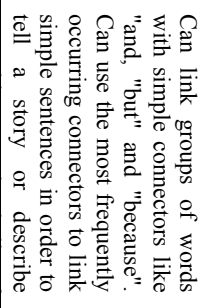 & 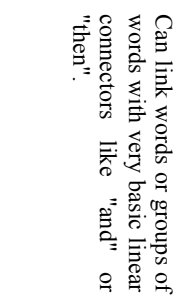 & 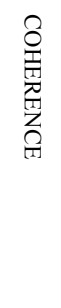 \\
\hline
\end{tabular}





\section{Chapter 5}

\section{Language learning effects through the integration of synchronous online communication: The case of video communication and Second Life.}

\subsection{Abstract}

This article attempts to shed some light on the possible learning benefits for language acquisition and intercultural development of authentic social interaction with expert peers through computer mediated communication (CMC) tools. The environments used in this study are video communication and the $3 \mathrm{D}$ virtual world Second Life.

For this study 41 students of Spanish were randomly allocated to three conditions: (1) control group, (2) experimental interaction group with video communication and (3) experimental interaction group with Second Life. All students were following the same language course at B1 level and carried out 5 communication tasks.

Different data sources were gathered to measure the impact that integration of CMC has on the development of the intercultural and communicative competence of L2 learners: (1) pre- and post- oral tests to measure the communicative growth of L2 learners; (2) surveys to gather participants' experiences; and (3) recordings of communication sessions for qualitative in-depth analysis of interaction. Significant differences in the development of communicative competence were found, with experimental groups scoring significantly higher than the control group.

\section{$5.2 \quad$ Introduction}

Synchronous computer mediated communication (SCMC) tools are being used by educators as a way to innovate and enrich education in general and stimulate intercultural communication competences and skills of L2 learners in particular. In the last decades researchers have tried to show the relevance of computer mediated communication $(\mathrm{CMC})$ in promoting second language acquisition and intercultural awareness. However, results are controversial: they refer to small studies which normally run for very short periods of time, the majority involve text chat based, they tend to be only descriptive and exploratory, and they often lack a control group.

1 This chapter has been published as: Canto, S., \& Jauregi, K. (2017). Language learning effects through the integration of synchronous online communication: the case of video communication and Second Life. Language Learning in Higher Education, $7(1), 21-53$ 
This article presents the results of a research study that attempts to investigate the learning benefits that authentic social interaction with expert peers through $\mathrm{CMC}$ has in language acquisition and intercultural development.

Previous studies show that written (mostly asynchronous) CMC, in addition to breaking down the barriers and inhibitions for target language (TL) use, helps the L2 learner to become more confident about his/her language, and to produce not only more talk (Kern, 1996), but more coherent (Felix \& Lawson, 1996) and lexically and syntactically more complex discourse (Warschauer, 1996). Text chat $\operatorname{logs}$ have been analysed as being effective to enhance language learning at grammatical (Pellettieri, 2000), lexical (Smith, 2004), syntactic (Sotillo, 2000), discourse (Warschauer, 1996) and intercultural levels (Belz \& Thorne, 2006; Toyoda \& Harrison, 2002; Tudini, 2007). However, Ortega (2009) reported that a closer look at text-based SCMC research reveals mixed findings and insufficient evidence.

In addition to text-chat sessions exploratory studies have been conducted in SCMC using different audio(visual) synchronous tools, such us audiographic conferencing (Ciekanski \& Chanier, 2008; Hampel, Felix, Hauck, \& Coleman, 2005), VOiP systems like Skype and voice chats (Develotte, Guichon, \& Vincent, 2010; Guth \& Maio, 2010; Wang, 2006, 2007; Bueno Alustey, 2011) or video communication (Guichon, 2010; Jauregi, 2015; Jauregi \& Bañados, 2008, 2010; Jauregi \& Melchor-Couto, 2014; O'Dowd, 2006). Most of these studies are exploratory and describe experiences as being motivating and contributing to communicative or intercultural development, but do not offer substantial evidence for it (Belz \& Thorne, 2006; Guth \& Helm, 2010; Müller-Hartmann, 2000; O’Dowd 2011; O’Dowd \& Ritter, 2006; Ware \& Kramsch, 2005).

Teaching experiences in 3D virtual worlds such as Second Life have been described (Molka-Danielsen \& Deutschmann, 2009; Deutschmann, Panichi, \& Molka-Danielsen, 2009), showing that foreign language learners can engage in interaction (Deutschmann et al. 2009; Peterson, 2010), meet native speakers of the target language (Kuriscak \& Luke, 2009) and engage in meaningful communicative and social spontaneous interaction (Jauregi, Canto, De Graaff, Koenraad, \& Machteld, 2011) while undertaking joint action.

Virtual worlds have been assessed as beneficial for learning (Bryant, 2006; Thorne, 2008) and as a space where users can experiment and interact with a variety of norms of social interaction (Steinkuehler, 2006). The realistic nature of the environment provides authentic learning conditions that are otherwise difficult to recreate in traditional classroom settings (Dieterle \& Clarke, 2008) and elicits in conjunction with adequate tasks collaborative interaction, such as peer-scaffolding focusing on repair and lexis, hypothesized to be beneficial to language development (Peterson, 2012). However, research on virtual worlds remains largely exploratory in nature and is subject to significant limitations (Peterson, 2011; González-Lloret \& Ortega, 2014).

Meta-analyses and syntheses, like those of Zhao (2003), Sauro (2011), Lin (2014) and Ziegler (2015) suggest that SCMC has a positive effect on language learning and provides optimal opportunities for language acquisition. The results of Lin's (2015) analysis supports the Interaction Hypothesis (Long, 1996) that online 
interactions/communications mediated by technology can generate similar o even superior opportunities for foreign language learning than are found in face to face settings.

This article presents the results of a research study that attempts to investigate the learning benefits that integrating opportunities for engaging in authentic social interaction with expert peers through $\mathrm{CMC}$ has in language acquisition and intercultural development.

The literature in SLA indicates that when language learners are exposed to communication contexts where beneficial types of collaborative interaction are encouraged (via tasks based on learner needs), their language learning may be facilitated (Pica, Kanagy, \& Falodun, 1993). When working together to solve communication tasks, the participants of an interaction may experience problems in understanding or breakdowns in communication and to remedy them they often engage in negotiation of meaning, interactional modifications that aim at ensuring shared understanding. According to a growing body of research (Lee, 2001; Fernández García \& Martínez Arbelaiz, 2002; Kötter, 2003; Smith, 2003, 2005, Wang, 2006; Clavel - Arroitia \& Pennock - Speck, 2015), the type of interaction that has been identified as "negotiation of meaning" is the one that provides optimal conditions for language acquisition since it offers opportunities to generate both comprehensible input and modified output.

This study follows socio-constructivist theories of learning (Vygotsky, 1978) and interactionist theories within SLA (Mackey \& Polio, 2009) that put social interaction at the heart of the learning process. Interactionists such as Pica (1994), Long (1985), Gass (1997) and others assert that conversational interaction facilitates second language acquisition under certain conditions: interaction, constructed via exchanges of comprehensible input and output, has an enhancing effect when meaning is negotiated and support structures are used.

We also take the development of intercultural communicative competence as a key goal of foreign language education and following Byram (1997) one of our objectives is to turn foreign language learners into intercultural speakers, by developing intercultural understanding through different social and cognitive activities involving analysis, reflection, and interaction.

As the previously cited research has identified interaction as a key issue in learning and acquisition processes we need to explore how networked tools favour or impede these processes.

\subsection{Research questions}

The present research aims to tackle the point addressed by Peterson (2011), who signals that research on virtual worlds remains largely exploratory in nature and is subject to significant limitations, and to study the impact that intercultural encounters with expert peers through video communication or virtual worlds compared to a control group have on the intercultural communicative competence of language learners. Concretely, the present research study addresses the following questions: 
RQ1: Do opportunities to engage in social interaction with expert peers (native speakers) through SCMC tools contribute more to enhance oral communicative competence as compared to the control group?

RQ2: What learning opportunities emerge in interactions conducted by native and non-native speakers through video communication and/or virtual worlds as compared to the control group?

RQ3: What are participants' learning experiences?

RQ1 was partly answered in Canto, S., Jauregi, K., \& van den Bergh, H. (2013). Integrating cross-cultural interaction through video communication and virtual worlds in foreign language teaching programmes. Burden or added value? ReCALL, 25(1), 105-121.

\section{$5.4 \quad$ Methodology}

\subsubsection{Participants}

Forty-one language students of Spanish from Utrecht University (The Netherlands) and fourteen native Spanish speakers from the university of Valencia (Spain) participated in the present study. The language learners were first year Spanish students from Utrecht University, while the students from Valencia were following a pre-service teacher education programme. The language proficiency level of the Spanish course was B1 of the Common European Framework of Reference for Languages (CEFR, 2001).

\subsubsection{Procedures}

In the present research study two environments were chosen to experiment with and compare with a control group: video communication and $3 \mathrm{D}$ virtual worlds. The research team had worked with them in previous pilots and wanted to further investigate their effect on language learning, encouraged by Zhao's (2003) narrative review that concluded that technology was not only useful for foreign language development, but also specifically for the enhancement of input, the provision of feedback, and for supporting authentic communication. In the first one, video communication, participants can engage in multimodal communication, talking, chatting, sharing pictures, documents and sound files, taking part in collaborative writing processes while seeing each other through the webcam (Jauregi \& Bañados 2008, 2010; Jauregi et al., 2012), while in the second one, the 3D virtual world of Second Life, participants represented by a virtual avatar can engage in action learning while communicating through voice and/or text chat with each other without seeing the real person behind the avatar (Jauregi et al., 2011). Both tools, although technically different, facilitate the interaction with expert peers that otherwise might be difficult to organize in educational institutions and according to Lin's (2014) meta-analysis provide learners with similar learning opportunities regardless of the mode of communication (video communication or $3 \mathrm{D}$ virtual worlds). Furthermore, Plonsky and Ziegler's (2016) meta-analyses research points towards a significant difference in learning outcomes when learners participate in 
CALL vs. traditional educational contexts: foreign language learning in contexts that use some form of technology provides a considerable advantage over traditional, non-technology based contexts in facilitating learning outcomes.

In this study, language students $(n=41)$ were randomly assigned to one of three research conditions: Video Communication (VC; $n=13$ ), Second Life (SL; $n=14)$ or Control $(\mathrm{C} ; n=14)$, and pre-service teachers $(n=14)$ were assigned to one of the two conditions according to their personal preferences, video communication or Second Life. During the period of observation the participants carried out five tasks, one per week. Before the task sessions, language learners and pre-service teachers participated in VC and SL tutorials to become familiarised with the tools.

The course for both VC and SL groups was blended learning. Each group met twice a week face to face with their teacher (a native speaker, the same one for all three groups) for two hour lessons, while a third meeting was a computer mediated one with the pre-service, native speaker teacher. Participants in these experimental groups communicated in triads (two language students, one native speaker) to carry out five tasks.

In the case of the control group, where no native speakers were involved, the difference was the way tasks were performed: they worked in groups of four language learners in the language classroom.

\subsubsection{Tasks}

The tasks (see Table 1) were designed following the task-based language learning approach used in the course. They were created based on studies which indicate that for learning tasks to be (a) successful, that is, to reach a prescribed goal, they need to be authentic, meet learner needs and provide opportunities for active use of the target language (Chapelle, 2001); and to be (b) effective they need to make use of the specific affordances provided by these environments (Hampel, 2006; Jauregi et al., 2011). The specific affordances of both tools could be summarized as follows: Second Life not only provides opportunities for social interaction, but also for immersion in a 3D environment, creating a sense of co-presence and making contextualization easy. It allows to simulate an environment that otherwise would be difficult to reproduce in real life and to engage in action through the movements of the avatars. The representation of the participants as graphic avatars can lead to individual and collective identity play. The environments in this type of worlds are persistent, they do not disappear, and mediated, where information can be included or excluded as needed, and extensive modes of communication can be used (audio, video, text, etc.). As well as these technical affordances, where perhaps the most unusual would be the opportunity to cross physical, geographical and temporal boundaries, Warburton and Pérez-García (2009) pointed out other educational affordances for these 3D virtual worlds such as learner experimentation, dynamic feedback, exploration and creativity. They remarked that these worlds help to facilitate collaboration, dissolve social boundaries, enhance student motivation and reduce anxiety. Video communication on the other hand, permits audio, video and text conferencing. The tool used in this study (Adobe Acrobat Connect Pro) also had an interactive whiteboard and allowed guided web browsing and desktop sharing. 
Users were also able to record their sessions. Video communication also offers file transfer and manipulation of documents, allowing the user to generate content (Nielson \& González-Ortega, 2010). Video communication tools permit naturalistic oral conversations, complement and illustrate verbal modes, can act as stimuli for interaction, support socio-affective interaction and permit the use in communication (Lamy \& Hampel, 2007).

The tasks in this study were scheduled weekly after their two classes with their teacher and were the same for all three groups, only adapted in order to take advantage of the specific affordances of the VC or SL medium and of the classroom. For example, in task 1 students were meant to share a house and comment on the things they needed. The Second Life experimental group was able to walk around a house created for them, being able to see the characteristics of the objects and interact with them, whereas the video communication and experimental groups were provided with a Power Point presentation with photographs that depicted what was supposed to be their house. All tasks had a preparatory and performance phase with support materials in the form of documents to guide them through the tasks.

Table 5.1. Description of tasks developed.

\begin{tabular}{ll}
\hline Tasks & Description \\
\hline Session 1: Cool People & $\begin{array}{l}\text { Students: } \\
\text { visit an apartment they are meant to share } \\
\text { talk about themselves and exchange cultural information triggered by } \\
\text { pictures } \\
\text { choose an outing option (go to the cinema, to a museum or to walk in } \\
\text { the city). }\end{array}$ \\
& Participants plan a holiday and reflect on past holiday experiences. \\
& $\begin{array}{l}\text { Participants have to play different roles given the indications of a } \\
\text { People \& adventures }\end{array}$ \\
$\begin{array}{l}\text { Session 3: } \\
\text { Movie celebrity people }\end{array}$ & $\begin{array}{l}\text { Participants impersonate different characters and experience the } \\
\text { Session 4: }\end{array}$ \\
$\begin{array}{l}\text { People with heart } \\
\text { Session 5: }\end{array}$ & Students participate in a cultural television game style context \\
People \& cultures & between a Dutch and a Spanish team.
\end{tabular}

\subsubsection{Sessions 2 and 5: People and adventure and People and cultures}

The qualitative analysis of interactions across conditions comes particularly from the second and fifth tasks, People and adventure and People and cultures, which we further specify below.

Task 2, People and adventure, was divided in two parts: the preparation of a holiday together and the holiday itself. Participants had to discuss their preferences and reach an agreement on the destination. During the process they were encouraged to talk about their last holiday, any bad accommodation experiences they might have had previously, make a list of things they might need for their chosen destination, and talk about the activities they could undertake upon arrival. 
For the SL group, the interactions took place in an area within Second Life designated for the NIFLAR ${ }^{2}$ project but it also made use of readily available locations as well as venues specially designed for particular tasks.

At the beginning of the task, the SL group was teleported to a pizzeria holodeck $^{3}$ where they discussed their preferences and reached an agreement on their destination. Here they had the opportunity to talk about their previous holidays and make the preparations. They were then teleported to their hotel and in a role-play manner they had to sort out any problems they might encounter (leaking shower, unmade bed, dirty floors, etc.). Finally, they headed to their destination where they could go for example sailing, surfing, horse riding, skiing or ice skating. They were provided with a taskHUD ${ }^{4}$ with additional objects (ski outfits, receptionist uniform, bikini, etc.) that could be used during task performance.

The VC group was able to contextualise the task via images uploaded onto the video communication environment, Adobe Acrobat Connect Pro. The participants themselves uploaded their own in order to talk about past holidays and the researchers placed images that depicted possible bad accommodation experiences (dirty floors, broken windows, noisy hotel guests, etc.) and various types of sports that could be practiced during both types of holidays.

As for the control group, each member was asked to bring to the lesson photographs from a past holiday and the rest of the visual material (accommodation problems and activity possibilities) was provided by the teacher during task performance. The non-personal pictures used in the $\mathrm{VC}$ and control groups were the same ones and an attempt was made to make them as similar as possible to the scenarios in Second Life.

Task 5, People and Cultures, was organised as a cultural quiz in the style of a television game-show. Dutch and Spanish teams would compete in terms of cultural knowledge of the other country. Questions for which the teams could score points were displayed on a screen and the opponents had to judge the adequacy of the answers. The control group, where students were paired to compete against each other, used only the same images as the SL and VC group related to the target culture, and the instructor, in an expert role, acted as adjudicator.

\subsubsection{Instruments}

Three sources of data were collected for this study: (1) oral tests taken before and after the interaction sessions to measure communicative growth; (2) analysis of interaction sessions in the three research conditions, and (3) post-questionnaires. Additionally, informal debriefing interviews not reported in this study were also held.

2 NIFLAR: Networked Interaction in Foreign Language Acquisition and Research.(www.niflar.eu)

3 A holodeck stores Second Life scenarios and lets the user load them whenever wanted in a limited space. They are used to save

content (furniture settings or even entire environments) and are similar to holodecks used in sci-fi movies.

4 A taskHUD is a control panel with different buttons you can click on to do context-specific actions. 


\section{Oral tests}

The pre- and post-test were the same for the three research conditions and administered via a computer in a language lab. The questions had been video recorded by a native speaker and students had to record (voice only) their answers after each question. The test consisted of 11 open-ended questions that ranged from personal information and studies (3 items), previous experiences in Spanishspeaking countries (1 item), student life (3 items), weather and gastronomy (2 items), economy (1 item) and recommendations for foreigners visiting their country ( 1 item). Although the topics that came up in the oral tests were dealt with in one way or another during the tasks, the oral tests did not have the same structure as the task sessions.

Language learners were assessed on measures of communicative language competence based on descriptors that were inspired by the scales proposed by the Common European Framework of Reference for languages (CEFR). Five measures were assessed on a 10 point scale: (a) range of language, (b) grammatical accuracy, (c) fluency, (d) thematic development and (e) coherence (see Appendix). Two native speakers of Spanish separately rated the tests and since there was a high correlation between all five indicators $(.89 \leq r \leq .98)$, they were collapsed into one measure of oral skill. An estimate of inter-rater agreement between both raters was calculated and proved to be high $(\alpha=0.91)$.

Surveys

After the conclusion of the project a final survey was digitally distributed to all three groups of learners and native student teachers in order to evaluate participants' experiences. The survey for VC and SL groups had 29 items with open and closed questions concerning the virtual environment, tasks, speech partner, learning potential of the sessions, organization, and global project evaluation. For the control group, questions related to the usability of the networking tools and the interaction with native speakers were eliminated from the survey since these elements were not present during task performance. In all three surveys for the closed items a fivepoint Likert scale was used.

\section{Interaction analysis}

In order to analyse the interactions from all groups we used the following categories: (1) negotiation of formal meaning (Pica, 1994; Long 1985; Gass, 1997); (2) negotiation of cultural meaning; (3) interactional features; and (4) task engagement and involvement.

Three factors were taken into account regarding the selection of recordings for this study: (a) accessibility of the recordings, (b) representativeness and (c) previous use in earlier analysis. The recordings database was sometimes difficult to navigate, since participants themselves were in charge of the recording process and file names were not always clear. Easily identifiable files and quality of the recording were primary selection criteria. Once the file had been selected we looked for representativeness of B1 language level. The recordings in Second Life were made by one participating student per group with the help of the screencasting and video editing software Screen Flow and under the supervision of a university 
technician. For video communication, Adobe Acrobat Connect Pro had a recording feature and one student per group was in charge of the recording each session. In the control group, a camera on a tripod was set in the classroom to film the sessions.

Recordings were analysed according to four parameters: (1) negotiation of meaning, (2) cultural information gaps, (3) sociability features and (4) engagement in interaction.

(1) The negotiations examined here tend to follow Varonis and Gass's (1985) model of negotiation of meaning. This model presents a set of primes that occur in negotiation of meaning sequences: a trigger utterance $(\mathrm{T})$ that causes a comprehension problem and starts the negotiation sequence, an indicator (I) that signals the misunderstanding, a response $(\mathrm{R})$ to address the misunderstanding and an optional reaction to that response (RR). The nature of the triggers can vary, from lexical and morphosyntactic items to sociocultural issues; and the indicators of misunderstandings can manifest themselves in the form of echos (rising or falling intonation), explicit statements of non-understanding, silence, inappropriate responses, summaries and surprised reactions. The response from the interlocutor can take the form of repetitions, expansions, rephrasings, acknowledgements or reductions (Varonis \& Gass, 1985; Fernández-García \& Martínez-Arbelaiz, 2002). Once the negotiations were identified, they were sorted according to Toyoda and Harrison's (2002) trigger categories: word level (recognition of a new word, misuse/misunderstanding of a word, pronunciation); sentence level (grammatical errors); discourse level (sudden topic change, slow response). The negotiation strategies to bridge the communication breakdown were categorised according to those identified by Lee (2001): comprehension checks, clarification requests, confirmation checks, use of English to translate unknown meanings in Spanish, word invention, requests and use of approximation.

(2) The tasks designed for the study were seeded with cultural information gaps from the L1 and L2 cultures that were likely to result in negotiation of intercultural content. These tasks, designed with an intercultural focus, offered opportunities for interaction that would elicit information on everyday cultural customs and provide opportunities for contrasting and comparing beliefs and habits in order to elicit awareness and reflections on both cultures. In order to see if there was a difference in the negotiation of cultural meaning between the three groups we measured the negotiations not triggered at word level but by a cultural information gap that occurred in task 5, People and cultures.

(3) In order to establish other differences between tasks performed via networked interaction and those carried out in the classroom setting, we observed the interactional features that allowed learners to share their feelings and to demonstrate a sense of sociability (Chun, 1994; Darhower, 2002). These features included greetings and leave takings, assistance requests, use of humour and use of L1 or English.

(4) We considered task engagement to comprise learners' efforts, participation, involvement and positive conduct during the execution of the learning activities. We broadly observed Littlewood's (2004) definition of engagement as the learners' active personal involvement with the task and viewed engagement as student motivated behaviour. Task engagement, however, was not operationalised as 
number of turns or number of words learners produced while engaged in the tasks. Observation notes were used to spot learners' attitudes towards the language learning situations and tasks.

\subsection{Results}

\subsubsection{Quantitative data: pre- and post-tests}

Comparing scores in pre and post-tests across research conditions allows us to establish in which of the three groups the greatest amount of learning occurred. The results of the analysis of the oral tests (see Figure 5.1) indicate that there was communicative proficiency growth in both experimental (VC and SL) and control groups $(F(1,34)=147.7 ; p<0.001)$ but that in the control condition the increase in students' oral skills is significantly less than in either the VC or SL condition $(F(2$, 34) $=5.01 ; p=0.12$ ) (see Canto, Jauregi, \& van den Bergh, 2013).

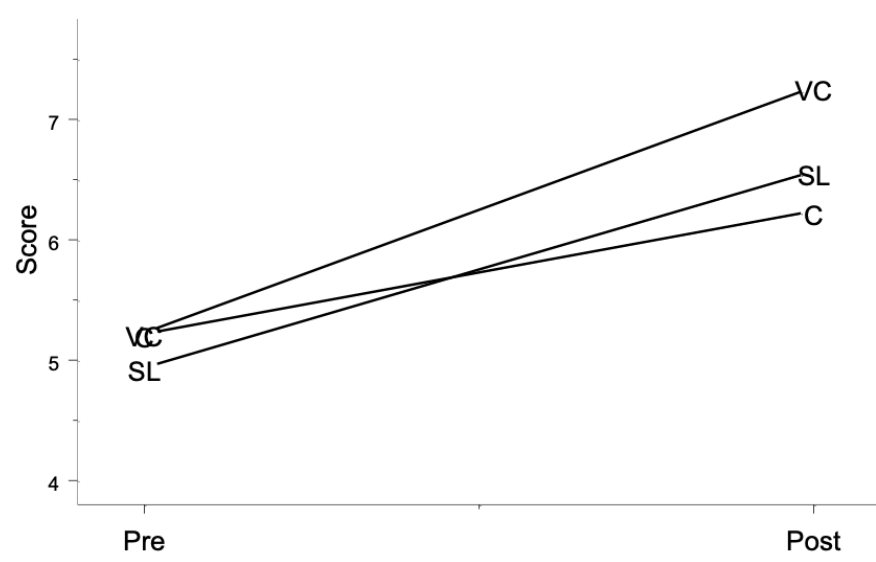

Figure 5.1. Oral language proficiency: Mean scores for pre- and post-oral tests of experimental and control groups. (VC: video communication; SL: Second Life; C: control).

\subsubsection{Qualitative data: Interaction analysis}

In order to assess the possible interaction characteristics performed by groups in all three conditions we analyse two tasks paying particular attention to the following categories: (1) negotiation of formal meaning; (2) negotiation of cultural meaning; (3) interactional features; and (4) task engagement and involvement.

\section{Negotiation of meaning}

As Table 5.2 below shows, in the analysis of the three recordings observed (task 2 VC group; SL group, control group), we found instances of negotiation in all groups, although there was a substantial difference between the number of negotiations encountered when the task was performed by the experimental groups 
(VC and SL) and those found in the same task by the control group: SL and VC groups accounted for 27 and 23 negotiations respectively and the control group for 2.

Table 5.2. Number of negotiations per group in task 2 .

\begin{tabular}{lccc}
\hline Group & Task duration & Negotiations & $\begin{array}{c}\text { Negotiations per 10 } \\
\text { minutes }\end{array}$ \\
\hline Second Life (SL) & $01: 15: 01$ & 27 & 3,6 \\
Video communication (VC) & $01: 20: 04$ & 23 & 2,9 \\
Control (C) & $00: 41: 00$ & 2 & 0,5 \\
\hline
\end{tabular}

Analysis of the recordings reveals that lexical difficulties appear to be the principal triggers as described in previous literature (Blake, 2000; Smith, 2003) as most of the negotiations between the participants are triggered by lexical confusions. Table 3 below summarises negotiation instances and since all triggers found in task 2 were at word level, they were first categorized following Toyoda and Harrison's (2002) classification of this type of trigger: recognition of a new word, misuse/misunderstanding of a word and pronunciation. The indicators of these negotiations are then sorted according to the strategies used by the participants (Lee, 2001): comprehension checks, clarification requests, confirmation checks, use of English, word invention, requests and use of approximation. Table 5.3 shows only the categories most used during the negotiation routines.

Table 5.3. Summary of negotiations with classification of triggers, indicators and responses.

\begin{tabular}{lccc}
\hline & SL & VC & C \\
\hline Negotiations & 27 & 23 & 2 \\
Trigger (word) & 27 & 23 & 2 \\
$\quad$ word recognition & 16 & 17 & 2 \\
misuse/misunderstanding & 10 & 2 & \\
pronunciation & 1 & 1 & 2 \\
Indicator & 7 & 8 & 2 \\
$\quad$ confirmation checks & 12 & 1 \\
clarification requests & 14 & 2 \\
comprehension checks & 6 & 3 & 2 \\
use of English & 5 & 13 & \\
invention of words & 1 & 2 & \\
Response & & 7 & \\
minimal & 11 & 9 & \\
modification & 9 & 4 & \\
elaborative & 7 & & \\
\hline
\end{tabular}

SL: Second Life group; VC: Video Communication group; C: Control group.

\section{Negotiation of cultural meaning}

Further observation of the recordings confirmed that negotiations occurred in all tasks but that they were not always triggered at a word level and instead the trigger depended on the type of task they were assigned. Task 5 (People and cultures) was a clear example of this. The task had been seeded with multiple information gaps involving culture specific situations from the L1 and L2 cultures that would call for intercultural negotiation and it is no surprise then that the majority of the triggers for 
negotiation routines were at a sociocultural level where the intercultural communication gap became apparent.

Table 5.4. Number of negotiations per group in task 5

\begin{tabular}{lccc}
\hline Group & Task duration & Negotiations & $\begin{array}{c}\text { Negotiations per 10 } \\
\text { minutes }\end{array}$ \\
\hline Second Life (SL) & $01: 46: 08$ & 26 & 2,5 \\
video communication (VC) & $01: 05: 33$ & 24 & 3,7 \\
control (C) & $00: 41: 00$ & 12 & 2,9 \\
\hline
\end{tabular}

The task generated in the experimental groups a high level of curiosity towards the other culture and participants engaged in rich exchanges as Example 5.1 (VC group) shows. This example had as trigger a photograph of a rucksack/backpack hanging from a Dutch flag, and the Spanish team had to guess its meaning. Having provided the wrong answer the Dutch team proceeds with the explanation: in The Netherlands it indicates that someone has graduated from secondary education. The native speaker signals her surprised reaction not only with an indicator of meaning recognition ( $; A h !)$ but also followed by a clarification request ( $; A h !$ ¿y entonces se quedan ahi las mochilas?/ Ah! and do the rucksacks/backpacks stay there?). The response of the language learner is an acknowledgement with an expansion (si/ fueral por dos semanas o asi - yes/outside/ for two weeks or so) by the student, followed by another indicator of confirmation of understanding by the native speaker which triggers another expansion response (porque es la idea que nunca tenemos que usar la mochila - because it is the idea that you don't have to use the rucksack/backpack anymore). The sequence is rounded off by the native speaker with a reaction to the response (;Ah! iqué originales! - Ah! how original!).

In Example 5.2 (SL group) the Dutch team had to explain what "un botellón" is, depicted in a photograph. Once the question had been answered both teams proceed to contrast information on this social activity popular among some young people. The example below also shows how the language learner shares understanding (contributing to the native speaker's explanation of the fact that they bring alcohol with a remark about bottles of wine and beer) and participates actively in meaning creation. 


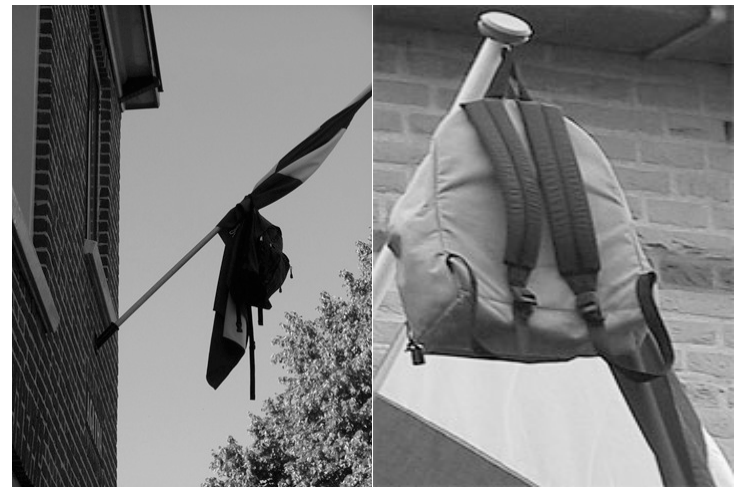

Picture 3.1. Photographs of a schoolbag hanging from a Dutch flag outside someone's house. Source: http://alt164-alt164.blogspot.com/2008_06_01_archive.html

Example 5.1. VC group task 5

NNS1: cuando has terminado el instituto/ ¿sí?
hay una fiesta y ponemos nuestras mochilas
fuera/ con la bandera de Holanda y / y es
como una fiesta que todo el mundo sabe que
has hmm terminado el instituto bien
NS: ¡Ah! ¿y entonces se quedan ahí las mochilas?
NNS1 : sí/ fuera/ por dos semanas o así (risas)

NS: ¡Ah!

NNS1: porque es la idea que nunca tenemos que usar la mochila (risas)
NNS1: when you have finished your secondary education / yes? there is a party and we put our rucksacks outside/ with the Dutch flag and / and it is like a party that everybody knows that you have hmm finished your secondary education well

NS: Ah! and then the rucksacks/backpacks stay there?

NNS1: yes/ outside/ for two weeks or so (laughter)

NS: Ah!

NNS1: because the idea is that we don't have to use the rucksack anymore (laughter)

NS: Ah! how original!

NS: ¡Ah! ¡qué originales!

NS: Native Speaker; NNS: Non-Native Speaker.

Example 5.2. SL group task 5

\begin{tabular}{|c|c|}
\hline $\begin{array}{l}\text { NS: Consiste en reunirse en un lugar, no importa } \\
\text { dónde }\end{array}$ & $\begin{array}{l}\text { NS: You basically meet up, it doesn't matter } \\
\text { where }\end{array}$ \\
\hline NNS1: [sí] & NNS1: [yes] \\
\hline NNS2: [hmm] & NNS2: [hmm] \\
\hline $\begin{array}{l}\text { NS: en la playa, en cualquier zona, en un parque, en } \\
\text { una plaza }\end{array}$ & $\begin{array}{l}\text { NS: on the beach, in any area, in a park, in a } \\
\text { public square }\end{array}$ \\
\hline NNS2: pero fuera & NNS2: but outside \\
\hline NNS1: yyy, [¿quién] organiza la fiesta? & NNS1: aand, [who] organises the party? \\
\hline $\begin{array}{l}\text { NS: } \quad \text { exacto] hmm, hmm. Vale, pues } \\
\text { normalmente se organiza entre pequeños grupos } \\
\text { de amigos que se concentran en un mismo lugar } \\
\text { con lo cual al final hay mucha gente }\end{array}$ & $\begin{array}{l}\text { NS: } \quad \text { exactly] hmm, hmm. Ok, normally it's } \\
\text { organised between small groups of friends } \\
\text { and they meet up in the same place and } \\
\text { therefore they end up with lots of people }\end{array}$ \\
\hline NNS2: mmm, sí & NNS2: mmm, yes \\
\hline
\end{tabular}




\begin{tabular}{|c|c|}
\hline NNS1: ;ah! & NNS1: ah! \\
\hline NNS2: grupos [diferentes] pero juntos & NNS2: [different] groups but together \\
\hline $\begin{array}{l}\text { NS: }[\mathrm{ehh}] \text {, grupos diferentes, exactamente, } \\
\text { pero juntos... y consiste, eh, en tomar alcohol } \\
\text { en la calle }\end{array}$ & $\begin{array}{l}\text { NS: [ehh], different groups, exactly, but } \\
\text { together... and you basically, eh, just drink } \\
\text { alcohol in the street }\end{array}$ \\
\hline $\begin{array}{l}\text { NNS1: [y] todas las personas eh traer eh unas } \\
\text { botellas de vino o [algunas cervezas] }\end{array}$ & $\begin{array}{l}\text { NNS1: [and] everybody eh bring eh a few bottles } \\
\text { of wine or [some beers] }\end{array}$ \\
\hline [mmm] & NNS2: $\quad[\mathrm{mmm}]$ \\
\hline NS: exacto & [hmm], exactly, yes \\
\hline NNS1: [¿y no está prohibido?] & NNS1: [and, isn't that forbidden?] \\
\hline $\begin{array}{l}\text { NS: [todo el mundo trae alguna cosa], eh, sí, eso } \\
\text { es lo que iba a comentaros (risas) }\end{array}$ & $\begin{array}{l}\text { NS: [everybody brings something], eh, yes, } \\
\text { that's what I was going to tell you (laughs) }\end{array}$ \\
\hline NNS2: Sí, en Holanda también es prohibido & NNS2: Yes, in Holland it's also forbidden \\
\hline NS: hmm, sí, no se puede beber en la calle & NS: hmm, yes, you can't drink in the street \\
\hline NNS2: no & NNS2: no \\
\hline
\end{tabular}

NS: Native Speaker; NNS: Non-Native Speaker.

In the control group the dynamics were different: there was no contrasting of opinions between the members of the team to reach an agreement over the correct answer and even when their answers were wrong not much curiosity was detected to find out more about the topic. In this case, the teacher was the expert and she was the one that provided the right answers, giving the language learners the opportunity to ask questions if they wanted. The impoverished exchange process can be seen in Example 5.3 (C, SL and VC groups), where the language learners had to guess the process to apply for a job in the public sector (teacher, doctor, secretary, etc.) in Spain.

Example 5.3. Task 5

C group

\begin{tabular}{ll}
\hline NNS: creo que es la (opción) b & NNS: I think it's (option) b \\
NS: no/ no es la b & NS: no/ it's not b \\
NNS: vale & NNS: OK \\
\hline NS: Native Speaker; NNS: Non-Native Speaker &
\end{tabular}

NS: Native Speaker; NNS: Non-Native Speaker

SL group

\begin{tabular}{|c|c|}
\hline $\begin{array}{l}\text { NSS1: en Holanda se hace a, pero no creo que es } \\
\text { lo mismo en España. }\end{array}$ & $\begin{array}{l}\text { NSS1: in Holland you do a, but I don't think it's } \\
\text { the same in Spain. }\end{array}$ \\
\hline $\begin{array}{l}\text { NS: pero... ¿allí hay oposiciones? }[\ldots] \text { oposiciones } \\
\text { hay que hacer un examen, es la } b\end{array}$ & $\begin{array}{l}\text { NS: but...ido you have "oposiciones" there? }[\ldots] \\
\text { "oposiciones" you have to do an exam, it's b. }\end{array}$ \\
\hline NSS2: ¿sí? & NSS2: really? \\
\hline $\begin{array}{l}\text { NS: sí, y quien saca la mejor nota consigue la } \\
\text { plaza }\end{array}$ & $\begin{array}{l}\text { NS: yes, and the one that scores highest gets the } \\
\text { job }\end{array}$ \\
\hline $\begin{array}{l}\text { NNS2: ¿sí? ¿es siempre o solamente para trabajos } \\
\text { especiales? }\end{array}$ & $\begin{array}{l}\text { NNS2: really? Is it always like that or just for } \\
\text { special jobs? }\end{array}$ \\
\hline $\begin{array}{l}\text { NS: por ejemplo cuando yo termine la carrera } \\
\text { puedo hacer unas oposiciones para ser } \\
\text { profesora }\end{array}$ & $\begin{array}{l}\text { NS: for example, when I finnish my degree I can } \\
\text { do "oposiciones" to be a teacher }\end{array}$ \\
\hline $\begin{array}{l}\text { NNS1: ¿es un tiempo para probar si estés } \\
\text { adecuado? }\end{array}$ & $\begin{array}{l}\text { NNS1: is it a time to test if you are right for the } \\
\text { job? }\end{array}$ \\
\hline
\end{tabular}

NS: Native Speaker; NNS: Non-Native Speaker 


\begin{tabular}{|c|c|}
\hline \multicolumn{2}{|c|}{ VC group } \\
\hline NSS1: ¿la c? ¿tú qué crees? & NSS1: c? what do you think? \\
\hline NSS2: pienso que es a & NSS2: I think it's a \\
\hline NS: tenéis que poneros de acuerdo & NS: you have to reach an agreement \\
\hline $\begin{array}{l}\text { NNS1: yo llamaría antes para saber más, siempre } \\
\text { te sirve saber más }\end{array}$ & $\begin{array}{l}\text { NNS1: I would call first to find out more, it's } \\
\text { always useful to know more }\end{array}$ \\
\hline $\begin{array}{l}\text { NS: bueno, entonces una dice la a y la otra la c } \\
\text { ¿no? }\end{array}$ & $\begin{array}{l}\text { NS: well then, one of you says a and the other one } \\
\text { c, right? }\end{array}$ \\
\hline NNS1: ¿se puede? & NNS1: is it possible? \\
\hline NS: es que es la b & NS: well, it's b \\
\hline [todos - risas $]$ & [all - laughter] \\
\hline NNS1: ¿en serio? & NNS1: really? \\
\hline $\begin{array}{l}\text { NS: oposiciones es un examen que tienes que } \\
\text { hacer para conseguir el trabajo }\end{array}$ & $\begin{array}{l}\text { NS: "oposiciones" is an exam that you have to do } \\
\text { to get the job }\end{array}$ \\
\hline NNS2: ¡ah, OK! & NNS2: ah, OK! \\
\hline $\begin{array}{l}\text { NS: la persona que tenga mejor nota se queda con } \\
\text { el trabajo }\end{array}$ & NS: the person that scores highest gets the job \\
\hline NNS2: iguau, qué raro! & NNS2: wow, how strange! \\
\hline NS: tienes que estudiar unos libros super gordos & NS: you have to study really thick books \\
\hline $\begin{array}{l}\text { NNS1: ya, ¿y qué pasa si después no te dan el } \\
\text { trabajo? }\end{array}$ & $\begin{array}{l}\text { NNS1: ok, and what happens if you don't get the } \\
\text { job? }\end{array}$ \\
\hline $\begin{array}{l}\text { NS: imagínate que haces el examen y hay } 35 \\
\text { plazas y tú te quedas la } 36 \text {, pues tienes que } \\
\text { esperar y volver a hacer el examen }\end{array}$ & $\begin{array}{l}\text { NS: imagine you do the exam and there are } 35 \text { jobs } \\
\text { and you end up being } 36 \text {, well then you have to } \\
\text { wait and do the exam again }\end{array}$ \\
\hline NNS1: ¡qué horror! & NNS1: how horrible! \\
\hline
\end{tabular}

NS: Native Speaker; NNS: Non-Native Speaker.

Interactional features

The interactional speech acts of interest that emerged from the data were greetings and leave takings, assistance request, the use of polite formulas and humour. Research observation confirmed that both experimental groups spent time greeting each other and talking about their current activities outside the task before beginning with task performance and that leave takings were generally used to arrange the next task and review the task just performed. Example 5.4 (VC group) below was taken from the $\mathrm{VC}$ group during the first few minutes of the interaction.

Example 5.4. VC group task 2

\begin{tabular}{ll}
\hline NS: la próxima tarea no la voy a poder hacer desde & NS: I am not going to be able to do the next task \\
aquí/ es que voy a estar en Japón & from here/ I am going to be in Japan \\
NNS1: ¿en Japón? & NNS1: in Japan? \\
NS: sí & NS: yes \\
NNS2: ¿y por qué? & NNS2: and why? \\
\hline
\end{tabular}

NS: Native Speaker; NNS: Non-Native Speaker.

The recording of the SL group starts with “¿estáis listas?/ are you ready?”. When the participants arrive at the first destination, the pizzeria holodeck, and upon seeing the food on the tables, one of the language learners asks her partner "Fleur, iaún tienes hambre?/ Fleur, are you still hungry?" which seems to indicate that in the minutes prior to activating the recording and the beginning sentence, an exchange had taken place around the topic of food. 
The control group on the other hand started the task very abruptly and lacking spontaneity, with one of the language learners stating "Me gustaria ir de vacaciones/I would like to go on holidays". Closure was also abrupt.

From the interactional speech acts observed there was one in particular that appeared to register more instances in the SL group than in the other two: the use of humour. In the episode where the participants are getting ready to go to the beach it becomes apparent that the native speaker cannot make her avatar put a bikini on, all she manages is to wear the box containing the items. The situation prompts funny comments like: "asi no puedes nadar/ you can't swim like that; con la caja tú no estás a la moda/ with the box you are not fashionable; si bajamos a la playa con estas cajas vamos a causar sensacion en la gentel if we go down to the beach with these boxes we are going to cause a sensation among the people”. Example 5.5 (SL group) draws on the reactions caused in the language learners when they encountered a hotel room they were not expecting (dirty and untidy).

Example 5.5. SL group

$\begin{array}{ll}\text { NS: ¿qué pasó con el espejo? } & \text { NS: what happened to the mirror? } \\ \begin{array}{l}\text { NNS1: no sé/ a lo mejor alguien estaba muy feo/y } \\ \text { Ne ha roto }\end{array} & \begin{array}{c}\text { very ugly/ and it broke } \\ \text { very }\end{array}\end{array}$

NS: Native Speaker; NNS: Non-Native Speaker.

Within the same situation, complaining about the hotel room, sarcasm also occurred (Example 5.6: SL group). One of the language learners, playing the role of hotel guest, and seeing the state of the room, questions herself whether they would have to pay for it, to which the receptionist (native speaker) responds with surprise.

Example 5.6. SL group

\begin{tabular}{ll}
\hline NNS1: ¿no es gratis? ¿pagamos por esto? & NNS1: isn’t this free? do we have to pay for this? \\
NS: pero/ ¿no era esto lo que habían reservado? & NS: but/ is this not what you had booked? \\
\hline NS: Native Speaker; NNS: Non-Native Speaker.
\end{tabular}

Observation reveals that also in the VC group a friendly atmosphere prevailed with constant laughter, allowing learners to share their feelings and demonstrate a sense of sociability (Chun, 1994; Darhower, 2002).

The supportive nature of a lot of the interaction was also observed when in the VC and SL experimental groups participants helped each other with technical issues when assistance was requested. Example 5.7 (SL group) is only one of the many instances where a language learner is explaining how the environment works when another interlocutor runs into problems. The avatars are getting their attire ready for their holiday, although some of them seem to be having difficulties performing the correct action with the desired effect.

Example 5.7. SL group

\begin{tabular}{lc}
\hline $\begin{array}{l}\text { NS: ¿cómo te has conseguido poner el bikini? } \\
\text { NNS1: tienes que ir a tu inventario y hacer click/y y } \\
\text { luego seleccionar }\end{array}$ & $\begin{array}{c}\text { NS: how did you manage to put your bikini on? } \\
\text { NNS1: you have to go to your inventory and click } \\
\text { / and then select }\end{array}$ \\
\hline NS: Native Speaker; NNS: Non-Native Speaker. &
\end{tabular}


These instances where assistance was requested were not part of the task itself, they were environment triggered exchanges. This seems to contrast with similar situations observed in the control group. There were times when one participant would try to ask for help to express herself and her attempts would be met with no response from her interlocutors. Example 5.8 (C group) shows how a language learner was trying to find the word for 'hat' in order to describe her picture. She made gestures referring to the object and specifically asked for the word but all she got for an answer was silence. Surprisingly enough, minutes later, one of the other language learners used that same word in her speech.

Example 5.8. C group

\begin{tabular}{l}
$\begin{array}{l}\text { NNS1: el hombre con la con la (gestos para indicar } \\
\text { "gorra") ¿cómo se llama? }\end{array}$ \\
$\begin{array}{c}\text { NNS1: the man with the with the (gestures to } \\
\text { indicate "hat") how do you say it? }\end{array}$ \\
\hline NNS: Non-Native Speaker.
\end{tabular}

The video recording of this scene seemed to show that her interlocutors were concerned with their own interventions and once the learner requesting assistance received no apparent help, she decided to leave her sentence unfinished and carry on.

\section{Task engagement}

The high levels of task engagement reported in other studies (Deutschmann, Panichi \& Molka-Danielsen, 2009; Gardner, 2010; Gánem-Gutiérrez, 2014) were also noted in both experimental groups. When discussing their previous holidays participants would seek engagement and personal involvement with their interlocutors for example by asking them if they had been to that place themselves: "¿conocéis Bodrum?/have you been to Bodrum?" (VC). The language learners from the control group however, proceeded to talk about their holidays one by one, with no interruptions from their interlocutors and with only a couple of questions at the end of each other's turns, questions that seemed to be prepared beforehand and did not appear to be spontaneous. When the same topic was being handled by VC and SL, participants engaged in frequent turn overlaps which shows involvement with the task topic and which is characteristic for pragmatic interaction style in Spanish (Escandell Vidal, 2004). In Example 5.9 (VC group) two of the VC participants are showing some photographs of their holidays and the others engage in the interaction immediately showing their interest by asking questions.

Example 5.9. VC group

\begin{tabular}{|c|c|}
\hline $\begin{array}{l}\text { NNS1: y aquí la tienda de campaña/ ¿está una } \\
\text { palabra? }\end{array}$ & NNS1: and here the tent/ is it a word? \\
\hline NNS2: ¿estabas con tus padres? & NNS2: were you with your parents? \\
\hline NNS1: sí/ y mi hermano y hermana & NNS1: yes/ and my brother and my sister \\
\hline $\begin{array}{l}\text { NS: ¿cuándo hiciste ese viaje? ¿cuándo fue? } \\
{[\ldots]}\end{array}$ & $\begin{array}{l}\text { NS: when did you go on that trip? When was it? } \\
{[\ldots]}\end{array}$ \\
\hline NS: aquí estoy yo con mi hijo & NS: here I am with my son \\
\hline NNS2: ¿cuántos años tiene? & NNS2: how old is he? \\
\hline
\end{tabular}

NS: Native Speaker; NNS: Non-Native Speaker. 
This involvement, with the task and its participants, not only manifested itself in the form of questions, but also participants often volunteered comments on each other's interventions, showing a positive attitude towards their interlocutors. In Example 5.10 from the SL group one of the language learners is talking about the things she always takes on holidays with her. The list of items (compass, walking boots, bikini, towel, thick jacket) is probably not what the other language learner was expecting and she does not let the opportunity go to show her surprise.

Example 5.10. SL group

\begin{tabular}{ll}
\hline NNS1: ¡qué completa! & NNS1: how complete! \\
NNS2: sí/ muy completa & NNS2: yes/ very complete \\
NNS1: entonces no hay no hay sitio en la maleta & NNS1: the there is no there is no room in the \\
para comprar cosas más & suitcase to buy more things \\
NS: no & NS: no \\
NNS1: ya está lleno & NNS1: it is already full \\
& \\
NNS2: sí & NNS2: yes \\
[risas] & [laughter] \\
NNS2: sí/ yo tengo pero// eh/eh/ es posible eh & NNS2: yes/ I have but// eh/eh/ it's possible eh to \\
comprar eh espacio & buy eh room \\
NS: sí/ otra maleta & NS: yes/ another suitcase \\
NNS1: ah/ sí sí & NNS1: ah/ yes yes \\
\hline
\end{tabular}

NS: Native Speaker; NNS: Non-Native Speaker.

The environments appeared to elicit a high degree of rich participation that led to personal involvement. We observed that in Second Life elements of the world generated a variety of conversations. For example, in the pizzeria they chatted about the movies displayed in wall posters; being able to drive a boat once they had reached their holiday destination prompted conversations about seatbelts and drivers' licenses ("ponte el cinturón que vamos muy rápido - ¿tú tienes el carné de conducir?/ wear your seatbelt we're going very fast - do you have a driver's licence?"); and visiting the hotel where they were meant to be staying made possible the transaction of booking the room. The interactions from the VC group and control group were characterized by a more descriptive language limited by the photographs being used. In Second Life actions triggered conversations and there was more topic switching and engagement opportunities enabled by in-world elements.

\subsubsection{Survey results}

The post-questionnaires of the experimental groups yielded largely positive responses. Learners identified a number of benefits of SCMC sessions such as being more aware of cultural contrasts and similarities, becoming more confident, talking more fluently, and taking more initiatives (see Table 5.5). When participants in the control group were asked if they thought that given the opportunity to interact with a native speaker they would improve their confidence, fluency, knowledge about the target culture, they would learn to speak better, more vocabulary and understand more, answers pointed towards an affirmative score (see Table 5.6). 
Table 5.5. Experimental groups language learners' $(n=27)$ responses about learning potential.

\begin{tabular}{lcc}
\hline What have you learned during the sessions? & Mean & SD \\
\hline To be aware of cultural contrasts and similarities & 3.85 & 0.82 \\
To talk more fluently & 3.89 & 0.70 \\
To become confident talking in the target language & 3.85 & 0.72 \\
To talk more & 3.48 & 0.85 \\
To take more initiative in the conversation & 3.33 & 1.00 \\
To be more motivated to talk & 3.26 & 0.98 \\
To use new words & 4.26 & 0.71 \\
To use idioms/expressions & 3.93 & 0.68 \\
To use grammar more accurately/correctly & 3.96 & 0.65 \\
\hline
\end{tabular}

Note. 1:Strongly disagree; 5 :Strongly agree.

Table 5.6. Control group language learners' $(n=14)$ evaluation responses.

\begin{tabular}{lcc}
\hline $\begin{array}{l}\text { Do you think that by having the opportunity to conduct interaction } \\
\text { tasks with native speakers }\end{array}$ & Mean & SD \\
\hline you learn to understand better the target language & 4.14 & 0.770 \\
you learn to speak better & 3.93 & 0.730 \\
you learn to speak more fluently & 3.93 & 0.917 \\
you learn more vocabulary & 3.86 & 0.663 \\
you learn to become more confident talking to native speakers & 4.21 & 0.802 \\
\hline
\end{tabular}

Note. 1:Strongly disagree, 5:Strongly agree.

The experiences revealed that the tasks used were perceived as motivating and useful and that the interactions with the pre-service native teachers contributed to enhancing learning processes and motivation.

Tasks were found useful and motivating by both language learners and preservice teachers alike in the VC and SL experimental groups. Students' learning improvements were not only perceived by the students themselves, they were also noticed by the pre-service teachers when asked to compare the first and last interaction sessions (Table 5.7). Among other things, the pre-service teachers clearly found that their language learner interlocutors had become more aware of cultural contrasts and similarities.

Table 5.7. Pre-service teachers' $(n=14)$ responses about language learning learners' improvement.

\begin{tabular}{lll}
\hline Comparing the first and the last session... & Mean & SD \\
\hline $\begin{array}{l}\text { I noticed an overall improvement in the communicative competence } \\
\text { of my foreign language learner comparing session 1 to the last }\end{array}$ & 4.57 & 0.65 \\
$\quad$ session. & 4.14 & 0.95 \\
They talked more in the last session & 4.36 & 0.84 \\
They were able to talk more fluently in the last session & 4.07 & 1.07 \\
They took more initiative during the last session & 3.64 & 1.01 \\
They asked more questions during the last session & 4.50 & 0.94 \\
They became more confident talking in the target language & 4.64 & 0.50 \\
They became more aware of cultural contrasts and similarities & 4.43 & 0.65 \\
They enlarged their lexicon and used more adequate words & 0.55 \\
They have learned to talk more accurately in terms of grammatical & 4.00 & 1.19 \\
$\quad$ constructions. & 4.21 & \\
They were more motivated to talk in the last session &
\end{tabular}

Note. 1:Strongly disagree, 5:Strongly agree. 
These results, reflecting the participants' impressions, seem to be in line with other studies (Peterson, 2010; Jauregi, 2015) where the majority of participants appreciated the opportunities provided to practice the target language with a native speaker and identified the SCMC environment as a low stress atmosphere that reduced communication anxiety compared to their classroom setting (GánemGutiérrez, 2014).

\subsection{Discussion}

The results obtained within our research show that the communicative opportunities offered by VC and SL have a positive impact on learners' communicative competence. A comparison between scores in pre- and post-tests across research conditions indicates that in the control condition the increase in students' oral skills is significantly less than in either the VC, or SL condition (RQ1), making these opportunities to engage in social interaction with expert peers (native speakers) a valuable aspect in foreign language courses. We believe that these networked interactions are relevant and have potential for language learning: they offer language learners opportunities for rich linguistic exposure and communicative practice close to real-life experiences (Coleman, 2002; Crookall, 2002; Purushotma, 2005), particularly when experts are engaged in task interaction.

The analysis of the interactions also revealed that the video communication and Second Life environments created more opportunities for negotiation of meaning. If negotiation of meaning provides optimal conditions for language acquisition as has been argued (Pica, Kanagy, \& Falodun, 1993), the opportunities offered by these tools should be appreciated. Other learning opportunities are the fact that the realistic nature of the environments provided authentic learning conditions that are otherwise difficult to recreate in traditional classroom settings (Dieterle \& Clarke, 2008), that users can experiment and interact with a wider variety of norms of social interaction (Steinkuehler, 2006) and that they stimulate intercultural communication competences (RQ2). These types of platforms may help bridge the distance between students and the target language culture, providing realistic sociocultural contexts for language learning (Schwienhorst, 2002; Zheng, Young, Brewer, \& Wagner, 2009) with the presence of native speakers. Our results also show that this type of interaction sessions have a positive impact on language learners' learning experiences, since they have the impression that they learn from them and it is so perceived by pre-service teachers (RQ3). The surveys also pointed towards a more confident attitude while talking in the target language and to being more motivated to talk, this being in line with other studies that believe that these type of platforms can help motivate learners who would normally be shy in face to face interaction to take part more actively (Freiermuth, 2002; Zheng et al., 2009). These findings build on previous studies that report satisfaction, feelings of improvement and decreased speaking anxiety on participants who took part in voice chats (Bueno Alustey, 2011; Jauregi et al., 2011). Our intention, agreeing with Sykes, Oskoz, \& Thorne (2008) is that language learners will start to integrate the pragmatic skills acquired in these platforms into their repertoire for use in nonmediated interaction contexts. 
The design of the study reflected also some of the basic characteristics for successful language learning in these environments: students worked in small groups to foster cooperative learning and to enhance opportunities for language use (Coleman, 2002) and tasks were learner centred, providing the students the opportunity to resolve problems without the 'authoritative persuasion' of a teacher (Freiermuth, 2002, p. 187). Participants' interviews held at the end of our study (but not reported here) revealed the emotional connections created during the project, and these may motivate learners to continue practising and successfully cultivate their relationships with others, either collaboratively in the virtual space or in other contexts (Sykes et al., 2008).

\subsection{Conclusions}

In both experimental groups (VC and SL), learners displayed a higher degree of interest and engagement than the control group while working together collaboratively (see Tables 2 and 3 on negotiation). This allowed them to gain valuable practice in managing their target language discourse in authentic settings. Learner experiences were largely positive and participation appeared to create high levels of motivation and interest. This seems to be in line with previous studies (Jauregi et al., 2011) which found that implementing networked interaction sessions with native speakers had an impact on the motivation of foreign language learners, particularly for learners with a lower proficiency level.

This study complements existing findings that suggested that participation in these types of environment not only provides access to a wide range of interlocutors but that it may also enhance cross-cultural understanding and knowledge of the target language culture (Tudini, 2003, 2007; Von Der Emde, Schneider, \& Kötter, 2001); that the electronic medium seems to afford more opportunities for active participation (Kern, 1995) and that it also provides a forum where participants can engage in negotiation of meaning at their own pace (Fernández-García \& Martínez-Arbelaiz, 2002). Participation in task-based VC and SL interactions made these learners and their interlocutors more aware of intercultural differences and similarities, as virtual worlds and video communication tasks were developed in such a way that both language learners and pre-service teachers had to reflect on their interlocutors' and their own culture by discussing, explaining and understanding contrasts, similarities and misunderstandings. Therefore, the tasks carried out in these CMC environments enhanced collaborative intercultural communicative development, since successful task completion required participants to work together and share the cultural information, views, and connotations necessary to complete the tasks.

Although the positive results obtained in our study are encouraging, we are aware of some limitations that might be worth taking into account when considering future studies. Firstly, our sample size was limited and although some data refers to all groups involved in the study, the negotiation analysis explores only two out of the five tasks performed by language learners. Secondly, task completion for the VC and SL groups took between 60 and 90 minutes while the control group spent only 30 minutes in task performance. This time limitation was due to timetabling 
restrictions and room and teacher's availability. The fact that the control group's interaction sessions were shorter might have influenced the results, but reflects classroom limitations. Thirdly, there is a need for additional research that investigates the long-term effects. The effects measured in this study were at short term, further research would need to look into what would happen in the long term and perhaps observe any improvements across tasks. Fourthly, we do not know whether the results are due to the presence/ absence of the native speaker in the different conditions, to the influence of the SCMC versus traditional face to face classroom encounters or to both. Future research should have to address these conditions separately. In addition, further research could operationalise engagement and compare quantitative results in order to analyse its relation to the specific platforms. The present results have to be interpreted cautiously since more research is needed to better understand the potential contributions of SCMC interactions in foreign language development. We suggest that future studies examine the different variables that might impact the results, such as the age of the learners, the target language, the type of interlocutor, educational setting and modality, the way interaction is supported.

\section{$5.8 \quad$ References}

Belz, J.A., \& Thorne, S.L. (Eds.). (2006). Internet-mediated intercultural foreign language education. Boston: Heinle \& Heinle.

Blake, R. (2000). Computer mediated communication: A window on L2 Spanish interlanguage. Language Learning \& Technology, 4(1), 120-136.

Bryant, T. (2006) Using World of Warcraft and other MMORPGs to foster a targeted, social, and cooperative approach toward language learning. Academic Commons.

Bueno Alastuey, M.C. (2011). Perceived benefits and drawbacks of synchronous voice-based computer mediated communication in the foreign language classroom. CALL Journal, 24(5), 419-432.

Byram, M. (1997). Teaching and assessing intercultural communicative competence. Clevedon: Multilingual Matters.

Canto, S., Jauregi, K., \& Bergh, van den H. (2013). Integrating cross-cultural interaction through video communication and virtual worlds in foreign language teaching programs: Is there an added value? ReCALL 25(1), 105121.

Chapelle, C. A. (2001). Computer applications in second language acquisition. Cambridge: Cambridge University Press.

Chun, D. (1994). Using computer networking to facilitate the acquisition of interactive competence. System, 22, 17-31.

Ciekanski, M., \& Chanier, T. (2008). Developing online multimodal verbal communication to enhance the writing process in an audio-graphic conferencing environment. ReCALL, 20(2), 162-182.

Clavel-Arroitia, B., \& Pennock-Speck, B. (2015). Telecollaboration in a secondary school context: Negotiation of meaning in English as a lingua franca/Spanish tandem interactions.@tic. Revista d'innovació Educativa, $15,74-81$. 
Coleman, D. W. (2002). Guest editorial: Simulation and computer-assisted language learning. Simulation \& Gaming, 33(2), 179-180.

Crookall, D. (2002). Editorial: Simulation in language learning. Simulation \& Gaming, 33(3), 273-274.

Council of Europe. (2001). (CEFR) Common European Framework of Reference for Languages: Learning, teaching, assessment. Cambridge: CUP / Council of Europe.

Darhower, M. (2002). Interactional features of synchronous computer-mediated communication: A sociocultural case study. CALICO Journal 19(2), 249275.

Deutschmann, M., Panichi, L., \& Molka Danielsen, J. (2009). Designing oral participation in Second Life - A comparative study of two language proficiency courses. ReCALL, 21(2), 206-226.

Develotte, C., Guichon, N., \& Vincent, C. (2010). The use of the webcam for teaching a foreign language in a desktop videoconferencing environment, ReCALL 23(3), 293-312.

Dieterle, E., \& Clarke, J. (2008). Multi-user virtual environments for teaching and learning. In M. Pagani (Ed.), Encyclopedia of multimedia technology and networking (pp. 1033-1041). Hershey, PA: Idea Group, Inc.

Escandell Vidal, M.V. (2004). Aportaciones de la pragmática. In J. Sánchez Lobato \& I. Santos Gargallo (Eds.), Enseñar español como segunda lengua (L2)/lengua extranjera (LE). Vademécum para la formación de profesores (pp. 179-199). Madrid, SGEL,

Felix, U., \& Lawson, M. (1996). Developing German writing skills by way of Timbuktu: A pilot study comparing computer-based and conventional teaching. ReCALL, 8(1), 12-19.

Fernández-García, M., \& Martínez-Arbelaiz, A. (2002). Negotiation of meaning in nonnative-nonnative speaker synchronous discussions. CALICO Journal, 19(2), 279-294.

Freiermuth, M. (2002). Connecting with computer science students by building bridges. Simulation \& Gaming, 3(3), 299-315.

Gámen-Gutiérrez, G. (2014). The third dimension. A sociocultural theory approach to design and evaluation of 3D virtual worlds tasks. In M. González-Lloret \& L. Ortega (Eds.), Technology-mediated TBLT. Researching technology and tasks (pp. 299-315). Amsterdam: John Benjamins.

Gardner, R. C. (2010). Motivation and second language acquisition: the socioeducational model. New York: Peter Lang

Gass, S. (1997). Input, interaction and the second language learner. Mahwah, NJ: Lawrence Erlbaum.

González-Lloret, M., \& Ortega, L. (Eds.). (2014). Technology-mediated TBLT: researching technology and tasks. Amsterdam: John Benjamin

Guichon, N. (2010). Preparatory study for the design of a desktop videoconferencing platform for synchronous language teaching. Computer Assisted Language Learning, 23(2), 169 - 182.

Guth, S., \& Helm, F. (Eds.). (2010). Telecollaboration 2.0. Bern: Peter Lang AG.

Guth, S., \& Maio, M. (2010). Close encounters of a new kind: The use of Skype and Wiki in telecollaboration. In S. Guth \& F. Helm (Eds.), Telecollaboration 2.0 (pp. 413-427). Bern: Peter Lang AG. 
Hampel, R. (2006). Rethinking task design for the digital age: A framework for language teaching and learning in a synchronous online environment. $\operatorname{ReCALL}, 18(1), 105-121$.

Hampel, R., Felix, U., Hauck, M., \& Coleman, J.A. (2005). Complexities of learning and teaching languages in a real-time audiographic environment. In Dvorak \& J. F. Lee (Eds.), German as a Foreign Language Journal, (pp. 146-157). New York: Newbury House.

Jauregi, K. (2015). Integrating telecollaboration for intercultural language acquisition at secondary education: Lessons learned. In F. Helm, L. Bradley, M. Guarda \& S. Thouësny (Eds.), Critical CALL. - Proceedings of the 2015 EUROCALL Conference, Padova, Italy (pp. 268-273). Research-publishing.net.

Jauregi, K., \& Bañados, E. (2008). Virtual interaction through video-web communication: A step towards enriching and internationalizing learning programs. ReCALL 20(2), 183-207.

Jauregi, K., \& Bañados, E. (2010). An intercontinental video-web communication project between Chile and The Netherlands. In S. Guth \& F. Helm (Eds.), Telecollaboration 2.0 (pp. 427-436). Bern: Peter Lang AG.

Jauregi, K., Canto, S., Graaff, de R., Koenraad, T., \& Machteld M. (2011). Verbal interaction in Second Life: Towards a pedagogic framework for task design. Computer Assisted Language Learning Journal 24(1), 77-101.

Jauregi, K., Graaff, de R., Bergh, van den H., \& Kriz, M. (2012). Native/non-native speaker interactions through video-web communication; a clue for enhancing motivation? CALL Journal 25(1), 1-19.

Jauregi, K., \& Melchor-Couto, S. (2014). Researching telecollaboration in secondary schools: Challenges and opportunities. In J. Colpaert, A. Aerts \& M. Oberhofer (Eds.), Research challenges in CALL (pp.191-199). Antwerp: Linguapolis.

Kern, R. (1996). Computer-mediated communication: Using e-mail exchanges to explore personal histories in two cultures. In Warschauer, M. (Ed.), Telecollaboration in Foreign Language Learning (pp. 105-119). Hawai'i: Second Language Teaching and Curriculum Centre.

Kötter, M. (2003). Negotiation of meaning and codeswitching in online tandems. Language Learning \& Technology, 7(2), 145-172.

Kuriscak, L.M, \&, Luke C. L. (2009). Language learner attitudes toward virtual worlds: An investigation of Second Life. In G. Lord \& L. Lomicka (Eds.), The next generation: Online collaboration and social networking in CALL (pp. 173-207). San Marcos, TX: CALICO.

Lamy, M. N., \& Hampel, R. (2007). Online communication in language learning and teaching. Basingstoke: Palgrave Macmillan.

Lee, L. (2001). Online interaction: negotiation of meaning and strategies used among learners of Spanish. ReCALL, 13(1), 232-244.

Lin, H. (2014). Establishing an empirical link between computer-mediated communication (CMC) and SLA: A meta-analysis of the research. Language Learning \& Technology, 18, 120-147.

Lin, H. (2015). A meta-synthesis of empirical research on the effectiveness of computer-mediated communication (CMC) in SLA. Language Learning \& Technology, 19, 86-117. 
Littlewood, W. (2004). The task-based approach: some questions and suggestions. ELT Journal, 58(4), 319-326.

Long, M. H. (1985). Input and second language acquisition theory. In S. Gass and C. Madden (Eds.), Input in second language acquisition (p. 377-393). Rowley, MA.: Newbury House.

Long, M. (1996). The role of linguistic environment in second language acquisition. In W. C. Richie \& T. K. Bhatia (Eds.), Handbook of research on language acquisition, Vol. 2: Second language acquisition (pp. 413-468). New York: Academic Press.

Mackey, A., \& Polio, C. (Eds.) (2009). Multiple perspectives on interaction: Second language research in honor of Susan M. Gass. New York: Routledge.

Molka-Danielsen, J., \& Deutschmann, M. (Eds.). (2009). Learning and teaching in the virtual world of Second Life. Trondheim, Norway: Tapir Academic Press.

Müller-Hartmann, A. (2000). The role of tasks in promoting intercultural learning in electronic learning networks. Language Learning and Technology, 4, 129147.

Nielson, K., \& González-Lloret, M. (2010). Effective online foreign language courses: Theoretical framework and practical application. The Eurocall Review, 17, 27-35.

O'Dowd, R. (2006). The use of videoconferencing and e-mail as mediators of intercultural student ethnography. In J.A Belz \& S.L.Thorne (Eds.), Internet-mediated intercultural foreign language education (pp. 86-120). Boston: Heinle \& Heinle.

O'Dowd, R. (2011). Online foreign language interaction: Moving from the periphery to the core of foreign language education? Language Teaching Journal, 44(3), 368-380.

O’Dowd, R., \& Ritter, M. (2006). Understanding and working with 'failed communication' in telecollaborative exchanges. CALICO Journal, 23(3), 120.

Ortega, L. (2009). Interaction and attention to form in L2 text-based computer mediated communication. In A. Mackey \& C. Polio (Eds.), Multiple perspectives on interaction (pp. 226-253). New York: Routledge.

Pellettieri, J. (2000). Negotiation in cyberspace: The role of chatting in the development of grammatical competence. In M. Warschauer \& R. Kern (Eds.), Network-based language teaching: concepts and practice (pp. 5986). Cambridge: Cambridge University Press.

Peterson, M (2010). Learner participation patterns and strategy use in Second Life: an exploratory case study. ReCALL, 22(3), 273-292.

Peterson, M. (2011). Towards a research agenda for the use of $3 \mathrm{D}$ virtual worlds in language learning. CALICO, 29(1), 67-80.

Peterson, M. (2012). EFL learner collaborative interaction in Second Life. ReCALL, 24(1), 20-39.

Pica, T. (1994). Research on negotiation: What does it reveal about second-language learning conditions, processes, and outcomes? Language Learning 44, 493527.

Pica, T., Kanagy, R., \& Falodun, J. (1993). Choosing and using communication tasks for second language instruction. In G. Crookes \& S. Gass 
(Eds.), Tasks and language learning: Integrating theory and practice. Vol 1. (pp. 9-34). Clevedon, England: Multilingual Matters.

Plonsky, L., \& Ziegler, N. (2016). The CALL-SLA interface: Insights from a second-order synthesis. Language Learning \& Technology, 20(2), 17-37.

Purushotma, R. (2005). Commentary: You're not studying, you're just ... Language Learning \& Technology, 9(1), 80-96.

Sauro, S. (2011). SCMC for SLA: A research synthesis. CALICO Journal, 28(2), 369-391.

Schwienhorst, K. (2002). Why virtual, why environments? Implementing virtual reality concepts in computer-assisted language learning. Simulation \& Gaming, 33(2), 196-209

Smith, B. (2003). Computer-mediated negotiated interaction: an expanded model. Modern Language Journal, 87(1), 38-57.

Smith, B. (2004). Computer-mediated negotiated interaction and lexical acquisition. Studies in Second Language Acquisition, 26, 365-398.

Smith, B. (2005). The relationship between negotiated interaction, learner uptake, and lexical acquisition in task-based computer-mediated communication. TESOL Quarterly, 39(1), 33-58.

Sotillo, S.M. (2000). Discourse functions and syntactic complexity in synchronous and asynchronous communication. Language Learning and Technology, $4(1), 82-119$.

Steinkuehler, C. (2006). Massively multiplayer online videogaming as participation in a discourse. Mind, Culture \& Activity, 13(1), 38-52.

Sykes J. M., Oskoz A., \& Thorne S. L. (2008). Web 2.0, synthetic immersive environments, and mobile resources for language education, CALICO Journal 25(3), 528-546.

Thorne, S. L. (2008). Transcultural communication in open internet environments and massively multiplayer online games. In S. Magnan (Ed.), Mediating Discourse Online (pp. 305-327). Amsterdam: John Benjamins.

Toyoda, E., \& Harrison, R. (2002). Categorization of text chat communication between learners and native speakers of Japanese. Language Learning and Technology, 6, 82-99.

Tudini, V. (2003). Using native speakers in chat. Language Learning and Technology, 7 (3), 141-159.

Tudini, V. (2007). Negotiation and intercultural learning in Italian native speaker chat rooms. Modern Language Journal, 91(4), 577-601.

Varonis, E.M., \& Gass, S. (1985). Non-native/non-native conversations: A model for negotiation of meaning. Applied Linguistics 6, 71-90.

Von Der Emde, S., Schneider, J., \& Kotter, M. (2001). Technically speaking: Transforming language learning through virtual learning environments (MOOs). The Modern Language Journal. 85(2), 210-225.

Vygotsky, L. S. (1978). Mind \& Society. Cambridge, MA: Harvard University Press.

Wang, Y. (2006). Negotiation of meaning in desktop videoconferencing-supported distance language learning. ReCALL, 18(1), 122-145.

Wang, Y. (2007). Task design in videoconferencing-supported distance language learning. CALICO Journal, 24 (3), 562-590.

Warburton, S., \& Pérez-García, M. (2009). 3D design and collaboration in massively multi-user virtual environments. In D. Russel (Ed.), Cases on 
collaboration in virtual learning environments: processes and interactions (pp. 414-426). Hershey, PA: IGI Global.

Ware, P. D., \& Kramsch, C. (2005). Toward an intercultural stance: Teaching German and English through telecollaboration. Modern Language Journal, 89, 190-205.

Warschauer, M. (1996). Comparing face-to-face and electronic communication in the second language classroom. CALICO Journal, 13(2), 7-26.

Zhao, Y. (2003). Recent developments in technology and language learning: A literature review and meta-analysis. CALICO Journal, 21(1), 7-27.

Zheng, D., Young, M. F., Brewer, M. F., R. A., \& Wagner, M. (2009). Attitude and self-efficacy change: English language learning in virtual worlds. CALICO Journal, 27(1), 205-231.

Ziegler, N. (2015). Synchronous computer-mediated communication and interaction: A meta-analysis. Studies in Second Language Acquisition, 134. 
Appendix. Assessment grid for pre and post-tests

\begin{tabular}{|c|c|c|c|c|c|}
\hline o & $v$ & un & $\omega$ & - & \\
\hline 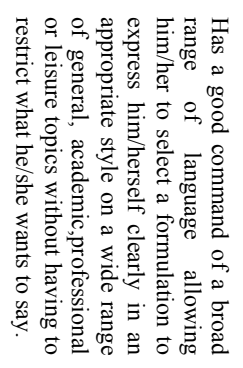 & 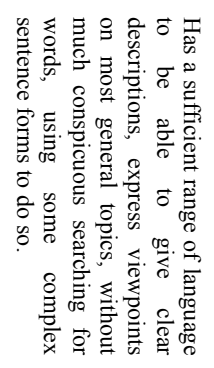 & 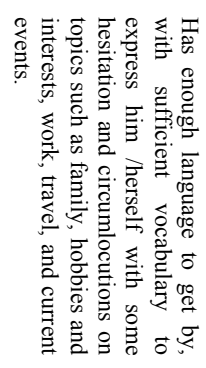 & 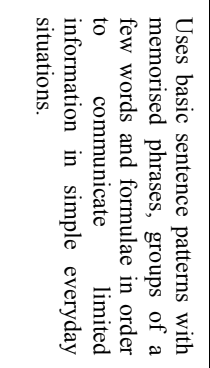 & 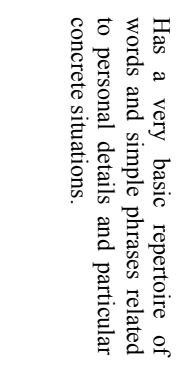 & $\begin{array}{l}\text { 䓪 } \\
\text { 命 }\end{array}$ \\
\hline 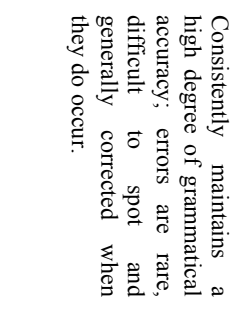 & 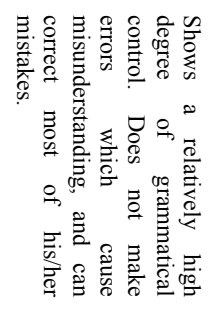 & 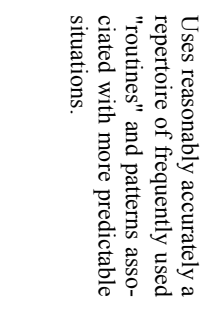 & 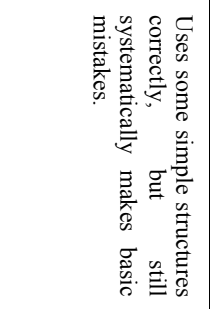 & 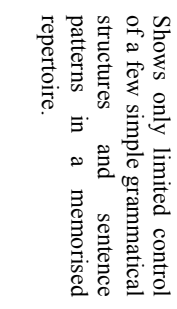 & \begin{tabular}{l}
$\overrightarrow{2}$ \\
$\hat{2}$ \\
\multirow{2}{2}{} \\
2
\end{tabular} \\
\hline 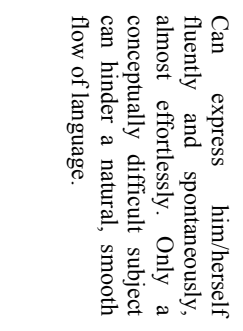 & 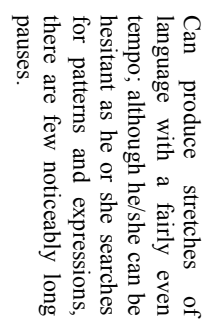 & 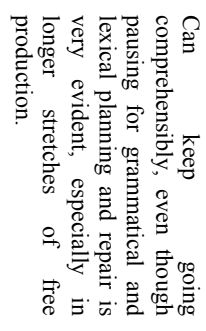 & 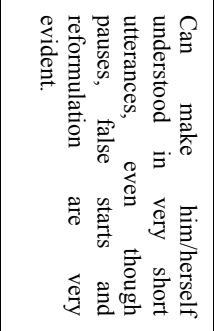 & 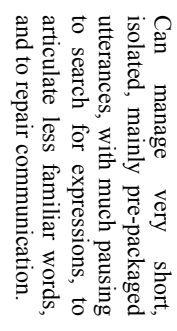 & $\begin{array}{l}\text { 결 } \\
\text { 罗 } \\
\text { 2. }\end{array}$ \\
\hline 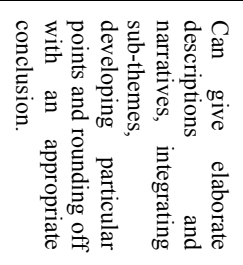 & 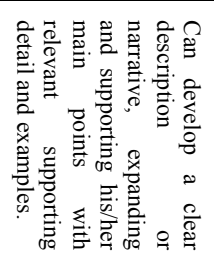 & 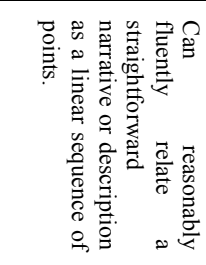 & 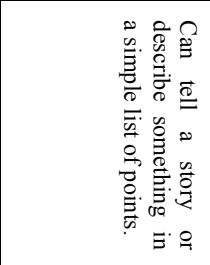 & & 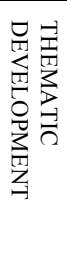 \\
\hline 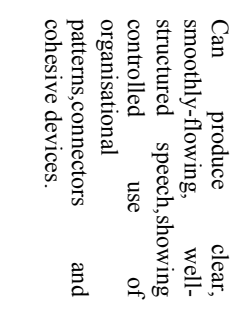 & 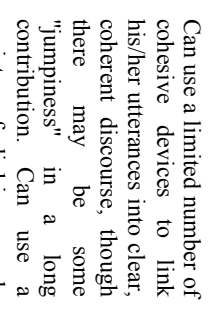 & 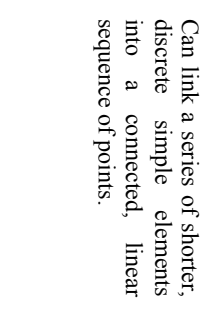 & 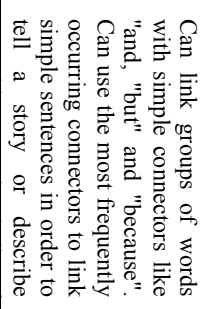 & 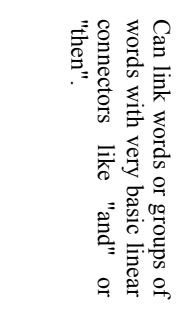 & 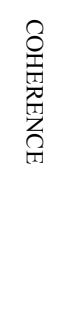 \\
\hline
\end{tabular}




\section{Chapter 6}

\section{Virtual worlds in language education: towards meaningful learning through interaction, action and play. 1}

\subsection{Introduction}

In a highly digitalised society, as the present one, the use of technology is available to all and is gradually permeating the education sector. In this continuous development of digital innovation, three-dimensional virtual worlds (3DVW) appear to offer excellent opportunities to enrich foreign language teaching through play, action and interaction beyond classroom walls.

In this chapter, we propose to unravel those aspects that make virtual worlds a motivating environment, low in anxiety and rich in learning opportunities, and we present pedagogical guidelines for their integration in the curriculum of foreign languages.

We will first analyse research studies that have looked into the added value of using virtual worlds in foreign language teaching both at university (NIFLAR ${ }^{2}$, EUROVERSITY ${ }^{3}$ projects) and high school level (TILA ${ }^{4}$ project). We will then propose criteria following the task based language teaching (TBLT) approach for the creation of meaningful tasks that are best suited to the characteristics of virtual worlds and finish with guideline proposals for organising intercultural online exchange projects, also known as telecollaboration.

\footnotetext{
1 This chapter has been published as: Jauregi, K. \& Canto, S. (2018). Mundos virtuales en la enseñanza de lenguas: hacia un aprendizaje significativo a través de la interacción, la acción y el juego. In M. González-Lloret \& M. Vinagre Laranjeira (Eds.), Comunicación Mediada por Tecnologías - Aprendizaje y Enseñanza de la Lengua Extranjera (pp. 88-107). Equinox eBooks Publishing, United Kingdom.

2 NIFLAR, Networked Interaction in Foreign Language Acquisition and Research, a two year project (2009-2011), received a grant from the European Commission within the Lifelong Learning Programme (www.niflar.eu).

3 EUROVERSITY: project funded by the European Commission within the Lifelong Learning Programme that deals with the integration of virtual worlds in educational settings (2012-2014) www.euroversity.eu

4 TILA: project funded by the European Commission within the Lifelong Learning Programme that focuses on the integration of telecollaboration for foreign language learning in secondary education (Telecollaboration for intercultural Language Acquisition, 2013-2015): www.tilaproject.eu
} 


\subsection{What are 3D virtual worlds?}

3D virtual worlds (3DVW) are immersive environments where users are represented by avatars (see figure 1), who as well as being able to communicate orally or via written chat can move or be teleported from one place to another with a simple click and carry out activities in a wide variety of scenarios. These two characteristics, the wide variety of scenarios where interactive learning events can take place and the communication possibilities 3DVWs offer, are the ones that give these immersive platforms their great didactic potential where action is key (Jauregi, 2013; Jauregi, Canto, De Graaff, Koenraad, \& Moonen, 2011; Jauregi, De Graaff, van den Bergh, \& Kriz, 2012; Dieterle \& Clarke, 2008; Deutschmann, Panichi, \& Molka-Danielsen 2009).

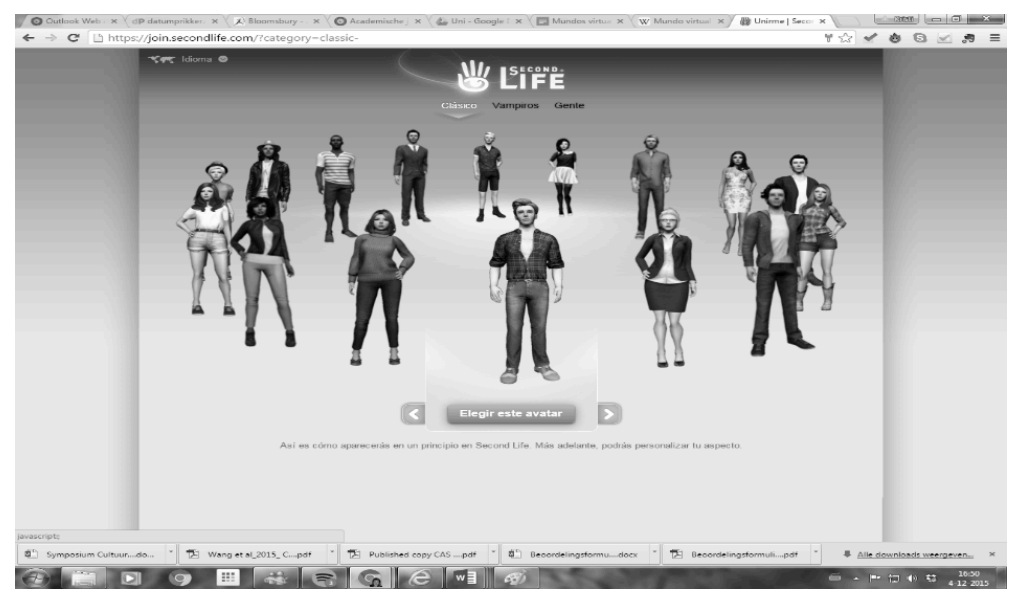

Figure 6.1: Avatars in the virtual world of Second Life.

3DVWs have the ability to create learning environments conceptually different to those from the classroom or interactive technologies, such as videocommunication (Skype, Google Hangouts). Learning is immersed in a simulated realistic context, which implies a shift in language pedagogy towards experiential learning through problem solving and spatially distributed forms of collaboration (Cornille, Thorne, \& Desmet. 2012). Teachers, as well as learning how to use this 3D technology, need to learn how to integrate these virtual experiences in a specific learning context.

Second Life, OpenSim, Active Worlds, Quest Atlantis or Minecraft are some of the existing 3DVWs in the market. In this chapter we will present the experiences carried out in the first two.

\subsubsection{Second Life}

Second Life (SL) is a virtual world created by Linden Lab and launched in 2003, with free access via the Internet. Users create an account, select an avatar and install 
a viewer in their computer through the homepage, www.secondlife.com. Once the avatar has been selected, this can be personalised by the user, changing colour and hairstyles, facial and physical characteristics, even gender. Users can choose a male, female or non human avatar according to their preferences. The first destination for new avatars in SL is Orientation Island, that includes tutorials to learn the skills needed in SL (i.e., how to move in the virtual world, how to change your avatar's appearance or how to use the different communication channels). SL is reserved for users who are sixteen or older.

\subsubsection{OpenSimulator}

OpenSimulator (OpenSim) is a free open source programme that is used to create and manage virtual worlds and it has to be hosted on a given server. Its characteristics are similar to those of SL with the difference that those institutions or persons that create a world here, not only do they manage them but they are also their owners. This is not the case in SL, that although it is free to use, it remains LindenLab's property. If the OpenSim that we choose to use is hosted in a secure server this virtual world can be used with minors in primary or secondary education ${ }^{5}$

The possibilities offered by these virtual worlds to enrich language learning are numerous, due to the characteristics of the virtual environment itself and the didactic uses that can be given to them (Sadler, 2012).

\subsection{Virtual worlds' properties}

3DVWs are probably one of the most complex educational digital environments at the moment (Kozlova \& Priven, 2015), but at the same time they are also the richest in terms of teaching possibilities due to several reasons. Firstly, they support synchronous multimodal communication through various communication channels which include audio, text-chat (open or private), activation of gestures made by the avatar and the possibility to connect a webcam. Secondly, 3DVWs provide users with realistic experiences or simulations of immersion in the $3 \mathrm{D}$ virtual world that include scenarios very similar to real places (a university classroom, a hotel reception, a living room in a house, bars, museums, factories, offices, hospitals, shops, theatres or even the desert), fantasy, unreal environments or historic replicas where different scenes can be recreated: a scary castle with screaming noises, Egypt during the reign of the Pharaohs or a safari park. Thirdly, avatars can move (walk, run, sit down, dance and even fly) and interact with objects, which facilitates action, that is, the possibility to carry out activities in different contexts: go ice skating, skiing, surfing, ride a bike, get into a taxi, order something at a restaurant, go shopping, etc. Being able to interact with objects allows for the creation of games where gamification elements that are motivating can be included (points, time invested, applause, etc.). Fourthly, objects can be created (clothes, furniture, buildings). This is a creative activity that, if carried out with other avatars, can lead

5 Primary education: students between 4 and 12 years old. Secondary education: students between 12 and 18 years old. 
to meaningful collaboration processes. Lastly, different types of documents can be uploaded and shared in the virtual world: videos, photos, PowerPoint, audio files o texts. Users can also attend and organize all sorts of events: conferences, parties, classes, workshops, concerts and even go to the cinema.

\subsection{Virtual worlds' didactic uses}

3DVWs can be used in multiple and varied ways for teaching. These will depend on the course pedagogical principles and objectives, students' needs and interests and technological conditions at our disposal.

3DVWs can be used, for example, to teach on line. In this case, the teacher organizes the lessons following similar guidelines to those used in the traditional classroom. Students follow the course on line from their individual locations and participate in the virtual classroom, answering the teacher's questions (via text or audio chat) or carrying out group activities. It is not surprising to see that those students who are normally shy to make a comment or hesitant to ask a question, feel more comfortable when they do it in a virtual world. Their representation via an avatar gives them some anonymity ${ }^{6}$, which might contribute to make them feel more at easy when expressing themselves. If a discussion takes place via the text chat users can see how it evolves progressively. This text chat from the discussion can also be saved for revision at a later stage and can be used as reference to emphasize relevant grammatical or intercultural aspects that might have emerged in the communication exchange.

$3 \mathrm{DVW}$ can also be used to create machinimas: recordings in the $3 \mathrm{DVW}$ that can be made by teachers to explain particular aspects of the target language or culture or used as a source for input. Students themselves can made use of these machinimas to recreate different discourse types: a court hearing, a television commercial, a theatre play, a product pitch, etc., which can be motivating for the student. To be able to make recordings in 3DVWs a special recording software is needed ${ }^{7}$. Camelot is a European project that has developed didactic materials for making machinimas for language learning (www.camelotproject.eu).

3DVWs provide an optimal platform to promote teamwork in an informal and relaxed environment, encouraging, among others, the development of oral communication skills. Here role-plays can be performed in the most suitable scenarios (a market, a camping, a police station, etc.) and games can be played. In this case, gamification elements should be included. Peterson (2011) analysed different research studies carried out on the use of games and virtual worlds for language learning and concluded that, although many of the studies were exploratory, they showed that these environments are motivating and contributed to the development of the students' communicative competences and vocabulary acquisition. In addition to this, these virtual spaces also seem to be beneficial for the learning process and the development of students' communicative and intercultural competence (Bryant, 2006; Canto, De Graaff, \& Jauregi, 2014; Thorne, 2008),

6 The person's image does not appear on the screen, voice can be altered and even their name can be made up.

7 There are several free options on the net. 
especially since users can experiment and interact using a wide variety of social interaction norms through role-plays in appropriate scenarios (Cooke-Plagwitz, 2008; Steinkuehler, 2006) with native speakers (Canto, et al., 2014) and non-native speakers (Peterson, 2010, 2012).

Recently, 3DVWs have been used as a platform to facilitate telecolaboration projects. That means that 3DVWs offer the possibility to carry out tasks with students from other countries, in the digital platform and within their institutional context, in order to develop the user's communicative and intercultural competence (Canto et al., 2014). Projects like NIFLAR show the positive results achieved by Dutch and Spanish university students, who carried out telecolaboration tasks as part of their language and teacher training courses respectively (Jauregi \& Canto, 2012; Canto, Jauregi, \& van den Bergh, 2013).

In all these didactic uses it is important to highlight the realistic nature of the digital environment, that offers authentic communication conditions which are difficult to recreate in the traditional classroom (Dieterle \& Clarke, 2008). On the one hand, O'Dowd (2011) points out the ability of these worlds to increase the level of authenticity in classroom practices. On the other hand, Molka-Danielsen \& Deutschmann (2009) highlight the immersive and interactive nature of these virtual worlds. The presence of stimuli inherent to the virtual world encourages participants to become involved with the environment where they can create and modify their world in real time.

\subsection{Colaboration tasks in virtual worlds}

Although in the field of second language acquisition there is not a single definition accepted by all of "task" (Moonen, De Graaff, \& Westhoff, 2006; Moonen, 2008), there seems to be consensus on the main characteristics that define it: it has to be meaning oriented, with defined objectives and it has to encourage language acquisition (Bygate, Skehan, \& Swain, 2001; Canto et al., 2014). To ensure that tasks are meaning rather than form oriented they should not only offer rich input (Krashen, 1985) but should also stimulate an exchange of opinions or information and negotiation of meaning (Long, 1996), which is promoted by creating an information gap. In addition, it is important that learners use all available (linguistic) resources to achieve task goals. It is imperative that tasks have well formulated objectives and results that are not just the "use of language" (Ellis, 2003, 2012), since language should be used as a means to achieve an objective and not as a goal in itself (Ellis 2003, 2012; Jauregi, 2015; Long, 2015).

Communication's intercultural component should also be present in task design for virtual worlds (Byram, 1997; Möllering \& Levy, 2012; Thorne, 2010). If the goal of foreign language learning and teaching is to help students communicate in an appropriate manner with target language native speakers, to understand not only the other but oneself too (Kramsch, 1993), they need to develop a competence to help them discover the new culture, to rediscover their own and to understand and accept the differences (Byram, 1997).

Deutschmann \& Panichi (2009) present a guide with specific aspects to take into account when designing tasks for these virtual platforms: in the virtual 
world, the visual context where communication takes place is relevant; other interlocutors, besides those engaged in the conversation, can interfere in the communication; contexts can be adapted to promote learning and tasks should promote oral communication, that is, to complete the task successfully an intense oral communication is required. Therefore, tasks should generate both language learning, promoting authentic input and output (Doughty \& Long, 2003; Ellis, 2003) as well as intercultural learning (Byram, 1997). They should also be structured in such a way that the learners are encouraged to speak, to share ideas and opinions in the process of collaboration towards the achievement of the intended objective, taking into account the specific characteristics of the virtual world used, in order to enrich the interaction context to the maximum (Deutschmann et al., 2009). González-Lloret and Ortega (2014) point out five essential characteristics that tasks should have when carried out in technology mediated contexts: 1) they have to focus on meaning, 2) they have to have a goal oriented communicative purpose, 3) they have to be student centred, 4) they need to be authentic, with a relation to the real world, 5) they have to offer opportunities for reflection. Learners' needs, interests and styles should deserve special attention (Dörnyei \& Ushioda, 2010; GonzálezLloret, 2014) without forgetting that if the previous technological conditions are not fulfilled, the tasks will lose their pedagogical potential.

\subsection{Telecolaboration projects with virtual worlds}

Within the different European projects $^{8}$ we were part of, we designed, carried out and evaluated different telecolaboration experiences, both for university students using SL and for secondary education students using OpenSim.

\subsubsection{University students}

In the Spanish Department at Utrecht University SL has been used since 2008 as a motivating environment to carry out telecolaborations with native speakers (from teacher training programmes from the universities of Valencia, Girona and Granada). During the course, students carry out five telecolaboration tasks (see Table 6.1). In the classroom they prepare and evaluate these tasks and the telecollaboration part takes place outside teaching hours, with group formations consisting of one native speaker with two students of Spanish as a foreign language.

8 NIFLAR, EUROVERSITY and TILA. 
Table 6.1. Tasks carried out in the Spanish as a Foreign Language course, B1 level (CEFR).

\begin{tabular}{|c|c|}
\hline Tasks & Description \\
\hline Task 1: & Students: \\
\hline Sharing & (1) meet in the apartment they are going to share \\
\hline Accommodation & $\begin{array}{l}\text { (2) exchange personal and cultural information (photos) and } \\
\text { or go for a walk in the city) }\end{array}$ \\
\hline Task 2:On holidays & Participants plan and go on a holiday \\
\hline Task 3 :The movies & $\begin{array}{l}\text { Participants play different roles according to specific instructions given from a } \\
\text { script (birthday party, in a bar, giving/receiving presents) }\end{array}$ \\
\hline Task 4:Identity & $\begin{array}{l}\text { Participants adapt their avatars' physical characteristics and experiment the } \\
\text { reactions from others depending on their appearance and voice }\end{array}$ \\
\hline Task 5:Culture & $\begin{array}{l}\text { Students take part in a television game show about each other's culture, the } \\
\text { Dutch team against the Spanish team }\end{array}$ \\
\hline
\end{tabular}

Both, the Spanish as a foreign language students and the native speakers are very positive about the experiences. According to surveys carried out with the language learning students, they identify the following beneficial aspects of the virtual interaction with native speakers: they admit that they are more aware of cultural contrasts and similarities (development of intercultural competence), that they learn to speak more fluently, that they acquire new vocabulary and are able to take more initiative in the interactions. For the native students, who are specializing in the teaching of Spanish, this experience gives them the opportunity to learn first hand the challenges that language learners face when trying to communicate in a foreign language. They also develop digital and pedagogical skills, as well as their intercultural knowledge (Jauregi et al., 2011).

\subsubsection{Secondary school learners}

For the secondary school students the TILA project team opted for creating a virtual world in OpenSim. This world called TILA is a safe environment that respects students' privacy and is fully managed by the project team. In this article we describe one of the experiences that took place there: the cultural debate.

Students from a school in The Nederlands and from another school in Finland participated in this project. Groups were created (six students per group, three Dutch and three Finnish) and they all followed a tutorial in OpenSim before the interaction sessions started. For the project five debate tasks were designed and supervised by students in a teacher training programme at Utrecht University. These supervisors presented the tasks, helped students with the instructions, language and technology. The first debate was carried out from the schools, but due to management and technical problems the rest of the debates were organized from home.

The first task was conceived as an introduction to the project. Students met in a virtual village to exchange personal information and afterwards, in pairs, they 
commented on specific aspects of their own culture and established comparisons between the two (see Figure 6.2).

The location for the second task is a church where participants exchange information and opinions about social and religious rituals in their culture.

In the third task, the participants meet up with the major of virtual Chatterdale, who wants to build an airport and asks its inhabitants for advice. Afterwards, the participants go to a bar together and witness a murder (see Figures 6.3 and 6.4), which takes them to the following task.

In the fourth task, the participants are involved in the investigation of that murder and discuss with the police the possible suspects. In the last task, the students, by now members of a jury in the trial, listen to the witnesses, lawyers and judge and decide whether to convict or acquit the suspect (see Figure 6.5).

The results of the experience were very positive, as shown by the surveys and interviews conducted with the students. They liked the intercultural experience and immersive gameplay offered by virtual worlds in different locations. The Finnish students were slightly younger and their oral skills somewhat lower than those of the Dutch students, which created some anxiety, as reflected in the questionnaires and interviews conducted. The tasks that the Dutch participants liked most were those that revolved around the murder, whereas the favourites for the Finnish participants were those that favoured the exchange of personal, social and cultural information and opinion. The technology worked well, but there were some problems when planning the meetings. It was then decided to create WhatsApp groups to manage and plan virtual meetings more effectively.

\subsection{Virtual worlds' efficiency}

Research carried out within the NIFLAR and TILA projects show the added value of virtual worlds for language learning and teaching. Initial analyses of interactions between students of Spanish as a foreign language and students in teacher training programmes at Spanish universities are very encouraging. Jauregi et al. (2011) reported that the recordings of telecollaboration sessions in SL showed that the tasks generated lively interactions among the participants in which, in addition to following task instructions, the students exchanged information triggered by the environment: how to edit their avatar's appearance, how to activate the microphone, how to move in SL or how to put on skis. 


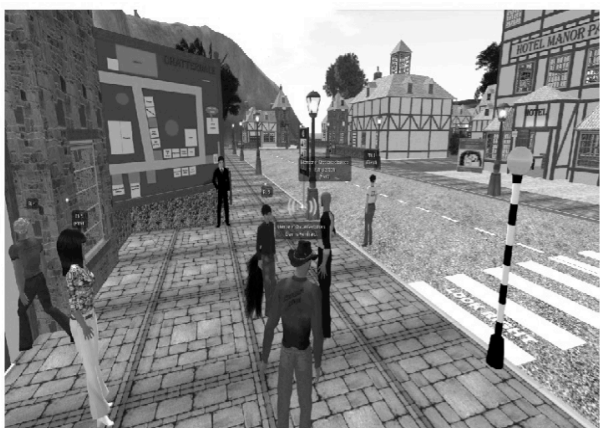

Figure 6.2: Screenshot of students carrying out a task in the Chatterdale village in OpenSim (TILA).

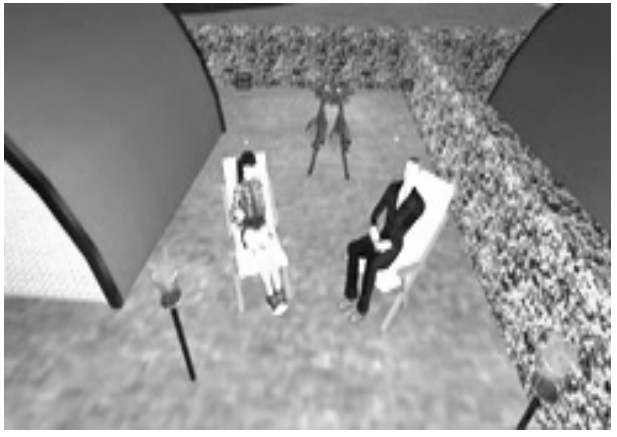

Figure 6.3. Students carrying out task 1.

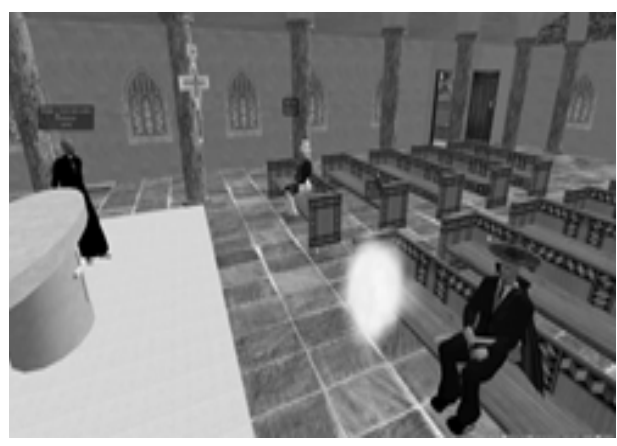

Figure 6.4. Students carrying out task 2.

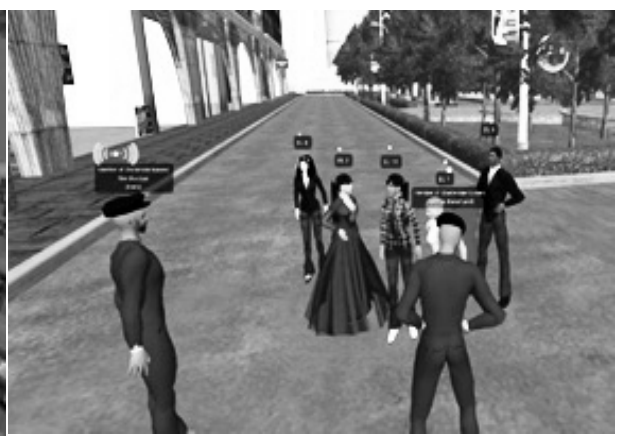

Figure 6.5. Students carrying out task 3.

These interactions, triggered by elements or situations inherent to the virtual world, are typical of the communication that arises in this type of environments. Indeed, much of the conversation that is generated in 3DVWs is activated by the specific context in which the conversation takes place and is largely unpredictable, as is the case with real communication. Participants pointed out in interviews that took place after interaction sessions that these unpredictable situations, related to the specific context of the virtual world, are those that intensify the added value of the use of 3DVW. This contrasts with the predictability and lack of authenticity of many interactions in classrooms. Other advantages indicated by the participants are the flexibility offered by the use of an avatar to start a conversation (for example, comments on their appearance), the additional themes created by the environment, the discovery factor and elements of imagination. In addition, telecollaboration tasks stimulated participants to focus on intercultural aspects producing key elements of intercultural communication (Byram, 1997). Participants showed open and curious attitudes towards the culture of the other, exchanged knowledge about society and 
daily life, interpreted and related cultural events of the virtual world and expressed a critical cultural awareness towards cultural practices and events of their own culture, that of their interlocutors and of the virtual world.

In a later study, Canto et al. (2013) found indicators of improvement in students' oral communicative competence in contexts where virtual worlds had been introduced to carry out telecollaborative tasks with native speakers. The results showed that the telecollaboration sessions (experimental group) were more effective than the communicative teaching techniques in the classroom (control group). In this control group, the increase in oral communicative competence was significantly lower. The analysis of the interactions of these two groups also shows that the group that participated in the telecollaboration sessions interacted more (Jauregi, 2012) than the control group. In addition, a greater number of negotiation sequences were detected in the experimental group (Canto et al., 2014). The results also indicate that this type of telecollaboration has a positive impact on the learning experiences of language students, since they perceive that they learn from them. The students who had the opportunity to collaborate with native speakers pointed out that the telecollaboration sessions made them more aware of cultural contrasts and similarities. They also made them feel more confident when speaking, and now they were able to do it with more fluency and taking more the initiative. These improvements in oral skills were not only perceived by the language students, but were also signalled by their native speaker interlocutors when asked to compare the first and last interaction session.

\subsection{Conclusion}

The experiences and results presented in this chapter are a good starting point to promote the use of $3 \mathrm{DVW}$ in language teaching. However, we can not ignore studies that suggest that, unfortunately, this type of telecollaboration is considered an extracurricular activity and not an integral part of study programmes (Warschauer \& Ware, 2008).

It must also be taken into account that the use of 3DVWs may present some problems. Time has to be spent on learning to navigate and communicate in the virtual world, in addition to the specific technological requirements to be considered (see the SL site for a list of requirements). As with many new technologies, also in 3DVWs we can encounter technological problems (of sound, delays, etc.) that can hinder the interaction sessions. We should also not overestimate students' willingness to use new technologies. Although some students are very willing to innovate, others may feel some anxiety when using a 3DVW.

Despite these considerations, we have found indicators in our research that show that this type of practice makes a positive contribution to language learning processes and we think that they should become part of language programmes.

From the sites of the European projects mentioned in this article teachers can download free didactic guides, examples of good practices and tasks. In addition, those teacher training institutions and schools interested in telecollaboration projects could become part of the TILA community and make use of its virtual environment. Moreover, there is a new association, Euroversity 
Association (www.euroversityassociation.eu), which aims to assist those interested in the use of 3DVWs for educational purposes. In SL there are also several islands where activities for foreign language teachers are organized (EduNation and associations such as EuroCALL and CALICO)

Looking ahead, interesting technological advances in the field of 3D virtual reality, such as the development of the Oculus-Rift 3D glasses, will enable a much more immersive and intense experience in virtual worlds or games. It will not be the avatar who walks, jumps, fights, or surfs, but the user himself who, immersed in the 3DVW, performs all those actions. This will make for a more playful, impressive and enriching experience. We think that due to these advances, in the near future, there will be more researchers, teacher trainers and teachers who will integrate these 3DVWs into educational systems. In our opinion, telecollaboration will become an integral part of the curriculum of foreign language and teacher training. The virtual aspect seems to favour a more relevant and meaningful language learning experience through exploration, interaction and play. Classroom based teaching that follows the guidelines set by a specific manual belongs to the past.

\subsection{References}

American Council on the Teaching of Foreign Languages (ACTFL). (1999). Standards for foreign language learning (2nd ed.). Yonkers, New York: ACTFL

Bygate, M., Skehan, P., \& Swain, M. (2001). Researching pedagogic tasks. Second language learning, teaching and testing. Harlow, UK: Pearson.

Bryant, T. (2006). Using World of Warcraft and other MMORPGs to foster a targeted, social, and cooperative approach toward language learning. Academic Commons.

Byram, M. (1997). Teaching and assessing intercultural communicative competence. Clevedon, UK: Multilingual Matters.

Canto, S., De Graaff, R., \& Jauregi, K. (2014). Collaborative tasks for negotiation of intercultural meaning in virtual worlds and video-web communication. In M. González-Lloret \& L. Ortega (Eds.), Technology and Tasks: Exploring Technology-mediated TBLT (pp. 183-213). Amsterdam, Philadelphia: John Benjamins.

Canto, S., Jauregi, K., \& van den Bergh, H. (2013). Integrating cross-cultural interaction through video-communication and virtual worlds in foreign language teaching programs. Burden or added value?. ReCALL, 25(1), 105121.

Cooke-Plagwitz, J. (2008). New directions in CALL: An objective introduction to SL. CALICO Journal, 25(3), 547-557.

Cornille, F., Thorne, S., \& Desmet, P. (2012). Digital games for language learning: From hype to insight? ReCALL, 24(3), 243-356.

Deutschmann, M. \& Panichi, L. (2009). Instructional design, teacher practice and learner autonomy. In J. Molka-Danielsen \& M. Deutschmann (Eds.), Learning and teaching in the virtual world of SL. Trondheim: Tapir Academic Press. 
Deutschmann, M., Panichi, L., \& Molka Danielsen, J. (2009). Designing oral participation in SL - A comparative study of two language proficiency courses. ReCALL, 21(2), 206-226.

Dieterle, E., \& Clarke, J. (2008). Multi-user virtual environments for teaching and learning. In M. Pagani (Ed.), Encyclopedia of Multimedia Technology and Networking . Hershey, PA: Idea Group, Inc.

Dörnyei, Z., \& Ushioda, E. (Eds.). (2010). Motivation, Language Identity and the L2 Self. Bristol: Multilingual Matters.

Doughty, C., \& Long, M. (2003). Optimal psycholinguistic environments for distance foreign language learning. Language Learning \& Technology, 7(3), 50-75.

Ellis, R. (2003). Task-based language learning and teaching. Oxford, UK: Oxford University Press.

Ellis, R. (2012). Investigating the performance of tasks. In R. Ellis (Ed.), Language Teaching Research and Language Pedagogy (pp. 195-235). Malden, MA: John Wiley \& Sons Inc.

González-Lloret, M. (2014). The need for needs analysis in technology-mediated TBLT. In M. González-Lloret \& L. Ortega, L. (Eds.), Technology and Tasks: Exploring Technology-mediated TBLT (pp. 23-50). Amsterdam, Philadelphia: John Benjamins.

González-Lloret, M., \& Ortega, L. (2014). Towards technology-mediated TBLT: An introduction. In M. González-Lloret \& L. Ortega (Eds.), Technology and Tasks: Exploring Technology-mediated TBLT (pp. 1-22). Amsterdam, Philadelphia: John Benjamins.

Guth, S., \& Helm, F. (Eds.). (2010). Telecollaboration 2.0: Language literacies and intercultural learning in the 21st century. Bern: Peter Lang.

Guth, S., \& Helm, F. (2012). Developing multiliteracies in ELT through Telecollaboration. ELT Journal, 66(1), 42-51.

Jauregi K., \& Canto, S. (2012). Impact of native-nonnative speaker interaction through video communication and Second Life on students' intercultural communicative competence. In L. Bradley \& S. Thouësny (Eds.), CALL: using, learning, knowing (pp. 151-156). Dublin: Research-publishing.net.

Jauregi, K. (2015). Task development for telecollaboration among youngsters. In J. Colpaert, A. Aerts, M. Oberhofer \& M. Gutiérrez-Colón (Eds.), Task Design and CALL (pp. 312-322). Antwerp: Linguapolis.

Jauregi, K., Canto, S., De Graaff, R., Koenraad, T., \& Moonen, M. (2011). Verbal interaction in SL: Towards a pedagogic framework for task design. CALL Journal, 24(1), 189-207.

Kozlova, I \& Priven, D. (2015). ESL teacher training in 3D virtual worlds. Language Learning \& Technology, 191, 83-101.

Krashen, S. (1985). The Input Hypothesis: Issues and Implications. London: Longman.

Kuriscak, L., \& Luke, C. (2009). Language learner attitudes toward virtual worlds: An investigation of SL. In G. Lord \& L. Lomicka (Eds.), The Next Generation: Online collaboration and social networking in CALL (pp. 173207). San Marcos, TX: CALICO.

Long, M. (1996). The role of the linguistic environment in second language acquisition. In W. Ritchie, \& Bhatia, T. (Eds.), Handbook of language 
acquisition. Vol.2: second language acquisition (pp. 413-468). New York: Academic Press.

Long, M. (2015). Second language acquisition and task-based language teaching. Chichester: Wiley Blackwell.

Long, M., \& Robinson, P. (1998). Focus on orm: Theory, research and practice. In C. Doughty \& J. Williams (Eds.), Focus on form in second language acquisition (pp. 15-41). Cambridge: Cambridge University Press.

Molka-Danielsen, J., \& Deutschmann, M. (Eds). (2009). Learning and teaching in the virtual world of SL. Trondheim, Norway: Tapir Academic Press.

Möllering, M., \& Levy, M. (2012). Intercultural competence in computer-mediated communication. In M. Dooly \& R. O'Dowd (Eds.), Researching online foreign language interaction and exchange (pp. 233-266). Bern: Peter Lang.

Moonen, M. (2008). Testing the multi-feature hypothesis; Tasks, mental actions and second language acquisition. Utrecht, The Netherlands: Universiteit Utrecht.

Moonen, M., De Graaff, R., \& Westhoff, G. (2006). Focused tasks, mental actions and second language learning. Cognitive and connectionist accounts of task effectiveness. ITL - International Journal of Applied Linguistics, 152, 3553.

Motteram, G., Koenraad, T., Outakoski, H., Jauregi Ondarra, K., Molka-Danielsen, J., \& Schneider, C. (2014). The Euroversity Good Practice Framework EGPF and its application to minority languages and older learners. In S. Jager, L. Bradley, E. Meima \& S.Thouësny (Eds.), CALL design: Principles and practice (pp. 241-247). Research-publishing.net.

O’Dowd, R. (2011). Online foreign language interaction: Moving from the periphery to the core of foreign language education?. Language Teaching Journal, 44(3), 368-380.

Outakoski, H. (2014). Teaching an endangered language in virtual reality. In M. C. Jones \& S. Ogilvie (Eds.), Keeping languages alive: Documentation, pedagogy and revitalization (pp. 128-139). Cambridge: Cambridge University Press.

Peterson, M. (2010). Learner participation patterns and strategy use in SL: An exploratory case study. ReCALL, 22(3), 273-292.

Peterson, M. (2011). Towards a research agenda for the use of 3D Virtual Worlds in Language Learning. CALICO, 29 (1), 67-80.

Skehan, P. (1998). A cognitive approach to language learning. Oxford: Oxford University Press.

Steinkuehler, C. (2006). Massively multiplayer online videogaming as participation in a discourse. Mind, Culture \& Activity, 13(1), 38-52.

Sadler, R. (2012). Virtual worlds for language learning. From theory to practice. Berlin: Peter Lang.

Thomas, M., \& Reinders, H (Eds.). (2010). Task-based language learning and teaching with Technology. London: Continuum.

Thorne, S. (2006). Pedagogical and praxiological lessons from Internet-mediated intercultural foreign language education research. In J. Belz \& S. Thorne (Eds.), Internet-mediated Intercultural Foreign Language Education (pp. 2-30). Boston, MA: Heinle \& Heinle. 
Thorne, S. (2008). Transcultural communication in open Internet environments and massively multiplayer online games. In S. Magnan (Ed.), Mediating Discourse Online (pp. 305-327). Amsterdam: John Benjamins.

Thorne, S. (2010). The "intercultural turn" and language learning in the crucible of New Media. In S. Guth \& F. Helm (Eds.), Telecollaboration 2.0. (Language Literacies and Intercultural Learning in the 21st Century (pp. 139-164). Bern: Peter Lang.

Vinagre, M., \& Muñoz, B. (2011). Computer-mediated corrective feedback and language accuracy in telecollaborative exchanges. Language Learning \& Technology 15(1), 72-103.

Warschauer, M., \& Ware, P. (2008). Learning, change, and power: Competing discourses of technology and Literacy. In J. Coiro, M. Knobel, C. Lankshear \& D. J. Leu (Eds.), Handbook of research on new literacies (pp. 215-240). New York: Lawrence Erlbaum. 


\section{Chapter 7}

\section{Discussion}

\subsection{General discussion}

In this dissertation the effects of computer mediated communication (CMC) via telecollaboration with native speakers on foreign language learning are studied. We have chosen to look at the role of tasks and the environment and their effect on learners' spoken language proficiency and their understanding of target cultures. We believed that not only the relevance of meaningful tasks in conjunction with the technological environment but also an international setting with native speakers would help to enhance intercultural spoken communication skills. We wanted to find out which characteristics of these online exchanges are that enhance interaction and promote learning. Next, it is investigated whether these computer mediated interventions have any added value over the more traditional education or if on the contrary they are just another burden for teachers. Building on the findings of previous research (Jauregi \& Bañados, 2008; Canto \& Jauregi, 2010; Jauregi, Canto, De Graaff, Koenraad, \& Moonen, 2011) and data from the NIFLAR ${ }^{1}$ project, we developed and tested a series of tasks to be carried out in two different virtual platforms (the 3D virtual world of Second Life and a video communication tool) as well as in a traditional classroom setting. Tasks, implemented in students' educational programme, had to be carried out weekly and repeated measures were taken. In this concluding chapter we will summarise the main findings of the studies conducted. These findings will be discussed as well as their implications for further research, suggesting how $\mathrm{CMC}$ via telecollaboration could be implemented in educational institutions.

Based on the assumption that language learners develop their language skills through social interactions (Vygotsky, 1978; Warschauer, 1997; Ellis, 1999; Firth \& Wagner, 2007; Lantolf \& Thorne, 2006; Blaurock, 2011; Kurata, 2011) adequate task design should be key and match the communicative affordances of the environments used (Hampel, 2014). The importance of task design is first explored in chapter 2, where an initial experience enabled us to explore whether the specific affordances of the virtual environment could be adequately used for enhancing interaction.

In this chapter, a small scale study served as a discovery stage for the finetuning of language learning tasks to the specific affordances of educational communication environments, such as $3 \mathrm{D}$ virtual worlds. We created a grid with guidelines for the elaboration of interaction tasks to be carried out in synchronous elearning environments. We then applied the criteria in Second Life, aiming at 
exploiting the specific affordances of the virtual environment in interaction processes. We found that Second Life-specific tasks that stimulated learners to explore virtual worlds together while exchanging information triggered instances of dynamic communication exchange as well as quite large episodes of silence. However, other less context-specific for Second Life tasks were richer in communication. This led us to conclude that task design principles had to be further adapted for $3 \mathrm{D}$ virtual world settings, focusing on enhancing rich oral interaction to be necessary for task completion, while exploiting at the same time the possibilities of the virtual world as much as possible.

In chapter 3 this was extended to video communication. Here a set of methodological principles for task design in multimedia environments is presented in more detail in relation to the intercultural online tasks designed for the study. The chapter explored how the development of intercultural competence can be facilitated with the use of current technologies, such as virtual worlds and video communication. We provided evidence of negotiation of intercultural meaning between language learners and native speaker interlocutors, in order to understand how such negotiation of linguistic and intercultural meaning takes place and may best be stimulated in tasks designed in the two technological environments. The results showed clear and frequent instances of intercultural negotiation of meaning in both environments. Participation in task based virtual worlds and video communication interactions made these learners and their interlocutors more aware of intercultural differences and similarities, as virtual worlds and video communication tasks were developed in such a way that both language learners and native speakers had to reflect on their interlocutors' and their own culture by discussing, explaining and understanding contrasts, similarities and misunderstandings (Belz \& Kininger, 2002, 2003; Blake, 2008; Furstenberg, Levet, English, \& Maillet, 2001; O'Dowd \& Ware, 2009; Thorne, 2003; Zhu, Gareis, O'Keefe Bazzoni, \& Rolland, 2005). The findings in this chapter seem to support the beneficial outcomes of telecollaboration reported by scholars and summarized by O'Dowd and Eberbach (2004): the online cross-cultural exchanges helped to enhance oral communication skills (Blake, 2000; Abrams, 2003) and contributed to the learners' understanding of the target culture (Belz, 2003, 2007; Chun, 2011; Helm, 2009; O’Dowd, 2003, 2006; Liaw \& Master, 2010; Schenker, 2012).

The results presented in chapters 2 and 3 point to how important it is for tasks to be motivating. Motivation is key in order to incite the learner to invest mental energy into (1) task performance and learning by doing, (2) comprehending the input and (3) producing output that accompanies it (van den Branden, 2017). Authenticity is discussed as having positive effects on language learning motivation (Csizér \& Dörnyei, 2005; Dörnyei, 2001; Gilmore, 2007; Jauregi, De Graaff, Van den Bergh, \& Kriz, 2012; MacDonald, Badger, \& Dasli, 2006; Mishan, 2005; Pinner, 2012; Ushioda, 2001; Woo, Herrington, Agostino, \& Reeves, 2007) and for that reason, the feeling of authenticity of tasks may be a crucial factor. Task authenticity can be provided not only by the type of task that has to be carried out but also by the medium where it takes place. For example, a task set in a hotel room in Second Life, does not take the students to a real room in a real hotel, but it gives them the feeling of being in one by placing them in a virtual hotel room. The online 
environments used in this research help simplify stepping into the world of the task, especially the 3D world of Second Life, allowing students to make the task their own. For example, if a task is set on a beach there would be other objects present they could potentially interact with (a boat, a beach chair, an outside shower, etc.) making it a real life experience and producing different outcomes depending on the participants. Where traditional classroom methods force students to create mental images of scenes or objects, these situations can be made visible on the screen with the use of online technology, creating a meaningful context in which language learning can be embedded.

The findings in this study are in line with previous research that indicated that technology mediated tasks should focus on meaning, rather than on grammatical forms, be learner centred, authentic and draw on real world processes of language use (González-Lloret \& Ortega, 2014). If our aim is to develop learners' ability to use the target language in real communication, then tasks are one of the key elements in their learning process. In the context of real communication, classroom tasks should be related to what the learners are supposed to be able to do with the target language in the real world, inviting them to act primarily as language users and eliciting the kinds of communicative behaviour that naturally arises from performing real-life language tasks (van den Branden, 2006).

The analysis presented in chapter 4 tested whether the integration of crosscultural interaction thorough video communication and virtual worlds in foreign language teaching programmes constitutes a burden for teachers or if, on the contrary, it has an added value over more traditional education. In this chapter we examined the effect that providing opportunities to engage in synchronous social interaction with native peers had in the development of foreign language learners' oral communicative competence. The study compared oral communicative growth of experimental groups (video communication and virtual worlds) and a control group (classroom setting) according to pre and post oral tests. The results suggested that, on average, participants in the video communication and Second Life groups showed more improvement of their oral proficiency than students who did not participate in this type of interactions. However, the improvement appeared to be dependent on the initial proficiency of language learners. Students with lower oral language skills seemed to profit more from the two telecollaboration conditions than the more proficient learners. We were aware that the effects that learning contexts, pedagogic interventions and cognitive processes have in interaction come together with the patterns of abilities learners bring to those contexts (Robinson, 2005), that is, some learners may be suited to learn under one condition or from one technique versus others. We concluded that the synchronous learning environments used in conjunction with effective interaction tasks and the opportunities to engage in meaningful interaction with expert peers contributed not only to the significant difference in oral communicative growth between experimental groups (engaged in networked interactions with expert peers though video communication and virtual worlds) and a control group (carrying out the tasks face to face with classmates in the classroom setting) but also to empower intercultural learning experiences.

Having examined in chapter 4 the positive effect that these synchronous social interactions with native peers had in the development of students' oral 
communicative competence, the learning opportunities that emerge during these online cross-cultural exchanges were further explored in chapter 5, comparing two experimental groups of video communication and virtual worlds to the control group. It was shown that the two experimental groups outperformed the others regarding communicative competence. This interaction with native speakers through video communication and Second Life had also a positive impact in the development of the intercultural competence of foreign language learners.

The networked interactions offered language learners opportunities for rich linguistic exposure and communicative practice close to real-life experiences (Coleman, 2002; Crookall, 2002; Purushotma, 2005), particularly when experts were engaged in task interaction. The analysis of the interactions in this chapter also revealed that the video communication and Second Life environments created more opportunities for negotiation of linguistic and intercultural meaning. Amongst the other learning opportunities observed was the fact that the realistic nature of the environments provided authentic learning conditions that are otherwise difficult to recreate in traditional classroom settings (Dieterle \& Clarke, 2008), and that users can experiment and interact with a wider variety of norms of social interaction (Steinkuehler, 2006). We believe that the emotional connections created during the project (revealed during participants' interviews) may motivate learners to continue practising and successfully cultivate their relationships with others, either collaboratively in the virtual space or in other contexts (Sykes, Oskoz, \& Thorne, 2008). Participation in networked interactions appeared to create high levels of motivation and interest. This supports studies which found that implementing networked interaction sessions with native speakers had an impact on the motivation of foreign language learners, particularly for learners with a lower proficiency level (Jauregi et al., 2011).

The experiential, real-time, and multimodal features of some of these online environments, such as those of 3D virtual worlds like Second Life, are well suited to the learning interests and styles of our digital native learners (CookePlagwitz, 2009). The sense of telepresence (being there) and co-presence (being there together) amplified by avatars also makes learning more playful and resembles real life activities (Cooke-Plagwitz, 2008). In chapter 6 we looked at how avatarenabled immersion further fosters experiential learning and creativity, heightens engagement and motivation and promotes risk-taking that sets these $3 \mathrm{D}$ virtual worlds apart from other text-based digital platforms (Dawney, Mohler, Morris, \& Sanchez, 2012; González-Lloret \& Ortega, 2014; Peterson, 2016). These 3D virtual environments allow participants to simulate real-life scenarios and to explore their imagination and creativity in vibrant social platforms. Likewise, language learners can also simulate real-life tasks in immersive, target language environments. They can easily interact with other speakers worldwide via text or voice chat in Second Life and immerse themselves in real world scenarios without the burden of physical travels and costs (Canto, De Graaff, \& Jauregi, 2014; Clark, 2009).

Digital technology is changing learning and teaching styles and traditional language course designs no longer meet the learning needs and interests of our experiential learners, who prefer personalised learning in collaboration (Dede, 2005). We also need to move away from the conviction that to learn a foreign 
language learning the grammar rules correctly, applying them with sufficient speed and working hard are sufficient, because using a foreign language is more than practicing with one clear rule in a selected context (Slagter, 2000). Since we cannot ignore that technology is present in our society and in our students' lives we, as instructors, should aim to bridge the gap between the conventional ways of course delivery (relying on print material or static interfaces of learning management systems like Blackboard) and the plurality of teaching beyond the class walls making use of, for example, telecollaboration tools or digital games (Prensky, 2005a, 2005b). Immersive simulation and real time collaboration offer potential instructional venues for teachers to incorporate real-life tasks into foreign language learning that may be difficult to manage in a conventional classroom (GonzálezLloret \& Ortega, 2014). These authentic settings allow participants to process the linguistic input (Krashen, 2003) while also utilizing negotiation strategies to produce comprehensible output (Swain, 2000). On top of that, the interaction with target language native speakers offers participants the opportunity to develop their intercultural awareness as well as their language competence.

Although it is claimed that greater language proficiency results in an asymmetrical power relationship, in which non native speakers can be intimidated (FitzGerald, 2003), the tasks developed for the studies here presented drew on aspects from both cultures, making the language learners realise that the target language native speakers were interested in learning about their cultures. This kind of balance in the form of learning from each other empowers language learners, giving them a sense of equality and increased levels of self-confidence (Campbell, 2012).

For educational institutions, the integration of telecollaboration tools in foreign language learning favours opening up the classroom, presents more opportunities for project work and it can stand for "low cost" internationalization. Their foreign language learners benefit in turn from authentic interaction in realistic sociocultural contexts, with more opportunities for negotiation of linguistic and intercultural meaning and active participation, confidence gains, lower learner anxiety and valuable opportunities for cultural awareness. Although these telecollaboration tools help bridge the distance between students and the target language culture, educators intending to introduce them can face some challenges such as finding a partner to collaborate, technical issues regarding the quality of the audio, video and connection, time management obstacles (time zones, academic calendars) and the use of innovative blended pedagogies.

This research aims to make a contribution to support sociocultural perspectives. These perspectives, with their focus on contextual language learning, emphasise that language learning happens as a result of social interactions, with peer interaction facilitating language learners' assessment of their communication effectiveness (Lantolf \& Thorne, 2006).

\subsection{Some unresolved issues}

Online communication tools, such as the ones used to carry out this research, extend language learning opportunities in ways that would be difficult (if not impossible) to 
orchestrate in traditional classroom settings (Sykes et al., 2008; Thorne \& Black, 2008). The present research adds to an understanding of how online (learning) communication environments can help students communicate in situated contexts, engaging them in collaborative tasks to promote intercultural language learning. However, we are aware that certain elements used throughout this study could have influenced the results obtained and that alterations in the procedures could have produced other results.

One of those issues concerns the tool used to measure students' oral language proficiency. Language learners were assessed on measures of communicative language competence (range of language, grammatical accuracy, fluency, thematic development and coherence) based on descriptors that were inspired by the scales proposed by the Common European Framework of Reference for languages (CEFR). A different measuring scale based on descriptors from other assessment bodies (for example, the American Council on the Teaching of Foreign Languages, ACTFL) would have perhaps generated a different outcome.

Another issue is the fact that the two evaluators were native speakers of Spanish and also the researchers involved in the project. This could have also affected the results, even though the same measures for pre- and post-test were used, tests were double rated by both researchers and assessors were blind to conditions.

A further limitation relates to the control group. We did not use a control group using the same technology and the same tasks for interactions among course learners. This would help to better range the impact technology with or without the presence of native speakers has on the intercultural communicative competence of learners.

Finally, we have to mention the discrepancy between the tasks. Tasks carried out in Second Life were similar in essence to those carried out via video communication or in class, but each environment had its particular affordances which made tasks unique. Although the tasks used for interactions were carefully designed, we can always wonder if they were perfect. For example, we could have used a virtual house tour instead of using photographs, or perhaps grouped the students on a one to one basis instead of two to one, or include a small written reflection after each task. While we know now more than we did when we started, despite these concerns, further research is required to deepen knowledge on the issues discussed here.

Although we have obtained positive results, this research concerns university students in The Netherlands and it would be desirable to carry out similar studies with different types of participants. These studies would involve primary and secondary school learners or other educational institutions, languages other than Spanish as well as longitudinal studies. However, this is not an easy endeavour and there are practical issues to take into account. These are some of the challenges that might interfere when setting these projects in motion: technology (availability of computers, band with, software), lack of teacher training (familiarity with the tool and how to integrate in their teaching, task design, workload), finding partner schools or educational administrative requirements (parents' consents, funding).

The participants that took part in this study carried out their interactions with native speakers of the target language. It would be interesting to carry out a 
similar study in which the students interact with non-native speakers of the target language in order to test whether this factor alters the conclusions obtained here. Similarly, additional studies on the impact of online telecollaboration environments to teach other foreign languages than Spanish would be extremely relevant, since the use of these technologies in educational contexts is still limited and only a minority of practitioners choose to explore their potential (O'Dowd, 2010).

This thesis project embarked on a journey with the beliefs that online communication environments, such as the 3D virtual world of Second Life or video communication tools would have positive effects on language learners' understanding of target cultures and learners' spoken language proficiency, by bringing together foreign language learners and native speakers of the target language located in geographically distant places. However, simply giving students access to those communication environments, with the hope that they will communicate and improve their language use is naïve. This draws attention to the need for research that advances effective design principles (Hauck \& Warnecke, 2013) and that promotes full understanding of telecollaborative configurations in context in order to generate more studies that would throw light into the types of tasks, their characteristics and under which conditions they are more effective at producing interactions believed to be conductive to intercultural language learning (Blake, 2000; Jeong, 2011; Keller-Lally, 2006; Sauro, 2011; Smith, 2003; Yilmaz, 2011). Since technology is continuously evolving, this implies an iterative process of pedagogical innovation, piloting, adaptation and research.

All educational materials developed within the project have been made accessible to other practitioners so that they can also benefit from their use but this alone is not enough. It is also important that language teachers receive the necessary training and coaching to be able to implement telecollaboration practices in their teaching because the teacher plays an integral role in ensuring the success of telecollaborative exchanges (e.g., Belz, 2003; Dooly, 2008, 2010; Müller-Hartmann, 2007; Müller-Hartmann \& Schocker-v. Ditfurth, 2013). Telecollaboration practices should also take place as early as possible without it being limited to university students (Jauregi Ondarra \& Melchor - Couto, 2018). Projects such as TILA ${ }^{2}$ (Telecollaboration for Intercultural Language Acquisition) and $\mathrm{TeCoLa}^{3}$ (Pedagogical differentiation through telecollaboration and gaming for intercultural and content integrated language teaching) are making an effort to make this happen. While most research focuses on telecollaboration at the university level, efforts are being made to explore how it could be integrated into secondary language classroom contexts (Chen \& Yang, 2016; Jauregi, 2015; Ware \& Kessler, 2016). In recent years, scholars have also started to examine how students use the foreign language as lingua franca with non-native speakers in telecollaborative exchanges and positive results have been reported (Bueno Alastuey \& Kleban, 2016; Kohn \& Hoffstaedter, 2017).

2 TILA: Telecollaboration for Intercultural Language Acquisition, 2013-2015. www.tilaproject.eu

3 TeCoLa : Pedagogical differentiation through telecollaboration and gaming for intercultural and content integrated language teaching, 2016-2019. www.tecola.eu 
This manuscript describes our work, which by no means is complete nor final. I hope that these efforts, as well those of others in the field, will make an important contribution in helping to further understand the potential of online communication environments for intercultural language learning, since not only do they provide authentic opportunities to interact with native speakers of the target language but also contribute to help with their cultural awareness and ability to communicate more effectively. The world has evolved into a global society connected by the Internet, social media, and affordable and instantaneous communication where the classical method of foreign language instruction does not meet students' needs any more.

\subsection{References}

Abrams, Z.I. (2003). The effect of synchronous and asynchronous CMC on oral performance in German. Modern Language Journal, 87(2), 157-167.

American Council on the Teaching of Foreign Languages (ACTFL). (1999). Standards for foreign language learning (2nd ed.). Yonkers, New York: ACTFL.

Belz, J. A. (2003). Linguistic perspectives on the development of intercultural competence in telecollaboration. Language Learning and Technology, 7(2), 68-117.

Belz, J. A. (2007). The development of intercultural competence in online interaction. In R. O'Dowd (Ed.), On-line intercultural exchange: A practical introduction for foreign language teachers (pp. 163-215). Clevedon, UK: Multilingual Matters.

Belz, J. A., \& Kinginger, C. (2003). Discourse options and the development of pragmatic competence by classroom learners of German: The case of address forms. Language Learning, 53(4), 591-647.

Belz, J. A., \& Kinginger, C. (2002). The cross-linguistic development of address form use in telecollaborative language learning: Two case studies. Canadian Modern Language Review / Revue canadienne des langues vivantes, 59(2), 189-214.

Blake, R. (2000). Computer mediated communication: A window on L2 Spanish interlanguage. Language Learning \& Technology, 4(1), 120-136.

Blake, R. J. (2008). Brave new digital classrooms: Technology and foreign language learning. Georgetown, Washington D.C.: Georgetown University Press.

Blaurock, C. (2011). Skype ${ }^{\mathrm{TM}}$ : A portal into the $21^{\text {st }}$ century in a secondary Spanish classroom. Kent, Ohio: Kent State University College Press.

Bueno Alastuey, M. C., \& Kleban, M. (2016). Matching linguistic and pedagogical objectives in a telecollaboration project: A case study. Computer Assisted Language Learning, 29(1), 148-166.

Campbell, N. (2012). Promoting intercultural contact on campus: A project to connect and engage international and host students. Journal of Studies in International Education, 16(3), 205-227. 
Canto, S., \& Jauregi, K. (2010). Second Life as tool to enhance language learners' intercultural communicative competence. In ICT for Language Learning (Pixel ed.). Milan, Italy: Simoneli Editore.

Canto, S., De Graaff, R., \& Jauregi, K. (2014). Collaborative tasks for negotiation of intercultural meaning in virtual worlds and video-web communication. In M. Gonzalez-Lloret \& L. Ortega (Eds.), Technology and tasks: Exploring technology-mediated TBLT (pp. 183-212). Washington, DC: Georgetown University Press.

Chen, J.J., \& Yang, S.C. (2016). Promoting cross-cultural understanding and language use inresearch-oriented Internet-mediated intercultural exchange. Computer Assisted Language Learning, 29(2), 262-288.

Chun, D. M. (2011). Developing intercultural communicative competence through online exchanges. CALICO Journal, 28, 392-419.

Clark, G.B. (2009). These horses can fly! and other lessons from Second Life: The view from virtual hacienda. In R.Oxford \& J. Oxford (Eds.), Second language teaching and learning in the Net Generation(pp. 153172). Honolulu: University of Hawaii, National Foreign Language Resource Center.

Coleman, D. W. (2002). Guest editorial: Simulation and computer-assisted language learning. Simulation \& Gaming, 33(2), 179-180.

Cooke-Plagwitz, J. (2008). New directions in CALL: An objective introduction to Second Life. CALICO Journal, 25(3), 547-557

Cooke-Plagwitz, J. (2009). A new language for the Net Generation: Why Second Life works for the Net Generation. In R.Oxford \& J. Oxford (Eds.), Second language teaching and learning in the Net Generation(pp. 173180). Honolulu: University of Hawaii, National Foreign Language Resource Center.

Council of Europe. (2001). (CEFR) Common European Framework of Reference for Languages: Learning, teaching, assessment. Cambridge: CUP / Council of Europe.

Crookall, D. (2002). Editorial: Simulation in language learning. Simulation \& Gaming, 33(3), 273-274.

Csizér, K. \& Dörnyei, Z. (2005). Language learners' motivational profiles and their motivated learning behaviour. Language Learning, 55, 613-659.

Downey, S., Mohler, J., Morris, J., \& Sánchez, R. (2012). Learner perceptions and recall of small group discussions within $2 \mathrm{D}$ and $3 \mathrm{D}$ collaborative environments. Australasian Journal of Educational Technology, 28(8), 1405-1419.

Dede, C. (2005). Planning for neomillennial learning styles. EDUCAUSE Quarterly, 1, 7-12.

Dieterle, E., \& Clarke, J. (2008). Multi-user virtual environments for teaching and learning. In M. Pagani (Ed.), Encyclopedia of multimedia technology and networking (pp. 1033 - 1041). Hershey, PA: Idea Group, Inc.

Dooly, M. (Ed.). (2008). Telecollaborative language learning: A guidebook to moderating intercultrual collaboration online. Bern: Peter Lang.

Dooly, M. (2010). Teacher 2.0. In S. Guth \& F. Helm (Eds.), Telecollaboration 2.0: Language and intercultural learning in the 21st century (pp. 277-304). Bern: Peter Lang. 
Dörnyei, Z. (2001). Motivational strategies in the language classroom. Cambridge: Cambridge University Press.

Doughty, C. J., \& Long, M. H. (2003). Optimal psycholinguistic environments for distance foreign language learning. Language Learning \& Technology, $7(3), 50-80$.

Ellis, R. (1999). Learning a second language through interaction. Amsterdam/ Philadelphia: John Benjamins Publishing Company.

Firth, A., \& Wagner, J. (2007). Second/foreign language learning as a social accomplishment: Elaborations on a reconceptualized SLA. Modern Language Journal, 91, 800-818.

Fitzgerald, H. (2003). How different are we? Spoken discourse in intercultural communication. Clevedon: Multilingual Matters.

Furstenberg, G., Levet, S., English, K., \& Maillet, K. (2001). Giving a virtual voice to the silent language of culture: The CULTURA project. Language Learning \& Technology, 5(1), 55-102.

Gilmore, A. (2007). Authentic materials and authenticity in foreign language learning. Language Teaching, 40(2), 97-118.

González-Lloret, M., \& Ortega, L. (2014). Technology-mediated TBLT: researching technology and tasks. Amsterdam: John Benjamins.

Hampel, R. (2014). Making meaning online: Computer-mediated communication for language learning. In A. Peti-Stantić \& M. M. Stanojević (Eds.), Proceedings of the CALS Conference 2012 (pp. 89-106). Frankfurt: Peter Lang.

Hauck, M., \& Warnecke, S. (2013). Materials design in CALL: Social presence in online environments. In T. Michael, H. Reinders, \& M. Warschauer (Eds.), Contemporary computer-assisted language learning (pp. 95-115). London, UK: Bloomsbury.

Helm, F. (2009). Language and culture in an online context: what can learner diaries tell us about intercultural competence? Language and Intercultural Communication, 9(2), 91-104.

Jauregi Ondarra, M.K. (2015). Integrating telecollaboration for intercultural language acquisition at secondary education - lessons learned. In F. Helm, L. Bradley, M. Guarda \& S. Thouësny (Eds.), Critical CALL. Proceedings of the 2015 EUROCALL Conference, Padova, Italy (pp. 268-273). Research-publishing.net.

Jauregi, K. \& Bañados, E. (2008). Virtual interaction through video-web communication: A step towards enriching and internationalizing language learning programs. ReCALL Journal, 20(2), 183-207.

Jauregi, K., Canto, S., De Graaff, R., Koenraad, T., \& Moonen, M. (2011). Verbal interaction in Second Life: Towards a pedagogic framework for task design. Computer Assisted Language Learning, 24(1), 77-101.

Jauregi, K., Graaff, de R., Bergh, van den H., \& Kriz, M. (2012). Native non-native speaker interactions through video-web communication, a clue for enhancing motivation. Computer Assisted Language Learning Journal, 25(1), 1-19.

Jauregi Ondarra, M.K. \& Melchor-Couto, S. (2018). Successful telecollaboration exchanges in primary and secondary education? What are the challenges? . In P. Taalas, J. Jalkanen, L. Bradley \& S. Thouësny (Eds.), Future-proof 
CALL - language learning as exploration and encounters (pp. 112-117). Research-publishing.net.

Jeong, N.S. (2011). The effects of task type and group structure on meaning negotiation in synchronous computer-mediated communication. Selected Proceedings of the 2009 Second Language Research Forum. Somerville, MA: Cascadilla Proceedings Project.

Keller-Lally, A. M. (2006). Effect of task type and group size on foreign language learner output in synchronous computer mediated communication (Doctoral dissertation). Austin, University of Texas.

Kohn, K., \& Hoffstaedter, P. (2017). Learner agency and non-native speaker identity in pedagogical lingua franca conversations: Insights from intercultural telecollaboration in foreign language education. Computer Assisted Language Learning, 30, 1-17.

Krashen, S. (2003). Explorations in language acquisition and use. Portsmouth, UK: Heinemann.

Kurata, N. (2011). Foreign language learning and use: Interaction in informal social networks. London: Continuum International Publishing Group.

Lantolf, J., \& Thorne, S. (2006). Sociocultural theory and the genesis of second language development. Oxford: Oxford University Press.

Liaw, M.L., \& Bunn-Le Master, S. (2010). Understanding telecollaboration through an analysis of intercultural discourse. Computer Assisted Language Learning, 23(1), 21-40.

MacDonald, M.N., Badger, R., \& Dasli, M. (2006). Authenticity, culture and language learning. Language and Intercultural Communication, 6(3\&4), 250-326.

Mishan, F. (2005). Authenticity in language learning, Bristol: Intellect Books.

Müller-Hartmann, A. (2007). Teacher role in telecollaboration: Setting up and managing exchanges. In R. O'Dowd (Ed.), Online intercultural exchange. An introduction for foreign language teachers (pp. 167-193). Clevedon, UK: Multilingual Matters.

Müller-Hartmann, A., \& Schocker-v. Ditfurth, M. (2013). Developing teachers' intercultural communicative competences for task-supported language classrooms. Fremdsprachen Lehren und Lernen, 42(2), 85-98.

O'Dowd, R. (2003). Understanding the "other side": Intercultural learning in a Spanish-English email exchange. Language Learning \& Technology, 7(2), 118-144.

O'Dowd, R. (2006). Telecollaboration and the development of intercultural communicative competence. Munich, Germany: Langenscheidt-Longman.

O'Dowd, R. (2010). Online foreign language interaction: Moving from the periphery to the core of foreign language education? Language Teaching, 44(3), 368380 .

O'Dowd, R., \& Eberbach, K. (2004). Guides on the side? Tasks and challenges for teachers in telecollaborative projects. ReCALL,16(1), 129-143.

O'Dowd, R., \& Ware, P. (2009). Critical issues in telecollaborative task design. Computer Assisted Language Learning, 22(2), 173-188.

Peterson, M. (2016). Virtual worlds and language learning: An analysis of research. In F. Farr \& L. Murray (Eds.), The Routledge handbook of language learning and technology (pp. 308-319). New York, NY: Routledge. 
Pica, T., \& Doughty, C.J. (1985). Input and interaction in the communicative language classroom: A comparison of teacher-fronted and group activities. In S.M. Gass \& C. Madden (Eds.), Input in second language acquisition (pp. 115-132). Rowley, MA: Newbury House Publishers.

Pinner, R. S. (2012). Examining authenticity and motivation from an international perspective. JACET ESP Annual Report, 14, 26 -35.

Prensky, M. (2005a). Engage me or enrage me: What today's learners demand. EDUCAUSE Review, 40(5), 61-64.

Prensky, M. (2005b). Listen to the natives. Educational Leadership, 63(4), 8-13.

Purushotma, R. (2005). Commentary: You're not studying, you're just ... Language Learning \& Technology, 9(1), 80-96.

Robinson, P. (2005). Aptitude and second language acquisition. Annual Review of Applied Linguistics, 25, 45-73.

Sauro, S. (2011). SCMC for SLA: A research synthesis. CALICO Journal, 28(2), 369-391.

Schenker, T. (2012). Intercultural competence and cultural learning through telecollaboration. CALICO Journal, 29(3), 449-470.

Slagter, P. J. (2000). Learning by instructing (Doctoral dissertation). Utrecht: University of Utrecht.

Smith, B. (2003). Computer-mediated negotiated interaction: an expanded model. Modern Language Journal, 87(1), 38-57.

Steinkuehler, C. (2006). Massively multiplayer online videogaming as participation in a discourse. Mind, Culture \& Activity, 13(1), 38-52.

Swain, M. (2000). The output hypothesis and beyond: Mediating acquisition through collaborative dialogue. In J.P.Lantolf(Ed.), Sociocultural theory and second language learning (pp. 97-114). Oxford: Oxford University Press.

Sykes, J., Oskoz, A., \& Thorne, S. (2008). Web 2.0, synthetic immersive environments, and mobile resources for language education. CALICO Journal 25(3), 528-546.

Thorne, K. (2003). Blended learning: how to integrate online and traditional learning. New Jersey: Kogan Page.

Thorne, S. L., \& Black, R. (2008). Language and literacy development in computermediated contexts and communities. Annual Review of Applied Linguistics, 27, 133-160.

Ushioda, E. 2001. Language learning at university exploring the role of motivational thinking. In Z. Dörnyei \& R. Schmidt (Eds.), Motivation and second language acquisition (pp. 91-124). Honolulu: UH SLT\&CC.

Van den Branden, K. (2006). Task-based language teaching in a nutshell. In K. Branden (Ed.), Task-based language education: From theory to practice (pp. 1-16). Cambridge: Cambridge University Press.

Vygotsky, L. S. (1978). Mind in Society. Cambridge, MA: Harvard University Press.

Ware, P., \& Kessler, G. (2016). Telecollaboration in the secondary language classroom: case study of adolescent interaction and pedagogical integration. Computer Assisted Language Learning, 29, 427-450.

Warschauer, M. (1997). Computer-mediated collaborative learning: Theory and practice. Modern Language Journal, 81(4), 470-481. 
Woo, Y., Herrington, J., Agostino, S., \& Reeves, T.C. (2007) Implementing authentic tasks in web-based learning environments. Educause Quarterly, 3, 36-43.

Yilmaz, Y. (2011). Task effects on focus on form in synchronous computermediated communication. The Modern Language Journal, 95, 115-32.

Zhu, Y., Gareis, E., O'Keefe Bazzoni, J., \& Rolland, D. (2005). A collaborative online project between New Zealand and New York. Business Communication Quarterly, 68, 81-96. 



\section{Samenvatting}

\section{INTEGRATIE VAN VIRTUELE UITWISSELINGEN IN PROGRAMMA'S VOOR VREEMDETALENONDERWIJS: DE CASUS VAN VIDEOCOMMUNICATIE EN VIRTUELE WERELDEN}

Als taal een sociale activiteit is om aan deel te nemen (Kramsch, 1994), moet taalonderwijs niet alleen gericht zijn op beheersing van de vormaspecten en regels van een taal. Van oudsher wordt taal gezien als een code die bestaat uit woorden die door regels met elkaar zijn verbonden. Deze benadering van taalonderwijs vereist slechts het leren van vocabulaire en grammaticaregels. Bovendien is in deze (beperkte) zienswijze de verwerving van grammatica en vocabulaire het hoofddoel van taalonderwijs. Taal wordt hier niet als een communicatieve realiteit gezien, maar simpelweg als een geheugenoefening.

In het tijdperk van grammaticaonderwijs, toen de nadruk lag op structurele patronen, speelde taal zelf de hoofdrol in de klaslokalen van vreemde talen. Correctheid van vormaspecten was het belangrijkste en vrijwel enige doel van vreemdetalenonderwijs.

In de wereld van vandaag worden onderwijsprogramma's afgestemd op de student en diens plaats in de maatschappij, waarbij adequaat gebruik van de taal onontbeerlijk is voor meer autonomie, verantwoordelijkheid en samenwerking onder studenten (Slager, 2000). Als onderwijzers hebben wij als doel om taalleerders effectief te leren communiceren, niet alleen binnen maar vooral ook buiten het klaslokaal. Daartoe moeten we hen adequate leermogelijkheden bieden.

Onderwijs moet meer student- en communicatiegericht zijn. Op dit moment ligt de focus echter op taal (als slechts een verzameling kennis). Docentgeleide instructie waarbij de antwoorden van studenten worden gestuurd en hun output wordt beperkt, zou plaats moeten maken voor een leeromgeving met meer interactie tussen studenten (Slagter, 2000), waarin betekenisvolle opdrachten en motivatie van studenten van het grootste belang zijn (Van den Branden, 2006; Dörnyei, 2001, 2002). We moeten studenten betrekken bij een actief leerproces en focussen op wat ze met de taal kunnen doen in plaats van wat ze erover weten. Taal is een sociale activiteit waaraan mensen niet alleen deelnemen voor het overbrengen en interpreteren van betekenissen, maar ook voor sociale en interpersoonlijke relaties (Kramsch, 1993). Om deze communicatie mogelijk te maken moeten vreemdetaalleerders kennis en begrip opdoen van de cultuur waarin een taal wordt gesproken (Hall, 2004).

Om effectief te kunnen communiceren moeten taalleerders zich bewust zijn van de verschillen en overeenkomsten tussen hun eigen cultuur (Byram, 1997) en die van de taal die ze leren (Alptekin, 2002; Byram, 2009). Cultuur en communicatie zijn onlosmakelijk met elkaar verbonden, omdat cultuur communicatie vormt en communicatie op haar beurt cultuur creëert en vormgeeft (Hall, 1959). Daarom wordt de term 'languaculture' (Agar, 1994) geëntroduceerd, die de onvermijdelijke verbinding tussen taal en cultuur definieert. Deze term 
illustreert de nauwe relatie tussen taal en cultuur, die worden beschouwd als niet van elkaar te onderscheiden concepten.

Omdat taalleerders hun taalvaardigheid ontwikkelen door sociale interacties (Vygotsky, 1978; Warschauer, 1997; Ellis, 1999; Firth \& Wagner, 2007; Lantolf \& Thorne, 2006; Blaurock, 2011; Kurata, 2011), moeten we hen mogelijkheden bieden voor betekenisvolle interactie. Dit betekent dat we adequate opdrachten moeten ontwikkelen waarbij betekenisvolle communicatie tussen de deelnemers vereist is (Jauregi \& De Graaff, 2009). Conventioneel vreemdetalenonderwijs wordt gekenmerkt door de afwezigheid van betekenisvolle interactie in de doeltaal. In de meeste gevallen studeren onze taalleerders in een institutionele setting met minder interactie in de vreemde taal dan we zouden willen. We verwachten deze interactie van hen omdat het doel van het leren van een vreemde taal is om adequaat te kunnen communiceren in verschillende contexten. Helaas leren ze niet hoe ze dit moeten doen.

De opkomst van internettechnologie geeft docenten en studenten vele mogelijkheden om in contact te komen en samen te werken met sprekers van andere talen over de hele wereld, en maakt directe communicatie tussen vreemdetaalleerders (en moedertaalsprekers) beter mogelijk dan ooit tevoren. Deze online interculturele uitwisselingen worden gezien als ideale omgevingen om te leren over taal en cultuur omdat ze handige, authentieke, directe en snelle toegang geven tot moedertaalsprekers en hun culturen (Kramsch \& Thorne, 2002; Sykes, Oskoz, \& Thorne, 2008).

In dit proefschrift wordt onderzocht wat de effecten zijn van computergemedieerde communicatie (CMC) via online samenwerking met moedertaalsprekers, op het leren van een vreemde taal. We hebben ervoor gekozen om te kijken naar de rol van opdrachten en de omgeving en het effect daarvan op de spreekvaardigheid van de studenten en hun begrip van doelculturen. We vermoedden dat niet alleen de relevantie van betekenisvolle opdrachten in combinatie met de technologische omgeving, maar ook een internationale setting met moedertaalsprekers zou helpen de verbale interculturele communicatievaardigheden te verbeteren. We wilden weten welke eigenschappen van deze online uitwisselingen de interactie en het leren bevorderen. Vervolgens is onderzocht of deze computer-gemedieerde interventies van enige toegevoegde waarde zijn ten opzichte van het meer conventionele onderwijs, of dat ze eerder een extra belasting zijn voor docenten. Voortbouwend op de resultaten van eerder onderzoek (Jauregi \& Bañados, 2008; Canto \& Jauregi, 2010; Jauregi, Canto, De Graaff, Koenraad, \& Moonen, 2011) en data van het NIFLAR-project (Networked Interaction for Foreign Language Acquisition and Research), ontwikkelden en testten we een reeks opdrachten die zouden worden uitgevoerd op twee verschillende virtuele platformen (de virtuele 3D-wereld van Second Life en een videocommunicatie-tool) en in een conventionele klaslokaalsetting. Deze opdrachten, verwerkt in het onderwijsprogramma van studenten, moesten wekelijks worden uitgevoerd en er zijn herhaalde metingen gedaan.

Gebaseerd op de aanname dat taalleerders hun taalvaardigheid ontwikkelen door sociale interacties (Vygotsky, 1978; Warschauer, 1997; Ellis, 1999; Firth \& Wagner, 2007; Lantolf \& Thorne, 2006; Blaurock, 2011; Kurata, 2011), moeten 
adequate opdrachten worden ontwikkeld binnen de communicatieve mogelijkheden van de omgevingen die worden gebruikt (Hampel, 2014). Het belang van opdrachtontwikkeling wordt eerst verkend in hoofdstuk 2, waar we op basis van een eerste ervaring konden bekijken of de specifieke mogelijkheden van de virtuele omgeving adequaat in te zetten waren ter bevordering van interactie.

In dit hoofdstuk diende een kleinschalige studie als ontdekkingsfase voor het precies afstemmen van taalleeropdrachten op de specifieke mogelijkheden van onderwijsomgevingen voor communicatie, zoals virtuele 3D-werelden. We stelden een schema op met richtlijnen voor de uitwerking van interactie-opdrachten die zouden worden uitgevoerd in synchrone e-learning-omgevingen. Vervolgens gebruikten we deze criteria in Second Life, met als doel de specifieke mogelijkheden van de virtuele omgeving in interactieprocessen te benutten. We ontdekten dat Second Life-specifieke opdrachten waarbij studenten werden gestimuleerd om samen virtuele werelden te ontdekken en tegelijkertijd informatie uit te wisselen, zowel momenten van dynamische communicatie als behoorlijk lange stiltes uitlokten. Andere opdrachten die minder context-specifiek waren voor Second Life, lokten echter meer communicatie uit. Op basis hiervan concludeerden we dat de richtlijnen voor de ontwikkeling van opdrachten verder moesten worden aangepast op situaties in virtuele 3D-werelden. Veelvuldige mondelinge interactie moest noodzakelijk zijn voor het uitvoeren van de opdracht en de mogelijkheden van de virtuele wereld moesten zoveel mogelijk worden benut.

In hoofdstuk 3 wordt dit uitgebreid naar videocommunicatie. We bespreken hier meer gedetailleerd een aantal methodologische principes voor het ontwikkelen van opdrachten in multimedia-omgevingen, in relatie tot de voor de studie ontworpen interculturele online opdrachten. In dit hoofdstuk wordt verkend hoe de ontwikkeling van interculturele competentie gestimuleerd kan worden met gebruik van moderne technologieën zoals virtuele werelden en videocommunicatie. We dragen bewijs aan voor de onderhandeling over interculturele betekenis tussen taalleerders en moedertaalsprekers als gesprekspartners, om te begrijpen hoe een dergelijke onderhandeling over taal- en interculturele betekenis plaatsvindt en het beste kan worden gestimuleerd bij opdrachten in de twee technologische omgevingen. De resultaten lieten veelvoorkomende, duidelijke gevallen van interculturele onderhandeling over betekenis zien in beide omgevingen. Deelname aan opdrachten in virtuele werelden en interactie via videocommunicatie maakten deze studenten en hun gesprekspartners bewuster van interculturele verschillen en overeenkomsten, doordat deze opdrachten zodanig waren ontwikkeld dat zowel taalleerders als moedertaalsprekers moesten reflecteren op hun eigen cultuur en die van hun gesprekspartner. Zij moesten verschillen, gelijkenissen en misverstanden bespreken, uitleggen en beter leren begrijpen (Belz \& Kininger, 2002, 2003; Blake, 2008; Furstenberg, Levet, English, \& Maillet, 2001; O’Dowd \& Ware, 2009; Thorne, 2003; Zhu, Gareis, O'Keefe Bazzoni, \& Rolland, 2005). De resultaten in dit hoofdstuk lijken de voordelige uitkomsten van digitale uitwisseling te bevestigen die wetenschappers hebben beschreven en die O'Dowd en Eberbach (2004) samenvatten: de online interculturele uitwisseling droeg bij aan verbetering van de spreekvaardigheid (Blake, 2000; Abrams, 2003) en aan begrip van de doelcultuur 
(Belz, 2003, 2007; Chun, 2011; Helm, 2009; O’Dowd, 2003, 2006; Liaw \& Master, 2010; Schenker, 2012).

De resultaten zoals beschreven in hoofdstuk 2 en 3 tonen aan hoe belangrijk het is dat opdrachten motiverend zijn. Motivatie is essentieel om studenten te bewegen tot een mentale investering in (1) het uitvoeren van de opdracht en leren door te doen, (2) het begrijpen van de input en (3) het produceren van relevante output (van den Branden, 2017). Authenticiteit wordt gezien als een factor die positief effect heeft op motivatie voor het leren van een taal (Csizér \& Dörnyei, 2005; Dörnyei, 2001; Gilmore, 2007; Jauregi, De Graaff, Van den Bergh, \& Kriz, 2012; MacDonald, Badger, \& Dasli, 2006; Mishan, 2005; Pinner, 2012; Ushioda, 2001; Woo, Herrington, Agostino, \& Reeves, 2007) en daarom zou het gevoel dat een opdracht authentiek is een cruciale factor kunnen zijn. Deze authenticiteit kan worden bereikt door het soort opdracht dat moet worden uitgevoerd, maar ook door het medium waarin de opdracht plaatsvindt. Een opdracht die zich bijvoorbeeld afspeelt in een hotelkamer in Second Life neemt de studenten niet mee naar een echte kamer in een echt hotel, maar geeft hen wel het gevoel dat ze daar zijn doordat ze zich in een virtuele hotelkamer bevinden. De online omgevingen die in deze studie zijn gebruikt, met name de 3D-wereld van Second Life, maken het gemakkelijker om in de wereld van de opdracht te stappen, waarin studenten invloed krijgen op hoe de opdracht verloopt. Als een opdracht bijvoorbeeld plaatsvindt op een virtueel strand, zijn er andere objecten aanwezig waarmee interactie zou kunnen plaatsvinden (een boot, een strandstoel, een buitendouche, etc.) waardoor het een levensechte ervaring wordt met verschillende uitkomsten die afhangen van de deelnemers. Waar studenten zich bij conventionele lesmethoden zelf een voorstelling moeten maken van situaties of objecten, kunnen deze situaties met behulp van online technologie zichtbaar worden gemaakt op het scherm, waardoor een betekenisvolle context wordt gecreëerd waarin het leren van een taal kan worden ingebed.

De resultaten van deze studie zijn in lijn met eerder onderzoek waaruit bleek dat technologie-gemedieerde opdrachten authentiek en studentgericht moeten zijn, moeten focussen op betekenis in plaats van grammaticale vormen, en gebaseerd moeten zijn op echte taalgebruikprocessen (González-Lloret \& Ortega, 2014). Als ons doel is dat studenten de doeltaal voor echte communicatie leren gebruiken, vormen opdrachten een van de belangrijkste elementen van hun leerproces. In de context van echte communicatie moeten lesopdrachten gerelateerd zijn aan wat de studenten in de echte wereld met de doeltaal moeten kunnen, en hen uitnodigen zich primair als taalgebruiker te gedragen. Opdrachten moeten het soort communicatief gedrag uitlokken dat natuurlijkerwijs ontstaat bij het uitvoeren van taalopdrachten in het echte leven (van den Branden, 2006).

Met de analyse in hoofdstuk 4 is onderzocht of de integratie van interculturele interactie door videocommunicatie en virtuele werelden in onderwijsprogramma's voor vreemde talen een last is voor docenten, of juist van toegevoegde waarde is ten opzichte van conventioneler onderwijs. In dit hoofdstuk onderzochten we het effect van synchrone sociale interactie met moedertaalsprekers op de ontwikkeling van de spreekvaardigheid van vreemde-taalleerders. In de studie werd verbetering van de spreekvaardigheid van experimentele groepen 
(videocommunicatie en virtuele werelden) vergeleken met die van een controlegroep (klaslokaal) door middel van mondelinge pre- en posttests. De resultaten suggereerden dat deelnemers in de videocommunicatie- en de Second Life-groep gemiddeld meer verbetering van de spreekvaardigheid lieten zien dan studenten die niet hadden deelgenomen aan dit soort interacties. De verbetering leek echter af te hangen van het initiële vaardigheidsniveau van de taalleerders. Studenten met een lager niveau van spreekvaardigheid leken meer van de twee digitale omstandigheden te profiteren dan de studenten met een hoger niveau. We waren ons ervan bewust dat de effecten van leercontext, pedagogische interventie en cognitieve processen bij de interactie werden beïnvloed door de vaardigheidspatronen die studenten meebrachten (Robinson, 2005). In andere woorden, voor sommige studenten is de ene situatie of techniek geschikter dan de andere. We concludeerden dat de synchrone leeromgevingen in combinatie met effectieve interactie-opdrachten en de mogelijkheid tot betekenisvolle interactie met ervaren medestudenten niet alleen bijdroeg aan het significante verschil in verbetering van de spreekvaardigheid tussen de experimentele groepen (deelname aan netwerkinteracties met ervaren medestudenten via videocommunicatie en virtuele werelden) en de controlegroep (opdrachten in een klaslokaal, face to face met medestudenten), maar ook aan verbetering van interculturele leerervaringen.

In hoofdstuk 4 werd het positieve effect besproken van deze synchrone sociale interacties met moedertaalsprekers op de ontwikkeling van de spreekvaardigheid van studenten. In hoofdstuk 5 werden vervolgens de leermogelijkheden verder onderzocht die zich voordoen tijdens deze online interculturele uitwisselingen, door twee experimentele groepen te vergelijken met de controlegroep. We toonden aan dat de twee experimentele groepen beter presteerden op het gebied van communicatieve vaardigheden dan de controlegroep. De interactie met moedertaalsprekers via videocommunicatie en Second Life had daarnaast een positief effect op de ontwikkeling van de interculturele competentie van vreemdetaalleerders.

De netwerkinteracties maakten uitgebreide blootstelling aan de taal en levensechte communicatieoefeningen mogelijk voor taalleerders (Coleman, 2002; Crookall, 2002; Purushotma, 2005), voornamelijk wanneer er medestudenten met een hoger niveau deelnamen aan de interactie voor de opdracht. De analyse van de interacties in dit hoofdstuk toonde ook aan dat de videocommunicatie- en Second Life-omgevingen meer mogelijkheden boden voor onderhandeling over taal- en interculturele betekenis. Daarnaast werden andere leermogelijkheden geobserveerd, bijvoorbeeld dat het realistische karakter van de omgevingen authentieke leeromstandigheden opleverde die moeilijk zijn na te bootsen in conventionele klaslokaalsituaties (Dieterle \& Clarke, 2008), en dat gebruikers met een grotere variëteit aan normen voor sociale interactie in aanraking komen en ermee kunnen experimenteren (Steinkuehler, 2006). We vermoeden dat de emotionele connecties die tijdens het project werden gevormd (door participanten benoemd in interviews) studenten kunnen motiveren om te blijven oefenen en hun relaties met anderen succesvol te onderhouden, zowel bij samenwerking in de virtuele wereld als in andere contexten (Sykes, Oskoz, \& Thorne, 2008). Deelname aan netwerkinteracties leek in hoge mate motivatie en interesse op te wekken. Deze observatie ondersteunt 
onderzoek dat aantoonde dat de implementatie van interactieve sessies met moedertaalsprekers effect had op de motivatie van vreemde-taalleerders, in het bijzonder bij studenten met een lager vaardigheidsniveau (Jauregi et al., 2011).

De ervaringsgerichte, realtime en multimodale eigenschappen van sommige online omgevingen, zoals die van virtuele 3D-werelden zoals Second Life, sluiten goed aan bij de interesses en leerstijlen van onze studenten, die digital natives zijn (Cooke-Plagwitz, 2009). Het gevoel van telepresentie (er zijn) en co-presentie (er samen zijn) versterkt door avatars maakt het leren ook speelser en lijkt op activiteiten in het echte leven (Cooke-Plagwitz, 2008). In hoofdstuk 6 bekeken we hoe onderdompeling met behulp van avatars ervaringsgericht leren en creativiteit verder stimuleert, betrokkenheid en motivatie verhoogt, en aanmoedigt tot meer risico's nemen. Hiermee onderscheiden deze virtuele 3D-werelden zich van andere, op tekst gebaseerde digitale platforms (Dawney, Mohler, Morris, \& Sanchez, 2012; González-Lloret \& Ortega, 2014; Peterson, 2016). In deze virtuele 3D-werelden kunnen deelnemers scenario's uit het echte leven simuleren en hun fantasie en creativiteit gebruiken op levendige sociale platforms. Taalleerders kunnen eveneens opdrachten uit het echte leven simuleren door zich onder te dompelen in een doeltaalomgeving. Ze kunnen in Second Life gemakkelijk communiceren met andere sprekers van over de hele wereld via getypte tekst of voicechat en zich onderdompelen in realistische scenario's zonder daarvoor fysiek te hoeven reizen of te betalen (Canto, De Graaff, \& Jauregi, 2014; Clark, 2009).

Digitale technologie verandert leer- en onderwijsstijlen, en de conventionele vormgeving van taalcursussen sluit niet meer aan bij de leerbehoeften en interesses van onze ervaringsgerichte studenten, die de voorkeur geven aan gepersonaliseerd leren in samenwerking met anderen (Dede, 2005). Daarnaast moeten we de overtuiging loslaten dat het voor het leren van een vreemde taal genoeg is om de grammaticaregels correct te leren, ze snel te kunnen toepassen en hard te werken. Het gebruiken van een vreemde taal is namelijk meer dan oefenen met één duidelijke regel in een geselecteerde context (Slagter, 2000). Aangezien we de aanwezigheid van technologie in onze samenleving en het leven van onze studenten niet kunnen negeren, moeten we als docenten proberen de kloof te overbruggen tussen de conventionele onderwijsmethoden (met papieren materialen of statische interfaces van onderwijsmanagementsystemen zoals Blackboard) en de vele onderwijsmogelijkheden die verder gaan dan de vier muren van het klaslokaal, bijvoorbeeld met digitale samenwerkingsverbanden of virtuele games (Prensky, 2005a, 2005b). Onderdompeling in een simulatie en realtime samenwerking bieden instructiemogelijkheden voor docenten om opdrachten uit het echte leven te verwerken in vreemdetalenonderwijs, op manieren die lastig zouden zijn in een conventioneel klaslokaal (González-Lloret \& Ortega, 2014). In deze authentieke situaties kunnen deelnemers de taalinput verwerken (Krashen, 2003) en tegelijkertijd onderhandelingsstrategieën gebruiken om begrijpelijke output te produceren (Swain, 2000). Bovendien krijgen deelnemers door interactie met moedertaalsprekers van de doeltaal de mogelijkheid om zowel hun intercultureel bewustzijn als hun taalvaardigheid te ontwikkelen.

Hoewel gesteld wordt dat betere taalvaardigheid leidt tot een scheve machtsverhouding waardoor niet-moedertaalsprekers zich geïntimideerd kunnen 
voelen (FitzGerald, 2003), waren de opdrachten voor het huidige onderzoek gebaseerd op aspecten uit beide culturen, waardoor de taalleerders zich realiseerden dat de moedertaalsprekers van de doeltaal geïnteresseerd waren in hun cultuur. Een dergelijke balans in hoe studenten van elkaar leren geeft taalleerders een sterkere positie en daardoor een gevoel van gelijkwaardigheid en meer zelfvertrouwen (Campbell, 2012).

Voor onderwijsinstellingen biedt de integratie van virtuele uitwisselingen in vreemdetalenonderwijs voordelen zoals verder kijken dan het klaslokaal, meer mogelijkheden voor projectmatig werk en een goedkope vorm van internationalisering. Vreemde-taalleerders hebben op hun beurt voordeel van authentieke interactie in realistische socio-culturele contexten, met meer mogelijkheden voor onderhandeling over taal- en interculturele betekenis en actieve deelname, meer zelfvertrouwen, minder angst en waardevolle mogelijkheden voor het verbeteren van hun cultureel bewustzijn. Hoewel deze digitale uitwisselingen helpen de afstand tussen studenten en de doelcultuur te overbruggen, kunnen docenten voor verschillende uitdagingen komen te staan wanneer ze deze tools willen introduceren. Hierbij valt te denken aan het vinden van een samenwerkingspartner, technische problemen met de kwaliteit van audio, video en de verbinding, tijdmanagementproblemen (tijdzones, academische kalenders) en het gebruik van nieuwe, innovatieve combinaties van onderwijsmethoden.

We begonnen met dit proefschrift een ontdekkingsreis in de overtuiging dat online communicatieomgevingen zoals de virtuele 3D-wereld van Second Life of videocommunicatie-tools het begrip van de doelcultuur en de spreekvaardigheid van studenten konden helpen verbeteren, door vreemde-taalleerders en moedertaalsprekers van de doeltaal op geografisch ver uit elkaar gelegen plaatsen, bij elkaar te brengen. Het is echter naïef om te hopen dat studenten vanzelf zullen gaan communiceren en hun taalvaardigheid zullen verbeteren als ze simpelweg toegang krijgen tot deze communicatieomgevingen. Dit wijst op het belang van onderzoek naar effectievere richtlijnen voor het vormgeven van opdrachten (Hauck \& Warnecke, 2013) en volledig begrip van verschillende digitale uitwisseling constructies in context, zodat meer onderzoek kan worden gedaan naar de soorten opdrachten, de eigenschappen ervan en onder welke omstandigheden ze het meest effectief zijn in het uitlokken van de interacties waarvan men denkt dat ze bijdragen aan het interculturele taalleerproces (Blake, 2000; Jeong, 2011; Keller-Lally, 2006; Sauro, 2011; Smith, 2003; Yilmaz, 2011).

In dit stuk beschrijven we ons werk, dat op geen manier volledig of afgerond is. Ik hoop dat deze inspanningen, samen met die van anderen in het vakgebied, een belangrijke bijdrage zullen leveren aan begrip van de potentie van online communicatieomgevingen voor intercultureel taalonderwijs. Deze omgevingen bieden namelijk niet alleen mogelijkheden voor authentieke interactie met moedertaalsprekers van de doeltaal, maar dragen ook bij aan meer cultureel bewustzijn en effectievere communicatievaardigheden voor studenten. De wereld is een mondiale samenleving geworden die verbonden is door het internet, sociale media en betaalbare directe communicatie, waarin de klassieke methode voor vreemdetalenonderwijs niet meer in de behoeften van studenten voorziet. 



\section{Acknowledgements}

Carrying out this research project and writing this thesis was tough at times and I would not have been able to complete it without the help of many people along the way. What follows below is an attempt to put my gratitude towards all the people who helped me: this dissertation would not have existed without the help of all of them.

I would first and foremost like to thank my supervisors Huub van den Bergh and Kristi Jauregi. Without Kristi this dissertation wouldn't have seen the light. She gave me the opportunity to participate in all her projects, invited me to write and encouraged me to embark in this journey to write this thesis. Kristi, thanks for trusting me and introducing me to the telecollaboration world. Huub made me see that what was obvious for me was not for everybody. He insisted that I had to make others see what I was seeing. My one line ideas had to become paragraphs, and paragraphs with short sentences, none of those Spanish long winded ten line sentences. If it wasn't for Huub my conclusion chapter would have been: "Telecollaboration. Do it, it works." I am indebted to both of them, without their guidance and support I would probably still be staring at a blank computer screen. I valued their incredibly detailed feedback and critical questions as well as practical assistance. Huub, thank you for your endless optimism ("appeltje eitje!", for you everything was the easiest thing in the world), for your accurate comments and patience. Kristi, thanks for your professionalism, for your exhaustive reviews and your constructive comments and, not to forget, for the support you have given me throughout this process, particularly when times were tough. You have been an example of strength, your energy and enthusiasm are contagious.

Many other people have contributed in one way or another to the publication of this research. I would also like to thank them here for their help. This thesis was written in the plural we and without the contribution provided by all the co-authors of the articles and book chapters this thesis would have not developed into the book that lies before you. Therefore, as well as Kristi and Huub, I wish to thank Rick de Graaff, Ton Koenraad and Machteld Moonen. The data collected for this research would not have been possible without the collaboration of the University of Valencia (José Ramón Gómez Molina and his team in the Teaching Spanish as a Foreign Language MA programme) and the BA Spaanse Taal en Cultuur students at Utrecht University. I thank all the participants in my experiments and also the technical support we received (Lex Hermans). I would also like to acknowledge Florianne Sollie, for her professional and efficient translating services. The colleagues I met through the different projects linked to this research (NIFLAR, TILA, TeCoLa, EUROVERSITY) provided endless inspiration, advice, sympathy and encouragement in my journey. It has been a privilege to work with so many inspiring people.

My gratitude is also extended to my work colleagues at the Spanish department at Utrecht University, and in particular to Helena Houvenaghel for her encouragement. Going back in time, I would also like to take this opportunity to thank Peter Slagter for sparking my interest in language teaching and doing research. 
Finally, of course, I thank my family and friends: my parents, for giving me everything to be here today and my sister for her unconditional support. A big thank you goes to Helena, Ana, Nuria, Elvira, Laura, Blanca, Patricia, Rosa, Concha and Sarai for being there always; to Lonneke, Iris and Rachelle for listening to my string of complaints and also to Dennis and Erik for constantly asking me when I would finish. I thank my dear husband Maarten and my son Luca, for being my anchors. Maarten: thanks for supporting me. You can not imagine how much your pragmatism and flexibility have helped me during the process of completing this project. Your endless patience with my absence and understanding of the space I needed to think and write made this thesis possible. Thank you for making me feel calm during the difficult times and putting a smile on my face, and for sharing your life with me. 


\section{Curriculum Vitae}

Silvia Canto was born on $5^{\text {th }}$ June 1971 in Bilbao, Spain. In 1994 she graduated from Universidad de Deusto (Spain) where she studied English Philology. She received an MA degree in Translation (1997) from Middlesex University (UK). It was also there where her teaching career began in 1994 at the department of Hispanic Studies. She started working at Utrecht University in 2002 and this dissertation is the result of the research she has carried out while collaborating in several European projects. 